\title{
STUDIES ON CELL JUNCTIONS IN AN EX VIVO HUMAN LUNG INFECTION MODEL
}

\author{
vorgelegt von \\ Diplom-Ingenieurin der Biotechnologie \\ Andrea Peter \\ geb. in Cottbus
von der Fakultät III - Prozesswissenschaften der Technischen Universität Berlin zur Erlangung des akademischen Grades
Doktor der Ingenieurwissenschaften
- Dr.-Ing. -
genehmigte Dissertation

Promotionsausschuss:

Vorsitzender: Prof. Hajo Haase

Gutachter: Prof. Juri Rappsilber

Gutachter: Prof. Roland Lauster

Gutachter: Prof. Stefan Hippenstiel

Tag der wissenschaftlichen Aussprache: 09.10.2015

Berlin 2015 



\section{TABLE OF CONTENTS}

SUMMARY V

ZUSAMMENFASSUNG VI

\section{INTRODUCTION}

1.1 The human respiratory system ................................................................ 1

1.1.1 Structure and histology ................................................................. 1

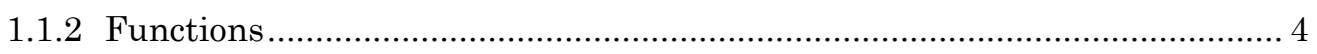

1.2 Respiratory tract infections ................................................................. 5

1.2.1 Pneumonia ................................................................................... 5

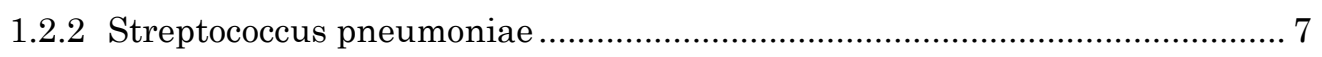

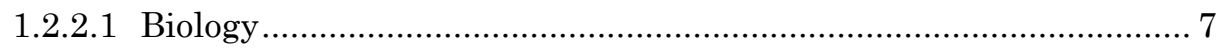

1.2.2.2 Virulence factors .................................................................. 8

1.3 Cell junctions.......................................................................................... 11

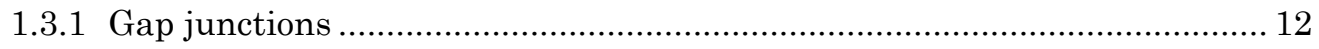

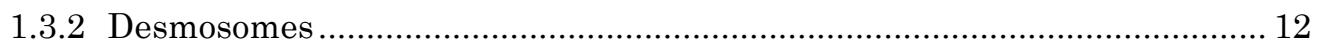

1.3.3 Adherens junctions .................................................................. 13

1.3.3.1 VE-cadherin ............................................................... 13

1.3.4 Tight junctions ............................................................................. 14

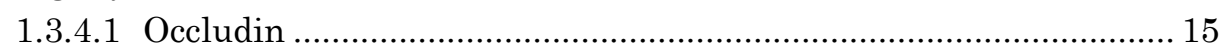

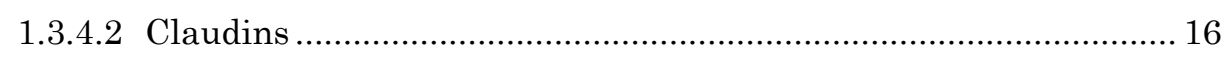

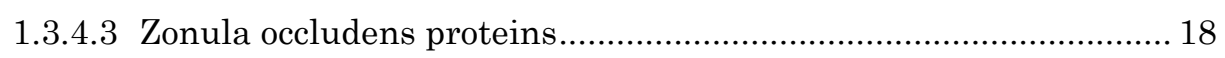

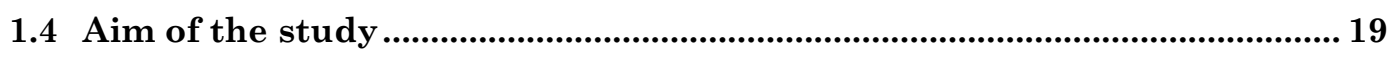

2 MATERIAL AND METHODS .................................... 21

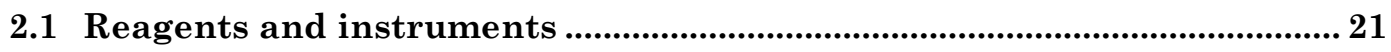

2.1 .1 Instruments.............................................................................. 21

2.1.2 Consumables ........................................................................... 22

2.1.3 Chemicals and reagents ............................................................. 22

2.1.4 Media for cell culture....................................................................... 24 


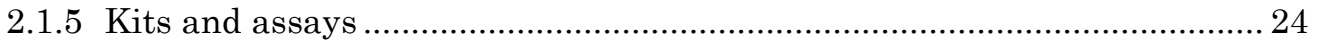

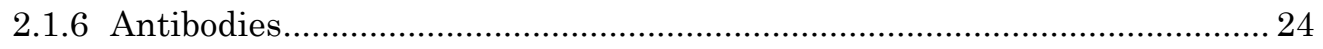

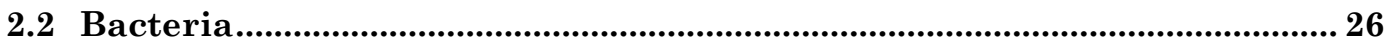

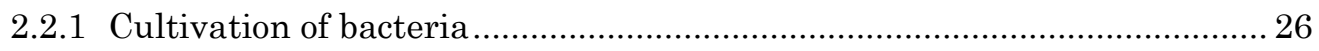

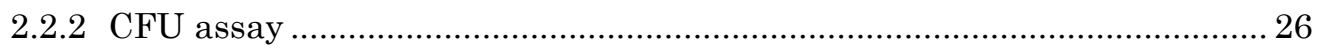

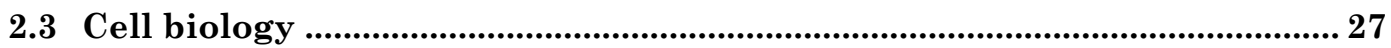

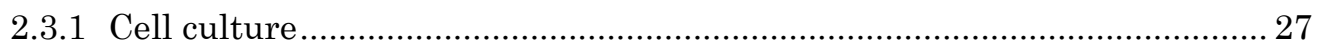

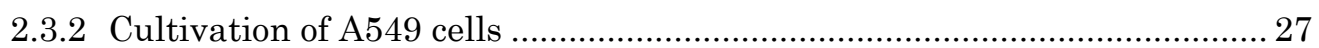

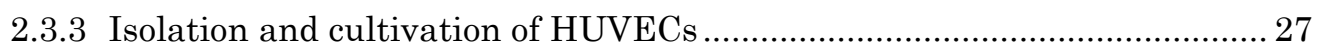

2.3.4 Preparation and culture of human lung tissue explants .......................... 27

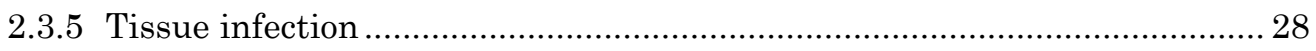

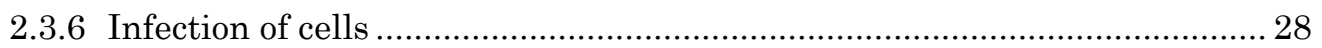

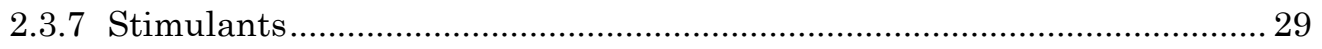

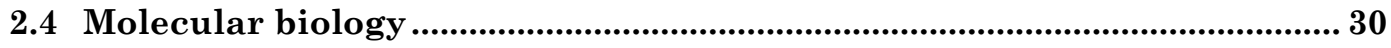

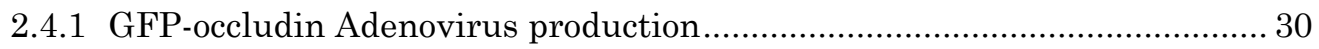

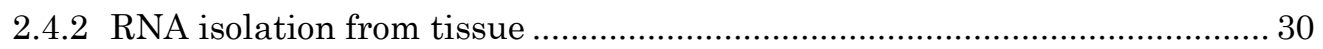

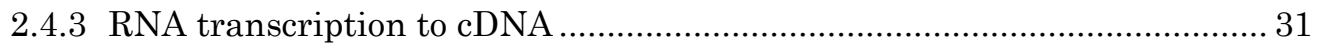

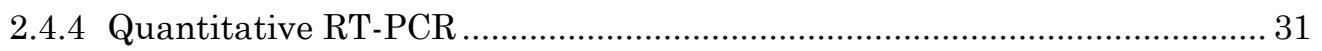

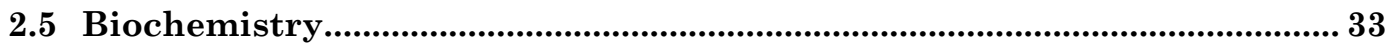

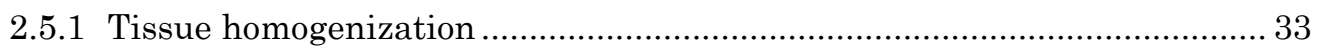

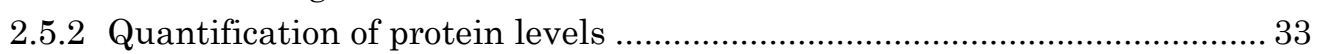

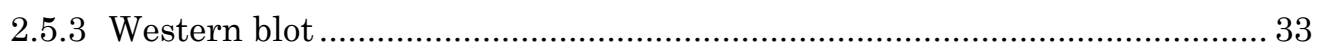

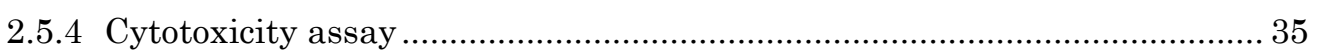

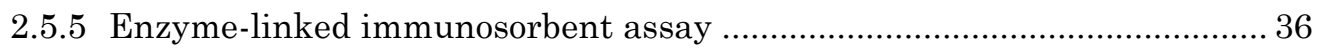

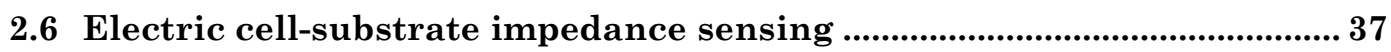

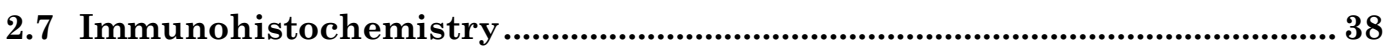

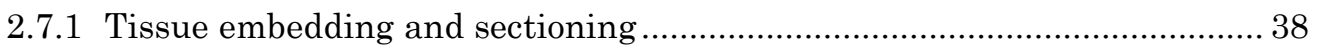

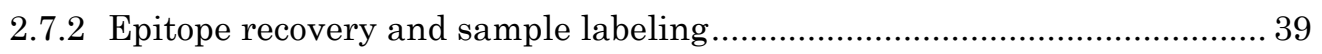

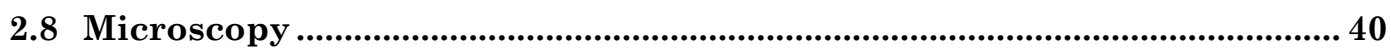

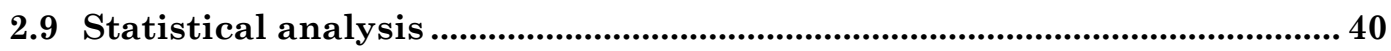

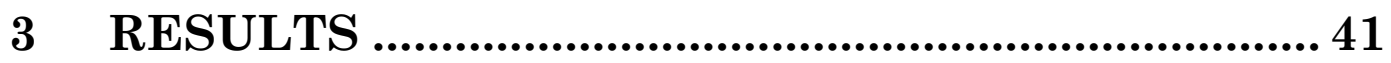

3.1 Distinct expression patterns of cell junction proteins in

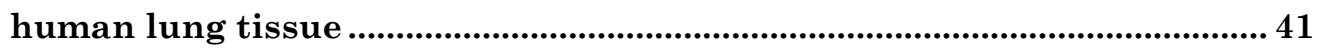

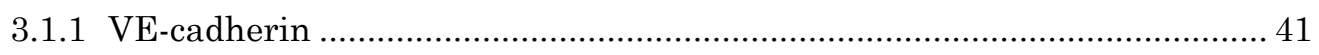

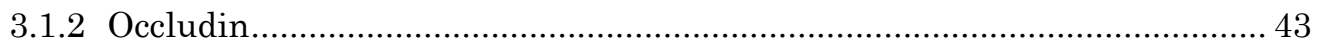

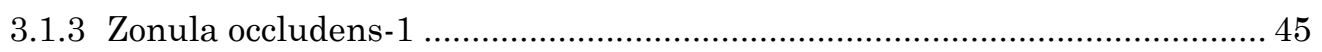

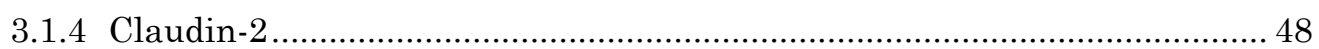




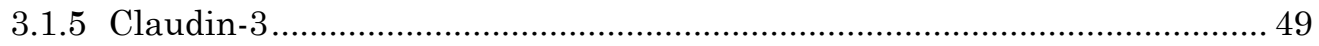

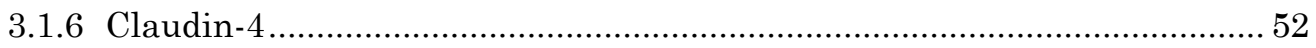

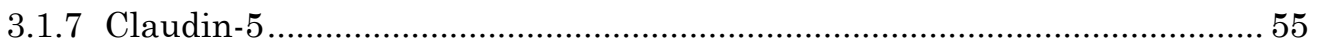

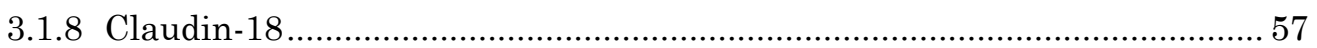

3.1.9 Summary of expression patterns .................................................... 58

3.2 Ex vivo human lung infection model ........................................................ 60

3.3 S. pneumoniae infection induces alteration of VE-cadherin, occludin, ZO-1 and claudin-5 in human lung tissue

3.4 The alteration of cell junctions is not transcriptionally regulated

3.5 Pneumolysin is not responsible for the alteration of cell junctions in infected human lung tissue

3.6 Pneumococci impair barrier function independently of the virulence factor pneumolysin in vitro

3.7 Hydrogen peroxide impairs barrier function and catalase prevents pneumococci-induced gap formation in vitro

3.8 The hydrogen peroxide deficient $S$. pneumoniae $\mathrm{D} 39 \Delta \mathrm{spxB}$ mutant is unable to induce alterations of cell junction proteins in human lung tissue

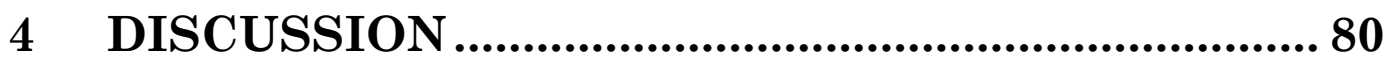

4.1 Ex vivo cultivated human lung tissue explants as an infection model 81

4.2 Tissue autofluorescence - a soluble problem? 84

4.3 Heterogeneous expression patterns of cell junction proteins in normal human lung tissue

4.4 Alteration of cell junction proteins in pneumococci-infected human lung tissue

4.5 Hydrogen peroxide - a key factor for junctional disruption during pneumococcal infection

4.6 Conclusions and further outlook 94

5 REFERENCES 96 


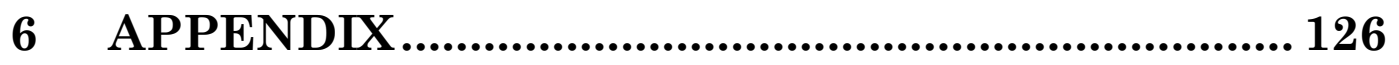

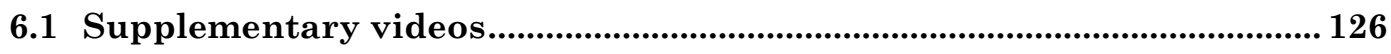

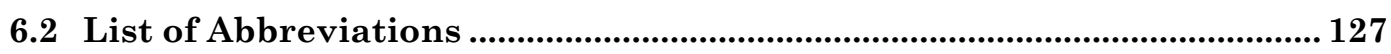

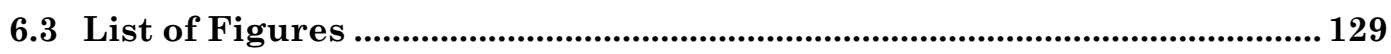

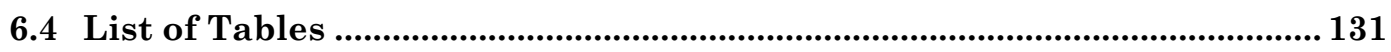

ACKNOWLEDGEMENTS ........................................ 132

SELBSTSTÄNDIGKEITSERKLÄRUNG ..................... 133 


\section{SUMMARY}

Cell junctions are multiprotein complexes within tissues representing the direct contact points of adjacent cells or between cells and the extracellular matrix. They function especially as barrier for pathogens and other exogenous components preventing their invasion into interstitial tissues and are therefore crucial for lung defense. A plethora of clinical studies has shown that disruption of pulmonary barrier is a pathological consequence of severe pneumonia, acute lung injury or acute respiratory distress syndrome. Experimental studies in animals and cultured cells strengthened the hypothesis that junctional disruption of the lung barrier contributes to a deleterious outcome. So far, the basic structure of human lung junctional organization is widely unknown and studies addressing their alteration upon pneumococcal infection are scarce.

In an ex vivo model of human lung explant culture the cell-specific expression patterns of adherens junction protein VE-cadherin and tight junction proteins occludin, ZO-1 as well as claudin-2, -3, -4, -5 and -18 were characterized using confocal laser scanning microscopy. Bronchiolar epithelium was tested positive for occludin, ZO-1, claudin-2, -3, -4, -5 and -18. Occludin and ZO-1 are expressed at the type I-type I cell interface as well as at the interface of type II alveolar epithelial cells whereas claudin-3, -4 and -18 are exclusively expressed at the interface of type II alveolar epithelial cells. Cell junctions in lung endothelial cells are formed by VE-cadherin, occludin, ZO-1, claudin-3 and claudin-5. The analyzed junction proteins appeared mostly as band-like structures connecting adjacent cells, except for claudin-2 and claudin-4, which exhibited punctate structures. Streptococcus pneumoniae, the most frequent pathogen of pneumonia, induces loss of characteristic alveolar structure and significant reduced protein abundance of VE-cadherin, occludin, ZO-1 as well as claudin-5 whereas claudin-2, -3, -4 and -18 appear to remain unchanged within 24 hours of infection. Strikingly, pneumococcal spxB-related hydrogen peroxide production was identified as key factor for junctional disturbance and impaired barrier function. 


\section{ZUSAMMENFASSUNG}

Zellkontakte (engl. cell junctions) sind Multiproteinkomplexe innerhalb von Geweben und stellen die direkten Kontaktpunkte benachbarter Zellen oder zwischen Zellen und der extrazellulären Matrix dar. Sie dienen vor allem als Barriere für Krankheitserreger, verhindern ihr Eindringen in interstitielle Gewebe und sind daher für die Lungenabwehr von entscheidender Bedeutung. Eine Vielzahl von klinischen Studien zeigten, dass Erkrankungen wie die Lungenentzündung oder das akute Atemnotsyndrom zu pulmonalen Barrierestörungen führen. Allerdings ist die grundlegende Struktur von Zellkontaktproteinen innerhalb der menschlichen Lunge weitgehend unbekannt und Untersuchungen, die deren Veränderung während einer Pneumokokkeninfektion addressieren sind kaum vorhanden.

In einem humanen ex vivo Lungengewebemodell wurden die Expressionsmuster des Adherens Junction VE-Cadherin und der Tight Junctions Occludin, ZO-1 sowie Claudin-2, -3, -4, -5 und -18 mittels konfokaler Laser Scanning Mikroskopie charakterisiert. Das Bronchialepithelium wurde positiv für Occludin, ZO-1, Claudin-2, -3, -4, -5 und -18 getestet. Occludin und ZO-1 sind sowohl an den Zellgrenzen von Typ I als auch an Typ II Alveolarepithelzellen exprimiert, während Claudin-3, -4 und -18 ausschließlich an den Zellgrenzen von Typ II Zellen vorkommen. Zellverbindungen in pulmonalen Endothelzellen werden von VE-Cadherin, Occludin, ZO-1, Claudin-3 sowie Claudin-5 gebildet. Die untersuchten Zellkontaktproteine erscheinen meist als bänderförmige Strukturen, die benachbarte Zellen miteinander verbinden. Streptococcus pneumoniae, der häufigste Erreger der Lungenentzündung, verursacht den Verlust der charakteristischen alveolären Struktur sowie eine signifikante Proteinreduktion von VE-Cadherin, Occludin, ZO-1 und Claudin-5. Die Claudine-2, -3, -4 und -18 bleiben auch 24 Stunden nach Infektion unverändert. Schließlich wurde das von Pneumokokken spxB-abhängig produzierte Wasserstoffperoxid als Ursache für die junktionale Störung und die Beeinträchtigung der pulmonalen Barrierefunktion identifiziert. 


\section{INTRODUCTION}

\subsection{The human respiratory system}

The human respiratory system refers to the entire system responsible for the process of respiration. In the following chapter the structure, specific cell types and function of the respiratory system are delineated.

\subsubsection{Structure and histology}

The human respiratory system is divided into the upper and the lower respiratory tract. The upper respiratory tract includes the nasal cavity and paranasal sinuses, pharynx and larynx. In this compartment, incoming air is filtered, humidified and warmed. Trachea, bronchi, bronchioles and lung are parts of the lower respiratory tract, which conducts the air to and from the gas exchange. The respiratory tree branches in a dichotomous fashion stemming from trachea to alveoli over 23 generations [1]. The trachea partitions into two primary bronchi, which continue branching (secondary, tertiary bronchi and bronchioles) until the level of terminal bronchioles (Figure 1.1a). The diameter and the length of each successive airway branch decreases progressively. The terminal bronchioles subdivide into respiratory bronchioles with scattered air sacs outpocketing from walls called alveoli (Figure 1.1b, c). Up to 480 million alveoli surrounded by a network of capillaries form a total surface area of approximately $75 \mathrm{~m}^{2}$ for the gas exchange of oxygen and carbon dioxide [2,3].

The trachea is a flexible tube with an inner diameter of about 2 to $3 \mathrm{~cm}$. Its membranous wall is reinforced by 16 to $20 \mathrm{C}$-shaped tracheal rings made of hyaline cartilage. The tracheal rings protect and maintain the airway. The upper respiratory tract, trachea as well as the main bronchi are lined by singlelayered ciliated columnar epithelium containing ciliated cells, neuro-endocrine cells, goblet cells and small basal cells (Figure 1.2a). 


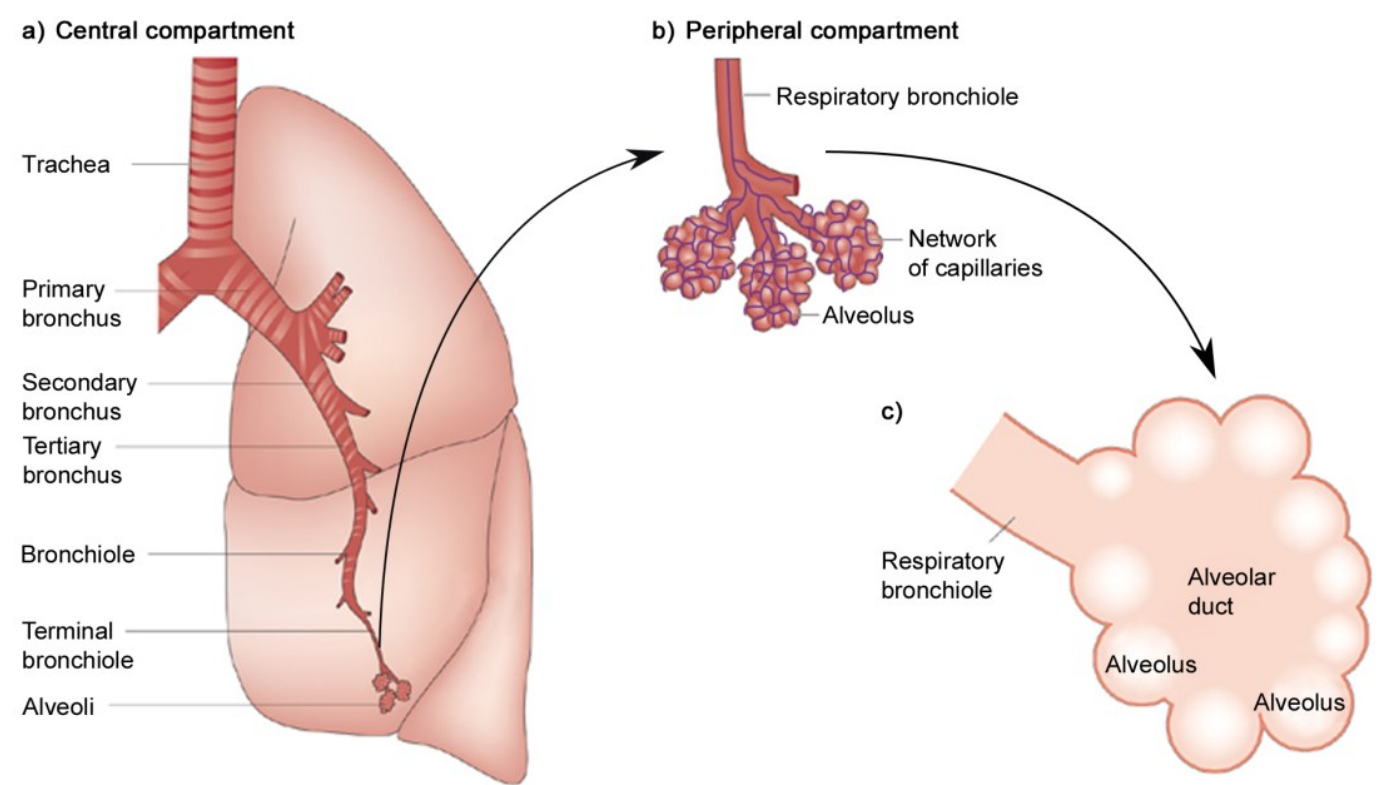

Figure 1.1: Overview of the anatomy of the lower human respiratory tract. (a) The lower respiratory tract consists of the trachea, bronchi and bronchioles. Bronchioles branch further into terminal bronchioles, respiratory bronchioles and alveoli. (b) Respiratory bronchioles lead to alveoli surrounded by a network of capillaries. (c) Alveolar ducts connect respiratory bronchioles to alveolar sacs, each containing numerous alveoli. Figure was adapted and modified from [4].

Goblet cells contain large membrane-bound mucin granules and secrete mucins, the major components of mucus [5]. From the $6^{\text {th }}$ up to the $16^{\text {th }}$ branching generation, the bronchioles are called terminal bronchioles, followed up to the $19^{\text {th }}$ generation by respiratory bronchioles, which have a diameter of about $0.5 \mathrm{~mm}$ [6]. Terminal as well as respiratory bronchioles are covered with simple ciliated cuboidal epithelium including ciliated and club cells. Club cells, formerly known as Clara cells, are nonciliated and secrete a component of pulmonary surfactant [7]. Additionally, the bronchioles are surrounded by a layer of smooth muscle.

The respiratory bronchioles branch into alveolar ducts, each containing several alveoli forming the $23^{\text {rd }}$ generation (Figure 1.1c). The alveoli consist of a single epithelial layer, which is composed of two distinct cell types, type I and type II alveolar epithelial cells (Figure 1.2b). Consequently, the epithelial monolayer contains three classes of cell-cell interfaces: (i) type I-type I cell interface, (ii) type I-type II cell interface and (iii) type II-type II cell interface. Type I alveolar epithelial cells are flat and cover about $95 \%$ of the alveolar surface area [3]. 
In contrast, cuboidal type II alveolar epithelial cells have a granulated cytoplasm and produce pulmonary surfactant. The secreted surfactant comprises phospholipids, proteins (especially SP-A, -B, -C and -D) and cholesterol and reduces the alveolar surface tension between the alveolar walls [8, 9]. Type II alveolar epithelial cells can proliferate and differentiate to replace damaged type I alveolar epithelial cells [10].

Within the walls of adjacent alveoli there is a dense network of capillaries. The inner linings of these alveolar capillaries are endothelial cells (Figure 1.2b). Endothelial cells can also be found in larger blood vessels, which belong to the pulmonary circulation. The basement membrane of type I alveolar cells and the endothelial cells of the capillaries form the blood-air (or alveolar-capillary) barrier, the gas exchange region of the lungs [11]. This barrier has a distance of less than $1 \mu \mathrm{m}$ to allow efficient gas exchange $[12,13]$. Alveoli additionally contain alveolar macrophages, fibroblasts, subepithelial connective tissue, collagen and elastic fibers.

a)

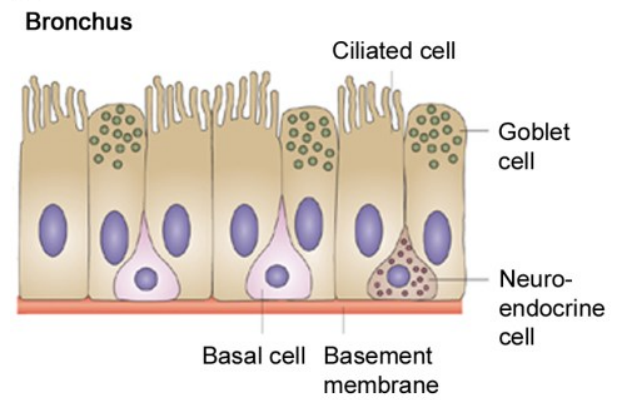

b)

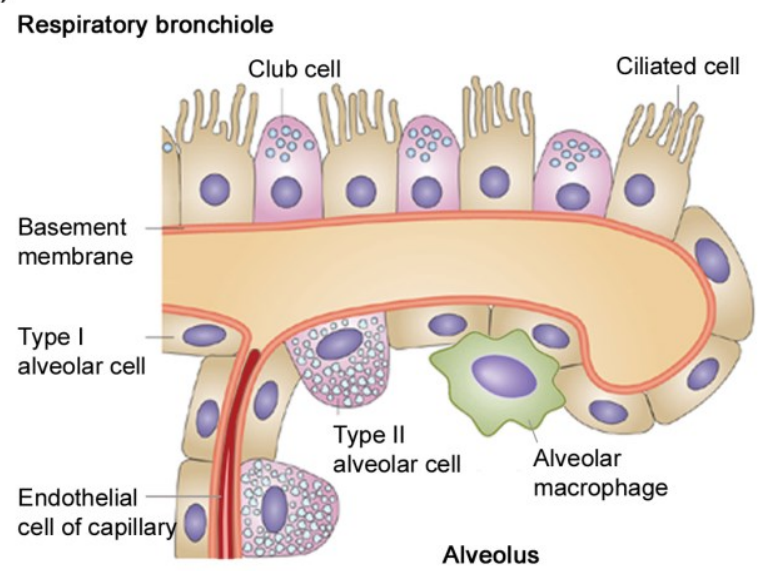

Figure 1.2: Cell types in bronchi, respiratory bronchioles and alveoli. (a) The upper respiratory tract, trachea and main bronchi are lined by single-layered epithelium containing ciliated cells, neuro-endocrine cells, goblet cells and small basal cells. (b) The finer bronchioles are covered with simple cuboidal epithelium including ciliated and club cells. The alveoli are composed of type I and type II alveolar epithelial cells as well as alveolar macrophages. The inner linings of capillaries are endothelial cells. Figure was adapted and modified from [4]. 


\subsubsection{Functions}

The major function of the respiratory system is respiration including pulmonary ventilation, transport of respiratory gases as well as internal and external respiration. The inhaled oxygen from the atmosphere is delivered to the alveoli and diffuses via type I alveolar cells into the alveoli surrounding capillaries, while carbon dioxide is released from the blood into the alveoli and can subsequently be exhaled.

In addition, the respiration system has protection and defense mechanisms. The epithelium of the upper respiration tract is lined with ciliated cells and mucus. Nasal cilia act as effective filters for inhaled large particles [14-16]. Small particles and pathogens (such as dust, bacteria or viruses) are trapped on the mucus produced by goblet cells and can either be swallowed or coughed and expelled. Mucus clearance is described to be essential for respiratory health [17-19]. Furthermore, the lower respiratory tract is classically assumed to be a sterile environment under healthy conditions but recent studies controvert this view $[20,21]$. 


\subsection{Respiratory tract infections}

Infectious diseases affecting the respiratory system are anatomically categorized into upper and lower respiratory tract infections. Upper respiratory tract infections include the common cold, sinusitis, otitis media, pharyngitis, tonsillitis as well as laryngitis. Bronchitis, bronchiolitis and pneumonia are classified as lower respiratory tract infections [22-24]. According to the World Health Organization (WHO) lower respiratory tract infections continue to be one of the leading causes of death worldwide and pneumonia accounts for about $15 \%$ of all deaths of children under the age at 5 [25, 26]. With estimated 450 million cases annually, pneumonia is an enormous clinical and economic burden for the healthcare systems [27, 28].

\subsubsection{Pneumonia}

Pneumonia is an inflammation of the lung with consolidations of inflammatory cells and fluid in the alveoli resulting in impaired gas exchange [29]. Depending on the situation acquired by the patient, pneumonia is referred to as community- or hospital-acquired pneumonia. Numerous factors may cause pneumonia including infections with pathogens or uncommon conditions such as environmental contaminants [30, 31] or autoimmune diseases [32]. Streptococcus pneumoniae is the most common agent of community-acquired pneumonia [33]. Further causes comprise bacteria such as Haemophilus influenzae, Chlamydophila pneumoniae, Staphylococcus aureus and Legionella pneumophila as well as rhino-, adeno- and coronaviruses, fungi or parasites.

Microorganisms are frequently inhaled or pulmonary aspirated. While in most cases mucociliary clearance serves as an efficient first line of defense to prevent them from entering the respiratory tract, some pathogens can overcome this protective barrier and access the lower respiratory tract. Here, respiratory epithelial cells with intercellular junctions as anatomical barrier protect from tissue invasion [34, 35]. Additionally, effector molecules such as antimicrobial peptides, defensins, lysozyme and lactoferrin are secreted and can directly target invading microbes. Within the alveoli, alveolar macrophages are the first immune cells getting in contact with invading microorganisms. 
Their main function is to eliminate microbes by phagocytosis and subsequent degradation. Moreover, they produce a large amount of different chemokines and cytokines which together with epithelial cell-derived chemokines lead to rapid recruitment of further immune cells like neutrophils, inflammatory monocytes and dendritic cells [36]. While immune cell recruitment is inevitable for antimicrobial defense and bacterial clearance, overwhelming cell recruitment can lead to strong accumulation of immune cells within the alveoli. Consequently, a leukocytosis is usually one of the laboratory indicators for the diagnosis of pneumonia. The pulmonary consolidation of fluid containing leukocytes, bacteria and cell debris in the alveoli causes impaired oxygen exchange with symptoms like cough, chest pain during breath and rapid respiration.

A severe complication of pneumonia is systemic spreading of the invading pathogen finally resulting in acute respiratory distress syndrome (ARDS), septic shock and sepsis [37-39]. A plethora of clinical studies has shown that pathogenesis of ARDS and sepsis include the influx of protein-rich fluid into the air spaces as a consequence of increased permeability of the blood-air barrier leading to fatal lung edema formation [40-43]. Experimental studies in animals and cultured cells strengthened the hypothesis that junctional disruption of the lung barrier significantly contributes to a deleterious outcome [44-46].

Bacterial community-acquired pneumonia is generally treated with antibiotics such as amoxillin and doxycycline [47]. However, increasing antimicrobial drug resistance against the most common pathogens became an awakening problem $[48,49]$. Therefore, novel therapeutic approaches and strategies for medical prevention are required. 


\subsubsection{Streptococcus pneumoniae}

\subsubsection{Biology}

S. pneumoniae, often referred to as pneumococcus, is a Gram-positive, a-hemolytic bacterium with a coccoid morphology (Figure 1.3a). It frequently colonizes the upper respiratory tract, especially the nasopharynx, in healthy hosts [50]. This colonization is usually asymptomatic and can either be cleared or progress to invasive diseases such as otitis media, meningitis, pneumonia and sepsis particularly in risk groups including young children, elderly people and patients with predisposing conditions such as asthma or HIV [51]. S. pneumoniae is encapsulated with a polysaccharide capsule that is crucial for virulence (chapter 1.2.2.2). On the basis of structurally and antigenically differences of the capsule, to date more than 90 pneumococcal serotypes are identified [52-54]. Due to antibiotic resistances, vaccines became evermore important to prevent pneumococcal infection. There are two different classes of pneumococcal vaccines available: (i) a pneumococcal polysaccharide vaccine (PPV) covering 23 serotypes [55] and (ii) pneumococcal conjugate vaccines (PCV) which contains polysaccharides of either 7, 9 or 13 serotypes coupled to a carrier protein [56]. Several vaccination programs against S. pneumoniae have been established. In Germany, the Standing Committee on Vaccination (STIKO) recommends vaccination of all children under 24 months of age with a pneumococcal conjugate vaccine as well as all adults older than 60 years and individuals belonging to certain risk groups with a polysaccharide vaccine [57]. The available pneumococcal vaccines only ensure immune response against the containing serotypes. As a consequence, eradication of vaccine serotypes with a co-occurring increase in disease caused by non-vaccine serotypes has been observed [58-61]. Therefore, current research focuses on the development of a serotype independent immunization e.g. by targeting important virulence factors of $S$. pneumoniae as a possible intervention point for vaccination [62]. The pneumococcal surface protein A (PspA), pneumococcal adhesion and virulence $\mathrm{A}$ (PavA) and pneumolysin have been shown to elicit protection against invasive infections and are currently the leading vaccine candidates [63-65]. 
a)

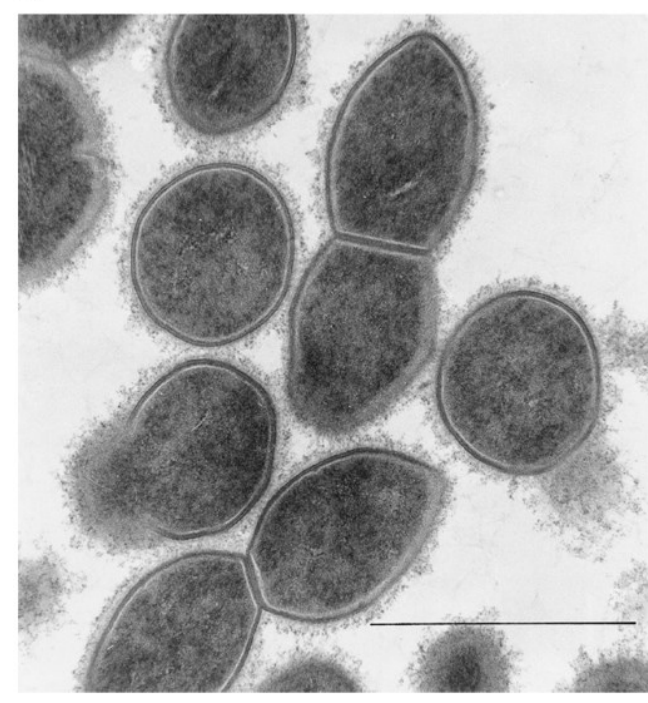

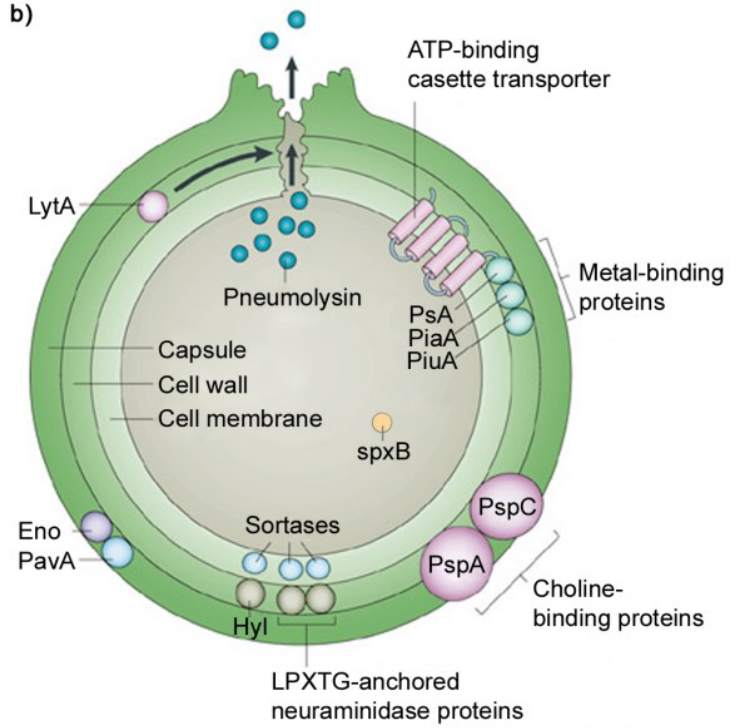

Figure 1.3: Streptococcus pneumoniae and its virulence factors. (a) Electron micrograph of nonencapsulated pneumococci. Bar represents $1 \mu \mathrm{m}$. (b) Virulence factors of $S$. pneumoniae. Important virulence factors are the capsule, the cell wall, pneumolysin, spxB encoding for pyruvate oxidase synthesizing hydrogen peroxide, metal- and choline-binding proteins, LPXTGanchored neuraminidase proteins, enolase (Eno), hyaluraonate lyase (Hyl), pneumococcal adhesion and virulence A (PavA) and autolysin (LytA). Figures were adapted and modified from $[54,66]$.

\subsubsection{Virulence factors}

S. pneumoniae possesses a wide variety of virulence factors with different functions. The most important and best studied include the polysaccharide capsule, the pore forming toxin pneumolysin, hydrogen peroxide as well as surface-associated proteins (Figure 1.3b).

\section{The pneumococcal capsule}

The pneumococcal capsule is covalently attached to the cell wall peptidoglycan of S. pneumoniae [67] and consists of polysaccharides. The different structure and chemical composition of the polysaccharide capsule are the basis for serotyping of pneumococci [68]. Clinical relevant pneumococcal strains are encapsulated and highly virulent while nonencapsulated strains are in most cases avirluent [69]. For that reason, the capsule has been described as the major virulence factor of $S$. pneumoniae. The capsule prevents mucociliary clearance by interfering with mucus binding and is therefore crucial in the early phase of pneumococcal colonization [70]. In addition, it was reported that the capsule inhibits complement activity and protects from phagocytosis $[71,72]$. 


\section{Pneumolysin}

Pneumolysin (PLY) is a pore-forming toxin produced by almost all clinical pneumococcal isolates [73]. It is localized within the bacterial cytoplasm and released either upon autolysis mediated by activation of the bacterial cell wall hydrolases LytA, LytC and choline-binding protein D CbpD [74] or via an autolysin independent mechanism [75, 76]. After its release as a soluble monomer, PLY binds to host membrane cholesterol, oligomerizes and forms pores of up to $30 \mathrm{~nm}$ in diameter [73]. Studies on the structural basis of pore formation by PLY reveal that following oligomerization conformational changes of PLY domains occur to produce a membrane-surface bound prepore. Subsequent movements of PLY domains brake the membrane bilayer resulting in a ring-shaped pore [77]. The formation of pores by PLY leads to host cell death as membrane integrity is destroyed [78]. Interestingly, screening of clinical isolates of $S$. pneumoniae revealed that mutations in PLY genes result in the expression of nonhemolytic forms of PLY, which were found in serotypes 1 and 8 [79-81].

The effects of PLY are dependent on both, dose and cell type [78]. However, PLYs critical role during pathogeneses has been demonstrated in various models of pneumococcal pneumonia. For example, PLYs cytotoxic activity results in pulmonary epithelial and endothelial cell damage in vitro $[82,83]$ and lung injury in vivo [84, 85]. It facilitates the invasion of pneumococci into the lower respiratory tract by damage of respiratory mucosa and reducing ciliary beating of bronchiolar epithelial cells [86, 87]. Moreover, PLY contributes to the development of bacteremia in mice [88]. As a result of PLY recognition by immune cells further effects are production of inflammatory chemokines and cytokines such as IL-1B and TNF-a, activation of the complement system and inhibition of neutrophil migration [89-93]. Although it has been reported that inflammatory responses to pneumolysin are mediated through the recognition of PLY by Toll-like receptor (TLR) 4 [94], a recent study showed that PLY can also activate TLR4-independent innate immune responses [95]. 


\section{Hydrogen peroxide}

The spxB-encoded pyruvate oxidase of S. pneumoniae catalyzes the production of hydrogen peroxide during bacterial growth [96] and the produced amount of hydrogen peroxide by pneumococci is comparable to that produced by activated neutrophils [41, 97]. SpxB-defective mutants showed reduced virulence in animal models for nasopharyngeal colonization, pneumonia and sepsis [96]. In the same study, spxB-defective mutants exhibited a down-regulation of adhesive properties of pneumococci through the production of acetyl phosphate. Hydrogen peroxide causes cellular injury and induces apoptosis in target cells both in vitro and in vivo [98, 99] resulting from oxidative DNA damage [100]. Pneumococci-derived hydrogen peroxide has cytotoxic effects on alveolar epithelial cells in vitro and mediates brain cell apoptosis during meningitis in vivo [101, 102]. Furthermore, it has been implicated in cell death of infected human macrophages [103]. Similar to pneumolysin, hydrogen peroxide also induces ciliary stasis and contributes to the impairment of mucociliary clearance in airway inflammation [104-106]. Hydrogen peroxide has inhibitory and bactericidal effects on other inhabitants of the upper respiratory tract such as $H$. influenzae, Moraxella catarrhalis and Neisseria meningitidis suggesting an effective mechanism for limiting or eliminating competitive flora [107].

\section{Other virulence factors}

Other virulence factors include metal- and choline-binding proteins such as PspA, LPXTG-anchored neuraminidase proteins, enolase, hyaluraonate lyase, PavA and autolysin (LytA). They are involved in adherence of pneumococci on host cell surfaces, they interact with the host complement system or bind and transport divalent cations inside the bacterial cytoplasm [50, 73, 108]. The overall functions of the virulence factors are facilitating colonization and invasion of S. pneumoniae and thereby contributing to pathogenesis. 


\subsection{Cell junctions}

Cell junctions are multiprotein complexes within epithelial and endothelial tissues, representing the direct contact points of adjacent cells or between cells and the extracellular matrix. They function especially as paracellular barrier [109, 110], connect cells and their cytoskeleton mechanically [111, 112] and enable intercellular communication [113]. Additionally cell junctions maintain the polarity of cells [114] and are involved in numerous signaling pathways [115-117]. In vertebrates cell junctions can be classified into four types: (i) tight junctions, (ii) adherens junctions, (iii) desmosomes and (iv) gap junctions (Figure 1.4a). Tight junctions are located at the furthest apical region of epithelial cells, encircle them belt-like and connect to tight junction strands in the opposing membrane of neighboring cells. At this so-called kissing point the intercellular space is obliterated (Figure 1.4b). Adherens junctions are directly placed below the tight junctions whereas both connect to actin filaments. Together with lateral located desmosomes, tight junctions and adherens junctions are referred to as junctional complex [118]. However, desmosomes are absent in the endothelium [119].

a)

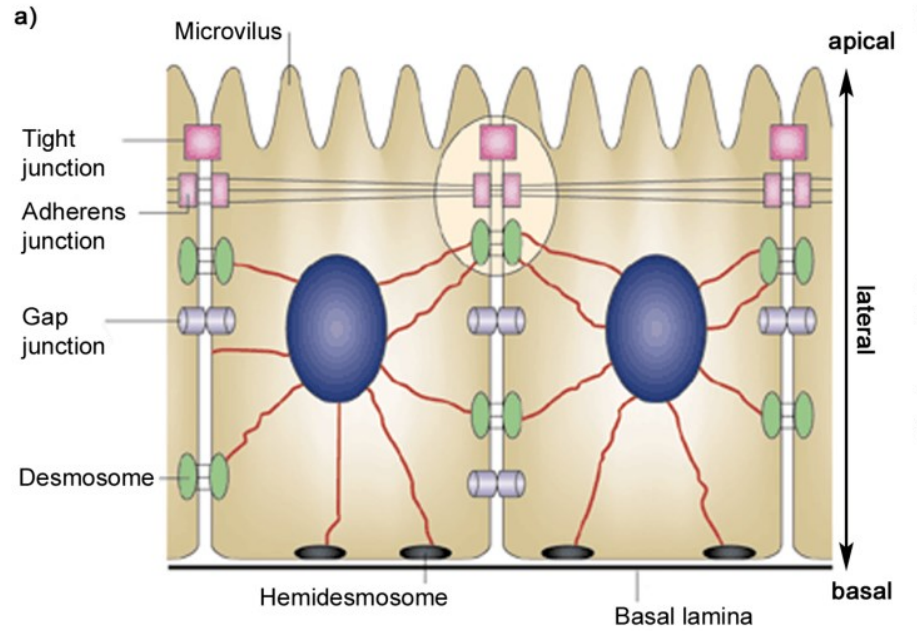

b)

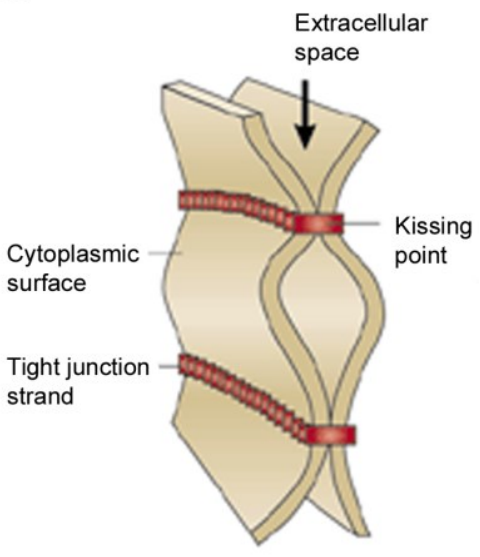

Figure 1.4: Junctional complex and structure of tight junctions. (a) Schematic overview of intercellular junctions of adjacent epithelial cells. Tight junctions and adherens junctions are located at the apical region and connect to the actin filament. Desmosomes and hemidesmosomes are linked to intermediate filaments. (b) Schematic drawing of tight junction structure. Each tight junction strand connects with another tight junction strand in the opposing membrane of adjacent cells to form a paired tight junction strand (kissing point), where the intercellular space is obliterated. Figures are adapted and modified from [120]. 
Another cell junction structure is formed by gap junctions, which directly connect cytosols of adjacent cells. Hemidesmosomes attach the basal surface of epithelial cells to the extracellular matrix. Both, desmosomes and hemidesmosomes, are linked to intermediate filaments.

\subsubsection{Gap junctions}

Gap junctions are clusters of intercellular channels formed by connexons [121]. Connexons are composed of homo- or heterohexamers of integral proteins, named connexins [30,31]. The membranes of two opposing cells come close to each other and apposed connexons align leaving an extracellular gap of about 2-3.5 nm [124-126]. Gap junctions permit the transfer of ions [127], second messengers such as cAMP [128, 129], siRNA [130] and small molecules with a molecular weight of up to $1 \mathrm{kDa}$ enabling effective electrical and biochemical coupling between adjacent cells. Gap junctions are present in all tissue-forming cells [131] and are of particular importance in glial cells [132] and cardiomyocytes $[133,134]$ rapidly forwarding action potentials. In this context, connecting cells with gap junctions provide both, increased speed in synaptic transmission and the ability to synchronize coupled cells for coordinated electrical and mechanical output enabling physiological processes such as muscle contraction [113].

\subsubsection{Desmosomes}

Desmosomes are primarily found in epithelial cells of the skin [135, 136] as well as in non-epithelial tissues such as the cardiac muscle [137-139]. They provide mechanical stability and strong adhesion between cells $[140,141]$ contributing to resist shearing forces. Their high degree of adhesive strength is based on multiple and strong non-covalent interactions between their molecular constituents [140]. The cytoplasmic tails of the desmosomal cadherins desmoglein and desmocollin associate with the plaque proteins plakoglobin, plakophilin and desmoplakin [141]. Desmoplakin binds to keratin intermediate filaments linking desmosomes to the cytoskeleton of the cell [142]. 


\subsubsection{Adherens junctions}

Adherens junctions form a continuous adhesion belt encircling adjacent cells and promote mechanical stability of cell junctions through their connection to the actin cytoskeleton. The adhesion belt is characteristically for epithelial and endothelial cells. In other cell types, e.g. fibroblasts [143] or neurons [144], adherens junctions take on discontinuous punctated morphologies. Adherens junctions are composed of calcium dependent transmembrane proteins of the cadherin family as well as a-catenin, B-catenin, $\mathrm{Y}$-catenin (plakoglobin) and p120-catenin [145]. The cytoplasmic domains of the cadherins associate with p120-catenin and B-catenin or Y-catenin [112]. In turn B-catenin binds a-catenin, resulting in formation of the cadherin - B-catenin - a-catenin complex [112] which interacts via mediator proteins such as vinculin [146-148] and EPLIN [149-151] with actin filaments and microtubules.

The most prominent members of the cadherin family are $\mathrm{E}$-, $\mathrm{N}$ - and $\mathrm{P}$-cadherin as well as VE-cadherin (chapter 1.3.3.1). Adherens junctions have multiple functions including maintenance of physical connection between cells and regulation of the actin cytoskeleton which is essential for morphogenesis and integrity of tissues and organs $[112,145]$. Furthermore, it is discussed that the formation of adherens junctions is required for the accurate organization of tight junctions $[119,152]$.

\subsubsection{VE-cadherin}

The major transmembrane constituent of adherens junctions in the endothelium is a classical cadherin called vascular endothelial (VE)-cadherin. It is strictly endothelial cell specific and constitutively expressed in all types of vessels including lymphatic vessels, arteries and veins [153, 154]. Endothelial cells form a selective trans- and paracellular barrier controlling the passage of fluids, leukocytes and macromolecules between blood vessels and underlying tissue. Therefore, VE-cadherin is the dominant adhesion molecule crucial for endothelial barrier integrity and regulates endothelial paracellular permeability $[152,155]$. Application of VE-cadherin blocking antibodies leads to increased vascular permeability in vitro [156] and in vivo [157] and recent 
studies reveal that the HIV-1 Tat C protein mediates tyrosine phosphorylation of VE-cadherin and B-catenin resulting in increased permeability of human brain microvascular endothelial cells [158, 159]. Furthermore, a null mutation of the VE-cadherin encoding gene $C d h 5$ in mice results in embryonic lethality at 9.5 days of gestation due to impaired remodeling and maturation of endothelial cells [160, 161]. Vessels regressed, disintegrated and collapsed causing vascular insufficiency and endothelial apoptosis. In these two studies it was additionally shown that loss of VE cadherin in mice leads to abnormal response of endothelial cells to vascular endothelial growth factor (VEGF) signaling [160, 161]. Consequently, VE-cadherin plays essential roles in vasculo- [162, 163] and angiogenesis [163-165] making it a main target of vascular therapy research. Beyond that, VE-cadherin mediates homotypic contact inhibition of endothelial cell growth [166], indirectly influences transcriptional signaling via its binding partners $[167,168]$ and establishes endothelial cell polarity [169-171].

\subsubsection{Tight junctions}

Tight junctions are cell junctions located at the apical side of epithelial and endothelial cells. They have two characteristic barrier functions: the gate and the fence function [172-174]. Tight junctions form a selective barrier between adjacent cells to regulate paracellular transport of molecules such as water, ions and solutes as well as immune cells (gate function) [174-176]. Therefore, tight junctions span the cells in a belt-like network by connecting to the tight junctions of neighboring cells. In contrast to adherens junctions, desmosomes and gap junctions, which leave a gap of several $\mathrm{nm}$ between opposing membranes, tight junctions completely seal the intercellular space at the socalled kissing point [177]. Tight junctions vary in their tightness depending on their protein composition, the number of tight junction strands and the type of tissue [120]. This tightness can be measured as transcellular electrical resistance. In addition, tight junctions function as intramembranous diffusion barrier for membrane proteins and lipids and maintain cell polarity by separating apical and basolateral membrane domains (fence function) [178, 179]. These barrier properties of tight junctions are essential for the function 
at the epithelial barrier in the intestinal lumen, at the blood-brain barrier or the blood-air barrier in the lung. Furthermore, tight junctions are involved in signal transduction processes, regulation of gene expression, cell proliferation and differentiation [180].

Tight junctions are composed of multiprotein complexes maintaining their barrier function. The major members of tight junctions are the transmembrane proteins occludin, tricellulin, junctional adhesion molecule (JAM) and proteins of the claudin family as well as tight junction-associated scaffolding proteins such as zonula occludens proteins. So far more than 40 proteins were identified as tight junction components [109, 181]. Due to this variety, the next chapters primarily address tight junction proteins that are relevant for this study.

\subsubsection{Occludin}

Firstly identified in 1993, occludin is hitherto one of the best studied tight junction proteins. It is an integral component of epithelial and endothelial tight junctions composed of four transmembrane domains and two extracellular loops [182]. Occludin appears to be directly involved in gate and fence functions of tight junctions. Overexpression of occludin in several cell types leads to formation of intramembranous particle strands comparable to tight junction structures [183, 184] and induces increased transepithelial electrical resistance accompanied by an elevated number of parallel tight junction strands [185, 186]. The indispensability of occludin for cortical actin organization and barrier integrity has also been demonstrated in various endothelial cell models [187]. Additionally, occludin seems to be required for cytokine-mediated regulation of tight junction barrier properties [188]. Furthermore, phosphorylation of occludin on C-terminal tyrosine, serine and threonine residues seems to directly correlate with the localization of occludin indicating that phosphorylation of occludin is crucial for tight junction formation [189, 190]. Non- or less phosphorylated occludin is distributed on basolateral membranes and further phosphorylation induces occludin to assemble at the tight junction region [191]. In addition, phosphorylation of 
occludin by protein kinase $\mathrm{C}$ leads to altered tight junction assembly in epithelial cells [192].

However, occludin-deficiency of embryonic stem cells did not affect polarization of epithelial cells [193]. Mice carrying a null mutation of occludin showed no alteration of barrier function but complex phenotypes such as drastic abnormalities in gastric morphology, testicular atrophy or calcification in the brain [194, 195]. On the other hand occludin knockdown causes mislocalization of the tight junction protein tricellulin indicating that tricellulin can compensate for some functions of occludin [196]. Although there are numerous studies addressing the cellular and molecular mechanisms of occludin, its function remains elusive [188].

\subsubsection{Claudins}

The claudin family comprises to date 27 members in humans termed claudin- 1 to claudin-27 [197, 198]. Comparable to occludin, they consist of a tetra-span transmembrane protein and two extracellular loops. Claudins are structurally related but share no sequence similarity with occludin [199]. Based on their sequence homology, claudins are categorized in classic and non-classic claudins. Classic claudins share a high degree of structural similarity and include claudin-1-10, -14, -15,-17 and -19, while non-classic claudins include claudin-11-13, -16, -18 and -20-27 [200]. Claudins exhibit distinct tissue- and cell-specific expression patterns [201, 202], e.g. claudin-1 is ubiquitously expressed whereas claudin-5 is primarily expressed in endothelial cells of blood vessels representing a major component of the blood-brain barrier [203, 204]. Accordingly, claudin knockout studies in mice reveal a high diversity of phenotypes (Table 1.1) [198, 202]. So far, claudin-1, -3, -4, -5, -7, -8, -10 and -18 were confirmed to be expressed in the human lung whereas reports about claudin-2 expression are controversial [205, 206]. 
Table 1.1: Murine claudin knockout models. Adapted and modified from [198].

\begin{tabular}{|c|c|c|c|}
\hline $\begin{array}{l}\text { Knockout } \\
\text { model }\end{array}$ & Affected organs & Impaired function & Literature \\
\hline Claudin-1 $1 /-$ & Skin & Barrier & {$[207,208]$} \\
\hline Claudin -2 & Kidney, liver & Barrier & {$[209,210]$} \\
\hline Claudin $-3^{-/}$ & - & - & {$[211,212]$} \\
\hline Claudin $-4^{-/}$ & Kidney & Barrier & [213] \\
\hline Claudin $-5 \%$ & Blood-brain barrier & Barrier & {$[204]$} \\
\hline Claudin- 7 -/ & Intestine & Adhesion & {$[214]$} \\
\hline Claudin- $10 \%$ & Kidney & $\mathrm{Na}^{+}$adsorption & {$[215]$} \\
\hline Claudin-11 & Inner ear & Barrier & {$[216]$} \\
\hline Claudin-14 -/ & Kidney & Regulation & [217] \\
\hline Claudin- $15 \%$ & Small intestine & Mucosal differentiation & [218] \\
\hline Claudin-16 & Kidney & Barrier & [219] \\
\hline Claudin-18 $\%$ & Lung, bone & $\begin{array}{l}\text { Barrier } \\
\text { Bone resorption and } \\
\text { osteoclast differentiation }\end{array}$ & $\begin{array}{l}{[220,221]} \\
{[222]}\end{array}$ \\
\hline
\end{tabular}

Claudins were described as $\mathrm{Ca}^{2+}$-independent cell-adhesion molecules [223].

They constitute a network of tight junction strands de novo indicating to function as major structural components of tight junctions in various tissues [199, 224, 225]. During tight junction strand formation, claudins of opposing membranes can interact with the same claudin in a homophilic manner (e.g. claudin-5 and claudin-5) or heterophilic with another claudin (e.g. claudin-1 and claudin-5) [200, 226, 227]. Therefore, barrier properties such as barrier permeability of cells are based on the distribution, composition and interaction of their expressed claudins [202]. Besides providing a physical barrier as a sealforming element, claudins regulate the paracellular pathway between epithelial and endothelial cells. Claudin-2, -7, -10,-15 and -16, form charge and size selective aqueous pores permitting the transport of ions and molecules $[202,228,229]$ whereas claudin- $-1,-3,-4,-5,-8,-11,-14$ and -18 have a sealing function [201]. 


\subsubsection{Zonula occludens proteins}

The tight junction transmembrane proteins are associated with a variety of proteins. Zonula occludens (ZO) proteins are located at the cytoplasmic side of cell junctions, interact with various types of proteins such as tight junction occludin [230, 231] and claudins [232] and link them to the actin cytoskeleton. Currently, three ZO proteins are identified: ZO-1, -2 and -3 . They share sequence homologies and exhibit PDZ domains, a Src homology 3 (SH3) domain and a guanylate kinase (GUK)-like domain, therefore being classified into the family of membrane-associated guanylate kinases (MAGUK) [233, 234].

ZO proteins function as scaffolds thereby clustering numerous kinases, phosphatases and transcriptional regulators at intercellular junctions [115]. They are crucial not only for tight junction but also for adherens junction formation [235, 236]. In a model of chronic obstructive pulmonary disease (COPD), ZO-1 as well as ZO-2 were significantly reduced and dislocated from the membrane of epithelial cells in bronchioles [237]. Additionally, ZO-1 and ZO-2 associate directly with connexins indicating a major role for recruiting molecules involved in intracellular signaling pathways [238, 239]. Knockout of ZO-1 or ZO-2 is embryonic lethal in mice [240, 241] and ZO-1 deficiency was associated with defects in yolk sac angiogenesis and apoptosis of embryonic cells suggesting a critical role for vascular permeability [240]. In contrast, ZO-3 deficient mice were viable and fertile with no phenotypic abnormalities indicating that ZO-3 is a dispensable component of cell junctions [241, 242]. 


\subsection{Aim of the study}

Cell junctions are multiprotein complexes within tissues representing the direct contact points of adjacent cells or between cells and the extracellular matrix. They function especially as barrier for pathogens and other exogenous components preventing their invasion into interstitial tissues and are therefore crucial for lung defense. A plethora of clinical studies has shown that disruption of pulmonary barrier is a pathological consequence of severe pneumonia, acute lung injury or acute respiratory distress syndrome. Experimental studies in animals and cultured cells strengthened the hypothesis that junctional disruption of the lung barrier contributes to a deleterious outcome. So far, the composition of cell junctions in the human lung is widely unknown and studies addressing the effects on them upon pneumococcal infection are scarce.

The aim of this study consists of two main issues.

(I) The following cell junction proteins are analyzed for their constitutive expression patterns in human lung tissue: VE-cadherin, occludin, zonula occludens-1 (ZO-1), claudin-2, claudin-3, claudin-4, claudin-5 and claudin-18. In addition, their cell-specific expression in different sections of the human lung is characterized.

The reasons for selecting these distinct cell junction proteins to examine junctional organization within the human lung are briefly outlined. As the major transmembrane constituent of adherens junctions and endothelial cell marker molecule VE-cadherin was chosen. Occludin is one of the best studied tight junction proteins known to be expressed in endothelial as well as epithelial cells. ZO-1, as representative of the ZO proteins, interacts with tight junctions and is therefore an excellent candidate for the proposed investigation objectives. There are discrepant reports about claudin-2 expression in the human lung that are aimed to be clarified in this study. Claudin-3, -4 and -5 belong to the group of classic claudins and are up-regulated in interstitial pneumonia but downregulated in inflammation in humans [206]. Due to opposing changes of 
claudin expression in different lung pathologies, these claudins were chosen for analysis. Claudin-18 is the only non-classic claudin known to be expressed in human lungs.

(II) Further, in a human ex vivo infection model lung tissue explants are infected with S. pneumoniae, the most frequent cause of pneumonia. Changes in cell junction protein expression or structure alterations in response to $S$. pneumoniae are defined. Factors leading to an altered structure and/or protein level are investigated. 


\section{Material AND Methods}

\section{$2.1 \quad$ Reagents and instruments}

\subsubsection{Instruments}

Table 2.1: Instruments.

\begin{tabular}{|c|c|}
\hline Instrument & Company \\
\hline ABI 7300 Real-Time PCR System & Applied Biosystems \\
\hline Compartment Dryer & Memmert \\
\hline ECIS Model 1600R & Applied Biophysics \\
\hline ELISA Plate Reader & STL \\
\hline FastPrep ${ }^{\mathrm{TM}}-24$ Instrument & MP Biomedicals \\
\hline Heracell $^{\mathrm{TM}} 240 \mathrm{i} \mathrm{CO}_{2}$ Incubator & Thermo Scientific \\
\hline Herasafe $^{\mathrm{TM}} \mathrm{KS}$ & Thermo Scientific \\
\hline Magnetic Mixer Viramag & Monotherm \\
\hline Mastercycler Gradient & Eppendorf \\
\hline Microcentrifuge 5417R & Eppendorf \\
\hline Microscope LSM 780 & Carl-Zeiss \\
\hline Mini-PROTEAN ${ }^{\circledR}$ Tetra Cell & Bio-Rad \\
\hline Mini Trans-Blot ${ }^{\circledR}$ Cell & Bio-Rad \\
\hline NanoDrop 2000c & Thermo Scientific \\
\hline pH Meter 766 Calimatic & Knick \\
\hline Photometer & Bio-tek Instruments \\
\hline Rotanta $460 \mathrm{R}$ & Hettich \\
\hline PowerPac ${ }^{\mathrm{TM}}$ Basic Power Supply & Bio-Rad \\
\hline Precision Balance 440-33 & Kern \\
\hline Steamer Multi Gourmet & Braun \\
\hline Vortex Mixer VV 3 & VW R \\
\hline
\end{tabular}




\subsubsection{Consumables}

Table 2.2: Consumables.

\begin{tabular}{|c|c|}
\hline Consumable & Company \\
\hline BD Microlance 3 Cannulas & BD Biosciences \\
\hline BD Plastipak Syringes & BD Biosciences \\
\hline Biopsy Cassettes Tissue-Tek III & Sakura \\
\hline Cell Culture Flasks & Falcon \\
\hline Cell Culture Plates & Falcon \\
\hline Cell Culture Tubes & Falcon \\
\hline CL-XPosure Film & Thermo Scientific \\
\hline Columbia Agar $+5 \%$ Sheep Blood & BD Biosciences \\
\hline Cuvettes & Sarstedt \\
\hline ECIS Cultureware 8W10E & ibidi \\
\hline Immun-Blot ${ }^{\circledR}$ PVDF Membrane $0.45 \mu \mathrm{m}$ & Bio-Rad \\
\hline Inoculation Loops & Sarstedt \\
\hline MicroAmp ${ }^{\mathrm{TM}}$ Optical 96-Well Reaction Plate & Applied Biosystems \\
\hline Scalpel & FEATHER $^{\circledR}$ \\
\hline Serological Pipets & Thermo Scientific \\
\hline Sterile Filters & Millipore \\
\hline Whatman Gel Blotting Paper & GE Healthcare \\
\hline$\mu$ Slides 8-Well & ibidi \\
\hline
\end{tabular}

\subsubsection{Chemicals and reagents}

Table 2.3: Chemicals and reagents.

\begin{tabular}{l|l}
\hline Reagent & Company \\
\hline Ammonium persulfate & Serva \\
Ampuwa & Fresenius Kabi \\
Catalase from bovine liver & Sigma \\
Bacto Todd Hewitt Broth & BD Biosciences \\
Bacto Yeast Extract & BD Biosciences \\
Bis-Acrylamide & Serva \\
Bovines Serum Albumin, Fraction V, $>96 \%$ & Sigma-Aldrich \\
Bromphenol blue & Biotech Pharmacia \\
\hline
\end{tabular}




\begin{tabular}{|c|c|}
\hline Chloroform & Merck \\
\hline Complete Protease Inhibitor Cocktail Tablets & Roche \\
\hline Dapi & Sigma \\
\hline Goat Serum & Sigma-Aldrich \\
\hline EDTA & Roth \\
\hline Ethanol & Merck \\
\hline Gelatin & Sigma-Aldrich \\
\hline Glycine & Sigma \\
\hline Glycerol & Roth \\
\hline Glycoblue & Ambion \\
\hline Igepal & Sigma \\
\hline Isopropanol & Sigma-Aldrich \\
\hline B-Mercaptoethanol & Sigma \\
\hline Methanol & Merck \\
\hline Mowiol 4-88 & Roth \\
\hline Non-fat Dry Milk Powder & Roth \\
\hline Na-deoxycholate & Sigma \\
\hline $\mathrm{NaCl}$ & Merck \\
\hline Rabbit Serum & Sigma-Aldrich \\
\hline Roti $^{\circledR}$-Aqua-P/C/I & Roth \\
\hline Roticlear & Roth \\
\hline Paraformaldehyde & Sigma-Aldrich \\
\hline PBS & Gibco \\
\hline Polybrene & Sigma-Aldrich \\
\hline SDS & Serva \\
\hline TEMED & Sigma \\
\hline Todd-Hewitt Broth & Oxoid \\
\hline Tris & Roth \\
\hline Triton X-100 & Sigma \\
\hline TRIzol $^{\circledR}$ & Invitrogen \\
\hline Tween-20 & Sigma-Aldrich \\
\hline Typsin/EDTA & PAA \\
\hline
\end{tabular}




\subsubsection{Media for cell culture}

Table 2.4:Media for cell culture.

\begin{tabular}{l|l}
\hline Reagent & Company \\
\hline Endothelial Cell Growth Medium MV2 & PromoCell \\
Foetal Bovine Serum Gold & PAA \\
Ham's F-12 & Lonza \\
L-Glutamine GlutaMax ${ }^{\mathrm{TM}}-\mathrm{I}$ & Gibco \\
RPMI 1640 & Gibco \\
\hline
\end{tabular}

\subsubsection{Kits and assays}

Table 2.5: Kits and Assays.

\begin{tabular}{l|l}
\hline Kit & Company \\
\hline Cytotoxicity Detection Kit & Roche \\
DC Protein Assay & Bio-Rad \\
High Capacity cDNA Reverse Transcription Kit & Applied Biosystems \\
Human IL1-B ELISA Ready-SET-Go! ${ }^{\circledR}$ Kit & eBioscience \\
Pierce ECL Western Blotting Substrate & Thermo Scientific \\
RNase-Free DNase & Promega \\
TaqMan Gene Expression Assays & Life Technologies \\
TaqMan Gene Expression Master Mix & Applied Biosystems \\
\hline
\end{tabular}

\subsubsection{Antibodies}

Table 2.6: Primary antibodies.

\begin{tabular}{l|l|l}
\hline Antibody & Host & Company \\
\hline Anti-Actin & Goat & Santa Cruz \\
Anti-Claudin-2 & Mouse & Invitrogen \\
Anti-Claudin-3 & Rabbit & Invitrogen \\
Anti-Claudin-4 & Mouse & Invitrogen \\
Anti-Claudin-5 & Mouse & Invitrogen \\
Anti-Claudin-18 & Rabbit & Invitrogen \\
Anti-EMP2 & Rabbit & Sigma \\
Anti-Occludin & Mouse & Santa Cruz \\
Anti-proSP-C & Rabbit & Millipore
\end{tabular}




\begin{tabular}{l|l|l} 
Anti-VE-cadherin & Goat & Santa Cruz \\
Anti-ZO-1 & Rabbit & Life Technologies
\end{tabular}

Both primary antibodies Anti-Pneumolysin (host: rabbit) as well as AntiS. pneumoniae (host: rabbit) are kind donations by Prof. Hammerschmidt, University of Greifswald, Germany.

Table 2.7 Secondary antibodies.

\begin{tabular}{|c|c|c|}
\hline Antibody & Host & Company \\
\hline Alexa Fluor ${ }^{\circledR} 488$ Anti-Mouse & Goat & Molecular Probes \\
\hline Alexa Fluor ${ }^{\circledR} 555$ Anti-Mouse & Goat & Molecular Probes \\
\hline Alexa Fluor ${ }^{\circledR} 594$ Anti-Mouse & Goat & Molecular Probes \\
\hline Alexa Fluor ${ }^{\circledR} 488$ Anti-Rabbit & Goat & Molecular Probes \\
\hline Alexa Fluor ${ }^{\circledR} 594$ Anti-Rabbit & Goat & Molecular Probes \\
\hline Alexa Fluor ${ }^{\circledR} 488$ Anti-Goat & Donkey & Molecular Probes \\
\hline Alexa Fluor ${ }^{\circledR} 488$ Anti-Goat & Rabbit & Molecular Probes \\
\hline Alexa Fluor ${ }^{\circledR} 594$ Anti-Goat & Rabbit & Molecular Probes \\
\hline Alexa Fluor ${ }^{\circledR} 488$ Anti-Mouse & Rabbit & Molecular Probes \\
\hline Alexa Fluor ${ }^{\circledR} 594$ Anti-Mouse & Rabbit & Molecular Probes \\
\hline Anti-Mouse IgG-HRP & Goat & Santa Cruz \\
\hline Anti-Rabbit IgG-HRP & Goat & Santa Cruz \\
\hline Anti-Goat IgG-HRP & Rabbit & Santa Cruz \\
\hline
\end{tabular}




\subsection{Bacteria}

Ex vivo human lung tissue and cells were infected with S. pneumoniae D39 wild type [243, 244] or S. pneumoniae D39Aply [245], carrying a pneumolysin deletion mutation [246], or S. pneumoniae D39 $\Delta s p x B$ with a deletion of the pyruvate oxidase gen [247]. For in vitro experiments, cells were infected with pneumococci deficient of the capsule (D39Acps) [248] or double deficient mutants of the capsule and pneumolysin (D39 $\Delta c p s \Delta p l y)$ [245].

\subsubsection{Cultivation of bacteria}

All S. pneumoniae strains were freshly plated from glycerol stocks on Columbia sheep blood agar plates and incubated at $37^{\circ} \mathrm{C}$ and $5 \% \mathrm{CO}_{2}$. Single colonies were transferred into sterile THY media (Bacto Todd Hewitt Broth supplemented with $0.5 \%$ Bacto Yeast Extract) and cultivated at $37^{\circ} \mathrm{C}$ to mid $\log$ phase $\left(\mathrm{OD}_{600}=0.2-0.4\right) . \mathrm{OD}_{600}=1$ equates to $10^{9}$ colony forming units $(\mathrm{CFU}) \cdot \mathrm{ml}^{-1}$. After centrifugation at $1800 \mathrm{~g}$ for $10 \mathrm{~min}$, bacterial pellet was resuspended in RPMI 1640 medium and diluted to a density of $10^{7} \mathrm{CFU} \cdot \mathrm{ml}^{-1}$.

\subsubsection{CFU assay}

Human lung tissue was infected with $S$. pneumoniae $\left(10^{6} \mathrm{CFU} \cdot \mathrm{ml}^{-1}\right)$ for $0 \mathrm{~h}$ (controlled load directly after infection), 8 and $24 \mathrm{~h}$. Afterwards, tissue samples were disrupted using the FastPrep-24 homogenizer and supernatants were plated on Columbia sheep blood agar plates. Bacterial colonies were counted and CFU per gram lung tissue were calculated. 


\subsection{Cell biology}

\subsubsection{Cell culture}

The cultivation of cells and human lung tissue was carried out under sterile conditions on a clean bench. Cells and tissue were cultured in a $\mathrm{CO}_{2}$ gassed incubator with $5 \% \mathrm{CO}_{2}$ at $37^{\circ} \mathrm{C}$.

\subsubsection{Cultivation of A549 cells}

The human alveolar basal epithelial cell line A549 was cultured in Ham's F-12 medium (with 10\% (v/v) heat-inactivated FCS and 1\% (v/v) L-glutamine). Cells were used to passage 20 and splitted at 90\% confluence. For that, culture medium was removed and cells were washed with PBS. Subsequently, $2 \mathrm{ml}$ of a Trypsin-EDTA solution was added to the flask and incubated until the cell layer was dispersed. Then, $8 \mathrm{ml}$ of medium was added and cells were aspirated by gently pipetting. Appropriate aliquots of cell suspension were transferred to new culture flasks with fresh medium.

\subsubsection{Isolation and cultivation of HUVECs}

Primary human umbilical vein endothelial cells (HUVEC) were obtained from umbilical cords and isolated as described [249-251]. HUVECs are grown on culture flasks coated with gelatin ( $0.5 \mathrm{mg}$ gelatin per $\mathrm{ml}$ sterile filtered $\mathrm{H}_{2} \mathrm{O}$ ). Flasks were coated by covering with a thin layer of gelatin and incubating for $30 \mathrm{~min}$ at $37^{\circ} \mathrm{C}$. Afterwards the gelatin was removed and cells were seeded. HUVECs were cultured in endothelial cell growth medium (with $10 \%$ (v/ v) heat-inactivated FCS and 1\% (v/ v) L-glutamine). For all experiments passage 1 was used.

\subsubsection{Preparation and culture of human lung tissue explants}

Fresh human lung explants were received from patients undergoing lung resection at thoracic surgery centers in Berlin. Written informed consent was obtained from all patients and the study was approved by the ethic committee at the Charité clinic (project EA2/079/13). The lung pieces originate from the 
periphery of the resected pulmonary lobes of tumor free normal lung tissue. Patients with pulmonary or systemic inflammation, tuberculosis, HIV or other chronic infections were excluded from this study. The fresh lung explants were transported in sterile RPMI 1640 medium on ice directly from the surgery to the laboratories and prepared immediately. Initially, the lung tissue was cut with a scalpel into little slices (thickness $\sim 3 \mathrm{~mm}$ ) and stamped into small cylinders (diameter $8 \mathrm{~mm}$ ). Each piece weighted about $100 \mathrm{mg}$. To remove residual amounts of antibiotics in the tissue and for tissue soothing, lung pieces were incubated in 24-well plates with RPMI 1640 medium at $37^{\circ} \mathrm{C}$ and $5 \% \mathrm{CO}_{2}$ overnight.

\subsubsection{Tissue infection}

Before infection, lung pieces were carefully transferred in well plates with fresh RPMI 1640 medium (with 10\% (v/v) heat-inactivated FCS). Human lung tissue explants were infected with $S$. pneumoniae strains $\left(10^{6} \mathrm{CFU} \cdot \mathrm{ml}^{-1}\right)$ or purified pneumolysin for $8 \mathrm{~h}$ and $24 \mathrm{~h}$ or as indicated. Therefore, $0.5 \mathrm{ml}$ control or infection medium was slowly injected into lung tissue, thereby assuring thorough stimulation of the tissue. All control tissue samples were injected with medium. After respective time points lung samples were fixed for immunohistochemistry, shock frozen in liquid nitrogen or frozen in TRIzol ${ }^{\circledR}$ and stored at $-80^{\circ} \mathrm{C}$ for further processing. Actual bacterial load was determined from serial dilutions of applied infection dose on Columbia sheep blood agar and incubation at $37^{\circ} \mathrm{C}$ for $24 \mathrm{~h}$ before colonies were counted and CFUs were calculated.

\subsubsection{Infection of cells}

Cells were infected with $S$. pneumoniae strains with MOI 50. The pneumococci were grown as described above, transferred either into Ham's F-12 or endothelial basal medium containing 2\% (v/ v) heat-inactivated FCS and adjusted to the appropriate dilutions. Bacteria then were added to the cells and incubated for $8 \mathrm{~h}$ or $16 \mathrm{~h}$ at $37^{\circ} \mathrm{C}$ and $5 \% \mathrm{CO}_{2}$. 
For adenoviral infection, HUVECs were seeded in 8-well $\mu$ Slides. At a confluency of $70-80 \%$, cells were infected by adding $10^{6}$ plaque-forming units (PFU) of GFP-Occludin adenovirus and 1\% (v/v) polybrene to each well. After $24 \mathrm{~h}$, transduction was verified by microscopic analysis. HUVECs were subsequent infected with $S$. pneumoniae strains as described above.

\subsubsection{Stimulants}

Human lung tissue and cells were infected and simultaneously stimulated with catalase. Therefore, bacterial suspension was mixed with catalase (300 $\mathrm{U} \cdot \mathrm{ml}^{-1}$ for human lung tissue and $192 \mathrm{U}$ for HUVECs). Furthermore, human lung tissue was stimulated with $10 \mu \mathrm{g} \cdot \mathrm{ml}^{-1}$ pneumolysin. Pneumolysin was kindly provided and purified as described before by Timothy J. Mitchell (University of Glasgow, United Kingdom) [252]. 


\subsection{Molecular biology}

\subsubsection{GFP-occludin adenovirus production}

For transient overexpression of occludin, an adenoviral vector system was chosen. Advantages of adenoviral overexpression in comparison to transfection of pure DNA vectors are the high transduction efficiency of nearly $100 \%$ with no restriction of cell viability and it is also capable for primary cells. Additionally, after the adenovirus is transduced into the target cell and is transported to the nucleus, it does not integrate into the host genome and is not replicated during cell division. Packaging and production of recombinant adenoviruses carrying the GFP-tagged full-length human occludin was achieved using the Gateway ${ }^{\circledR}$ technology (Invitrogen, Carlsbad, USA) according the manufacturer's instructions. pDONR ${ }^{\mathrm{TM}} 221$ was chosen as donor vector and pAd/CMV/V5-GW/lacZ was used as destination vector. Escherichia coli BJ5183 electroporation-competent cells were purchased from Stratagene (La Jolla, CA). Recombinant adenoviruses were amplified using HER911 cells, harvested and purified with a $\mathrm{CsCl}$ density-gradient centrifugation. Virus quantification was determined with a plaque assay and $10^{9} \mathrm{PFU}$ per $\mathrm{ml}$ were calculated. Adenovirus production was done in cooperation with AG Prof. Dr. Birgit Sawatzki (Institute for Medical Immunology, Charité Berlin).

\subsubsection{RNA isolation from tissue}

For mRNA analysis, $1 \mathrm{ml}$ TRIzol ${ }^{\circledR}$ was added to each lung tissue sample and homogenized using the FastPrep-24 homogenizer on dry ice. The samples then were frosted at $-80^{\circ} \mathrm{C}$ for at least $24 \mathrm{~h}$. The homogenized samples were thawed and kept at RT for 5 min to permit complete dissociation of the nucleoprotein complex. Subsequently, $0.2 \mathrm{ml}$ of chloroform was added and the tubes were shaken vigorously by hand for 15 seconds. After another short incubation at $\mathrm{RT}$, the samples were centrifuged at $13000 \mathrm{~g}$ for $15 \mathrm{~min}$ at $4^{\circ} \mathrm{C}$. Due to centrifugation, the mixture separates into a lower phenol-chloroform phase and an upper aqueous phase, which contains the RNA. The aqueous phase was transferred into a new Eppendorf tube and $0.5 \mathrm{ml}$ of isopropanol and $1 \mu \mathrm{l}$ of Glycoblue were added to each sample. For precipitation, the samples were 
stored at $-20^{\circ} \mathrm{C}$ for at least $30 \mathrm{~min}$. After centrifugation at $13000 \mathrm{~g}$ for $15 \mathrm{~min}$ at $4^{\circ} \mathrm{C}$, the supernatant was discarded and the pellet was washed with $1 \mathrm{ml}$ of $75 \%$ cold ethanol. For that, the samples were vortexed and centrifuged at $13000 \mathrm{~g}$ for $10 \mathrm{~min}$ at $4^{\circ} \mathrm{C}$. The supernatant was carefully removed and the pellet was air-dried until all the remaining ethanol was gone. RNA was dissolved in $50 \mu \mathrm{l} d \mathrm{~d} \mathrm{H}_{2} \mathrm{O}$ and RNA concentration was measured at the NanoDrop. To remove potential DNA from RNA samples, RNase-Free DNase was used according to the manufacturer's instruction. Following, RNA was precipitated with Roti $^{\circledR}$-Aqua-P/C/I and isolated as described before. $1 \mu \mathrm{g}$ RNA was used for transcription to cDNA. The rest of the RNA samples were stored at $-80^{\circ} \mathrm{C}$.

\subsubsection{RNA transcription to cDNA}

RNA was transcribed to cDNA using a High Capacity Reverse Transcription Kit. $4 \mu \mathrm{l}$ diluted RNA (250 $\mathrm{ng} \cdot \mu^{-1}$ ) was pipetted into a $0.5 \mathrm{ml}$ RNAse-free Eppendorf tube and stored on ice. A mastermix was prepared containing $10.2 \mu \mathrm{l}$ dd $\mathrm{H}_{2} \mathrm{O}, 2 \mu \mathrm{l}$ reverse transcription buffer, $2 \mu \mathrm{l}$ random primers, $0.8 \mu \mathrm{l}$ dNTPs and $1 \mu \mathrm{l}$ reverse transcriptase per reaction. $16 \mu \mathrm{l}$ mastermix were added per Eppendorf tube yielding a final volume of $20 \mu \mathrm{l}$. The reaction mixture was shortly vortexed and centrifuged. The tubes were incubated in a thermo cycler for $10 \mathrm{~min}$ at $25^{\circ} \mathrm{C}$, then for $2 \mathrm{~h}$ at $37^{\circ} \mathrm{C}$, and lastly for $5 \mathrm{sec}$ at $85^{\circ} \mathrm{C}$. After this incubation, the samples were diluted with $50 \mu \mathrm{dd} \mathrm{H}_{2} \mathrm{O}$ per tube and stored at $-20^{\circ} \mathrm{C}$.

\subsubsection{Quantitative RT-PCR}

Relative mRNA expression was measured using quantitative RT-PCR. cDNA samples were thawed and stored on ice. A reaction mixture was prepared containing $10 \mu \mathrm{l}$ Gene Expression Master Mix, $1 \mu \mathrm{l}$ Taqman Assay, and $4 \mu \mathrm{ldd}$ $\mathrm{H}_{2} \mathrm{O} .15 \mu \mathrm{l}$ of the reaction mixture and $5 \mu \mathrm{l}$ of a diluted cDNA sample were added per 96-well. Quantitative RT-PCR was performed on an ABI 7300 instrument. The input was normalized to the expression of GAPDH and relative expression (relative quantity, $\mathrm{RQ}$ ) of the respective gene in untreated tissue was set as 1 . 
Table 2.8: Taqman Gene Expression Assays for quantitative RT-PCR.

\begin{tabular}{l|l}
\hline Gen & Assay-ID \\
\hline hCDH5 & Hs00901463_m1 \\
hCLDN2 & Hs00252666_s1 \\
hCLDN3 & Hs00265816_s1 \\
hCLDN4 & Hs00976831_s1 \\
hCLDN5 & Hs01561351_m1 \\
hCLDN18 & Hs00212584_m1 \\
hGAPDH & Hs02758991_g1 \\
hIL18 & Hs01555410_m1 \\
hOCLN & Hs00170162_m1 \\
hTJP1 & Hs01551861_m1 \\
\hline
\end{tabular}




\subsection{Biochemistry}

\subsubsection{Tissue homogenization}

For western blot purposes, $500 \mu \mathrm{l}$ RIPA lysis buffer (50 mM Tris, $150 \mathrm{mM} \mathrm{NaCl}$, $1 \%$ (v/ v) NP40 substitute Igepal, 0.5\% (w/ v) Na-deoxycholate, 5 mM EDTA, $0.1 \%(\mathrm{w} / \mathrm{v}) \mathrm{SDS}, 1 \%(\mathrm{v} / \mathrm{v})$ protease inhibitors) was added to each lung tissue sample, and subsequently homogenized using the FastPrep-24 homogenizer on dry ice. After centrifugation at $13000 \mathrm{~g}$ for $15 \mathrm{~min}$ at $4^{\circ} \mathrm{C}$, supernatant was collected in a new Eppendorf tube and stored at $-20^{\circ} \mathrm{C}$.

\subsubsection{Quantification of protein levels}

Protein levels were determined by DC Protein Assay according to the manufacturer's instructions. The DC Protein Assay is a colorimetric assay based on the Lowry Assay [253]. The proteins are pre-treated with an alkaline copper tartrate solution and subsequent reduce the Folin reagent. The absorption at $750 \mathrm{~nm}$ is correlated to the concentration of protein within the sample. The standard curve was created using standards containing from 0.2-1.5 mg $\cdot \mathrm{ml}^{-1}$ BSA. The samples were diluted 1:10 with RIPA lysis buffer, incubated with DC Protein Assay reagents as indicated and finally absorptions were measured by a spectrophotometer.

\subsubsection{Western blot}

In order to investigate cell junction protein expression, human lung tissue was infected with S. pneumoniae strains for indicated times and doses. For protein extraction, 80-120 mg shock frozen tissue was weighed and put into 8 volumes of RIPA lysis buffer following disruption by the FastPrep-24 homogenizer. Afterwards, protein lysate was heated in Laemmli buffer at $95^{\circ} \mathrm{C}$, subjected to SDS-PAGE at 100-120 V for $1.5 \mathrm{~h}$ using a wet blot system. SDS-polyacrylamide gels were then blotted onto PVDF membranes at $100 \mathrm{~V}$ for $1 \mathrm{~h}$. After transfer of proteins, membranes were blocked with $5 \%$ (v/ v) non-fat dry milk powder buffer in PBS for $1 \mathrm{~h}$ at RT. Proteins were detected with specific antibodies, which were applied to the membrane overnight at $4^{\circ} \mathrm{C}$. Following antibodies were used for detection: VE-cadherin, occludin, ZO-1, actin, claudin-2, 
claudin-3, claudin-4, claudin-5, claudin-18. All antibodies were diluted 1:100 in blocking buffer. In all experiments actin was detected on the same membrane to ensure equal protein load. Membranes were subsequent incubated with appropriate secondary horseradish peroxidase (HRP)-labeled antibodies (diluted 1:2000 in blocking buffer) for $1 \mathrm{~h}$ at RT. Working solution of the Pierce ECL Western Blotting Substrate was prepared according to the manufacturer's instructions and added to membranes for 1 minute. The membranes were removed from the substrate, placed in plastic sheet protectors, exposed to CLXPosure Film and developed. All buffers and gels used for western blot analysis are listed below (Table 2.9). Densitometric analysis of western blots was carried out to quantify protein levels and correlate infected samples to controls. Values represent the mean fold change + SEM of respective cell junction protein versus control at respective time point, calculated from the band intensity and normalized to actin.

Table 2.9: Buffers and gels for western blot analysis.

\begin{tabular}{|c|c|}
\hline Buffer/ Gel & Composition \\
\hline Laemmli buffer & $\begin{array}{l}1 \mathrm{ml} \text { Tris-HCl, pH } 6.8(500 \mathrm{mM}) \\
0.8 \mathrm{ml} \text { Glycerol } \\
1.6 \mathrm{ml} \text { SDS }(10 \% \mathrm{w} / \mathrm{v}) \\
0.4 \mathrm{ml} \text { Bromphenol blue }(1 \% \mathrm{w} / \mathrm{v}) \\
0.4 \mathrm{ml} \mathrm{B-} \mathrm{Mercaptoethanol}(1 \% \mathrm{w} / \mathrm{v}) \\
3.8 \mathrm{ml} \mathrm{dd} \mathrm{H}_{2} \mathrm{O}\end{array}$ \\
\hline Electrophoresis buffer & $\begin{array}{l}3 \mathrm{~g} \text { Tris-Base } \\
14.4 \mathrm{~g} \text { Glycine } \\
1 \mathrm{~g} \text { SDS } \\
\text { Ad } 1000 \mathrm{ml} \mathrm{dd} \mathrm{H}_{2} \mathrm{O}\end{array}$ \\
\hline Blot buffer & $\begin{array}{l}3 \mathrm{~g} \text { Tris-Base } \\
14.4 \mathrm{~g} \text { Glycine } \\
200 \mathrm{ml} \text { Methanol } \\
\text { Ad } 1000 \mathrm{ml} \mathrm{dd} \mathrm{H}_{2} \mathrm{O}\end{array}$ \\
\hline SDS Collection gel & $\begin{array}{l}2.5 \mathrm{ml} \text { Tris-HCl, pH } 6.8(500 \mathrm{mM}) \\
100 \mu \mathrm{l} \text { SDS }(10 \% \mathrm{w} / \mathrm{v})\end{array}$ \\
\hline
\end{tabular}




\begin{tabular}{|c|c|}
\hline & $\begin{array}{l}1.33 \mathrm{ml} \text { Bis-Acrylamide (40\%) } \\
10 \mu \mathrm{l} \mathrm{TEMED} \\
50 \mathrm{\mu l} \text { Ammonium persulfate (10\%) } \\
6 \mathrm{ml} \mathrm{dd} \mathrm{H}_{2} \mathrm{O}\end{array}$ \\
\hline SDS Separation gel (10\%) & $\begin{array}{l}2,5 \mathrm{ml} \text { Tris- } \mathrm{HCl}, \mathrm{pH} 8,8(1,5 \mathrm{M}) \\
100 \mu \mathrm{l} \mathrm{SDS}(10 \% \mathrm{w} / \mathrm{v}) \\
2.5 \mathrm{ml} \text { Bis-Acrylamide }(40 \%) \\
10 \mu \mathrm{l} \mathrm{TEMED} \\
50 \mu \mathrm{l} \mathrm{Ammonium} \mathrm{persulfate}(10 \%) \\
4.85 \mathrm{ml} \mathrm{dd} \mathrm{H}_{2} \mathrm{O}\end{array}$ \\
\hline
\end{tabular}

\subsubsection{Cytotoxicity assay}

To determine cytotoxicity ex vivo, the Cytotoxicity Detection Kit was used. The Cytotoxicity Detection Kit is a colorimetric measurement of lactate dehydrogenase $(\mathrm{LDH})$ released from damaged cells. $\mathrm{LDH}$ is a cytoplasmic enzyme that is ubiquitous expressed in cells and released during cell or tissue damage. Lung pieces were prepared as described before, weighed and infected with $S$. pneumoniae $\left(10^{6} \mathrm{CFU} \cdot \mathrm{ml}^{-1}\right)$ for 8 and $24 \mathrm{~h}$. After respective time points, supernatant and tissue was collected. From here on, all samples were kept on ice. Lung tissue pieces were homogenized in 6-fold amount of lysis buffer (RPMI 1640 medium, 10\% (v/v) heat-inactivated FCS, 1\% (v/v) Triton X-100) based on each lung pieces weight. Supernatants were centrifuged at $2000 \mathrm{~g}$ for $10 \mathrm{~min}$ at $4^{\circ} \mathrm{C}$, lung homogenates were centrifuged at $13000 \mathrm{~g}$ and appropriate dilutions were prepared. $50 \mu \mathrm{l}$ of the supernatants, respective homogenates and background controls were added to a 96 -well plate. Then, $50 \mu \mathrm{l}$ of fresh reaction mixture was added to each sample and after an incubation of $20 \mathrm{~min}$ in darkness, the absorbance was measured by a spectrophotometer at $490 \mathrm{~nm}$. The percentage cytotoxicity in lung tissue was calculated as follows: Cytotoxicity $(\%)=\mathrm{LDH}$ (supernatant) $\cdot[\mathrm{LDH}$ (homogenates) - LDH (supernatant)] $]^{-1}$ x 100 . 


\subsubsection{Enzyme-linked immunosorbent assay}

IL1-B in cell-free supernatants was quantified by an enzyme-linked immunosorbent assay (ELISA) Ready-SET-Go! ${ }^{\circledR}$ Kit according to manufacturer's instructions. In brief, 96-well plate was incubated with capture antibody in coating buffer over night at $4^{\circ} \mathrm{C}$. The plate was washed three times with wash buffer and incubated with blocking diluent for $1 \mathrm{~h}$ at RT. After another washing, standard and samples were transferred to the plate and incubated for $2 \mathrm{~h}$ at RT. This was followed by five times washing and incubation of detection antibody solution for $1 \mathrm{~h}$ at RT. Then, the plate was washed five times, incubated with an Avidin-HRP diluent for 30 min at RT in the dark and subsequently washed again. Substrate solution was added, incubated for 15 min and reaction was stopped by adding stop solution. The absorbance was measured in a spectrophotometer at $450 \mathrm{~nm}$. 


\subsection{Electric cell-substrate impedance sensing}

Electric cell-substrate impedance sensing (ECIS) is a non-invasive and labelfree method to characterize adherent cell monolayers over time. This technology was invented by Giaever and Keese [254, 255] and allows simultaneous measurements of impedance $(\mathrm{Z})$, paracellular resistance or permeability $\left(R_{b}\right)$, the spacing between the cells $(\alpha)$ as well as the cell membrane capacitance $\left(\mathrm{c}_{\mathrm{m}}\right)$. Morphological changes of the cells alter the current paths and result in changes of impedance. For this approach, cells were seeded on gold film electrodes, which are embedded on the bottom of an 8-well ECIS array (8W10E). The used system was the ECIS Model 1600R with two ECIS array stations hosted in a $\mathrm{CO}_{2}$ gassed incubator. All ECIS experiments were conducted at a frequency of $40 \mathrm{kHz}$ and a measurement interval of 8 sec. Values were normalized as the ratio of measured resistance to baseline resistance. Cells were grown to confluence and infected with different $S$. pneumoniae strains at MOI 50. 


\subsection{Immunohistochemistry}

By immunohistochemistry the localization of proteins in tissue sections can be detected by dye-labeled antibodies.

\subsubsection{Tissue embedding and sectioning}

Tissue embedding and sectioning was done by Dr. Olivia Kershaw (Department of Veterinary Pathology, FU Berlin). After infection, lung tissue samples were freshly fixed in 3\% paraformaldehyde (in PBS). For paraffin embedding the tissue capsules remained sequently in the reagents listed below (Table 2.10). The tissue was initially dehydrated in an ascending alcohol series and then embedded in paraffin. Finally, the tissue samples were placed in metal capsules and poured with liquid paraffin. The blocks cooled at $4^{\circ} \mathrm{C}$, so the metal capsules could be easily removed from the paraffin blocks. The paraffinembedded tissue samples were then sectioned into $10 \mu \mathrm{m}$ thick slices with a sledge microtome (Jung, Heidelberg). These sections were applied to microscope slides (Superfrost ${ }^{\circledR}$ ), air-dried and finally dried for $1 \mathrm{~h}$ in an incubator at $60^{\circ} \mathrm{C}$.

Table 2.10: Paraffin embedding of tissue samples.

\begin{tabular}{l|l|l}
\hline Reagent & Time & Repetitions \\
\hline $10 \%$ formalin & $1 \mathrm{~h}$ & \\
tap water & $45 \mathrm{~min}$ & \\
$70 \%$ ethanol & $45 \mathrm{~min}$ & \\
$85 \%$ ethanol & $45 \mathrm{~min}$ & 2 \\
$96 \%$ ethanol & $45 \mathrm{~min}$ & 2 \\
Isopropanol & $1 \mathrm{~h}$ & 2 \\
n-Butyl acetate & $1 \mathrm{~h}$ & 4 \\
Paraplast Plus ${ }^{\circledR}$ & $1 \mathrm{~h}\left(60^{\circ} \mathrm{C}\right)$ & \\
\hline
\end{tabular}




\subsubsection{Epitope recovery and sample labeling}

For deparaffinization the tissue sections were heated at $60^{\circ} \mathrm{C}$ overnight and washed multiple times with Roticlear. Afterwards the tissue rehydrated in a descending alcohol series, ending in 0.01M PBS (Table 2.11).

Table 2.11: Deparaffinization and rehydrating of tissue samples.

\begin{tabular}{l|l|l}
\hline Reagent & Time & Repetitions \\
\hline Roticlear & $15 \mathrm{~min}$ & 3 \\
$100 \%$ ethanol & $15 \mathrm{~min}$ & \\
$100 \%$ ethanol & $1 \mathrm{~min}$ & \\
$96 \%$ ethanol & $10 \mathrm{~min}$ & \\
$80 \%$ ethanol & $5 \mathrm{~min}$ & \\
$70 \%$ ethanol & $5 \mathrm{~min}$ & 3 \\
$50 \%$ ethanol & $5 \mathrm{~min}$ & $5 \mathrm{~min}$ \\
PBS & & \\
\hline
\end{tabular}

Paraformaldehyde, used for fixation of tissue samples, crosslinks proteins in tissue samples and therefore can affect epitope recognition by the complementary antibodies. To unmask the antibody epitopes heat-induced epitope retrieval was performed. For this approach, tissue sections were incubated in Tris-EDTA buffer (10 mM Tris, $1 \mathrm{mM}$ EDTA, $\mathrm{pH} 9.0)$ at $95^{\circ} \mathrm{C}$ for 30 min. After epitope recovery, cells were permeabilized using 1\% Triton X-100 for 15 min and blocking was performed for 30 min using $5 \%$ serum of secondary antibody's origin, $1 \%$ BSA and $0.05 \%$ Tween-20. To prevent drying of the slices, the staining was performed in a dark moisture chamber. Primary antibodies (Table 2.6) were incubated overnight at $4^{\circ} \mathrm{C}$, followed by labeling with corresponding secondary antibodies for $1 \mathrm{~h}$ at RT (Table 2.7). For some experiments cells were double stained using the same procedure. Subsequently, nuclear counterstaining was done with DAPI and slides were mounted in Mowiol $\left(1 \mathrm{~g} \cdot \mathrm{ml}^{-1}\right.$ glycerol, $0.4 \mathrm{~g} \cdot \mathrm{ml}^{-1}$ Mowiol 4-88, $25 \mathrm{mg} \cdot \mathrm{ml}^{-1} 1$,4Diazabicyclo[2.2.2]octan, $130 \mathrm{mM}$ Tris-HCl, $\mathrm{pH}$ 8.5). 


\subsection{Microscopy}

Immunofluorescence of cells and human lung slices was analyzed by spectral confocal microscopy using a LSM 780 (objectives: Plan Apochromat 63x/1.40 oil DIC M27 and 40x/1.30 oil DIC M27). Based on a spectral image lambda stack, linear unmixing of tissue autofluorescence and overlapping spectra of fluorophores was performed using ZEN 2012 software. Each fluorescence image is a maximum intensity projection of a z-stack representing the entire $10 \mu \mathrm{m}$ section. To reveal lung and cell morphology, images were combined with differential interference contrast (DIC). All image sets were acquired using equal configurations. Images were processed using ZEN 2012 and ImageJ software (http://imagej.nih.gov/ij/). For 3D projections z-stacks were surface rendered, movies were designed using ZEN 2011 and compressed to quick time format with Camtasia Studio 5.0.

\section{$2.9 \quad$ Statistical analysis}

Data were statistically analyzed using GraphPad Prism software and are presented as means \pm SEM of at least three independent experiments. The nonparametric rank sum Mann-Whitney U-test was used to test for significant differences between means. A value of $p<0.05$ was considered statistically significant. 


\section{Results}

\subsection{Distinct expression patterns of cell junction proteins in human lung tissue}

Initially, cell junction proteins were analyzed for their constitutive expression and structure in naive human lung tissue. The obtained human lung tissue originated from the lower respiratory tract and consisted of bronchioles and alveoli. The bronchioles divide into smaller terminal bronchioles and each of the terminal bronchioles divides to form respiratory bronchioles. Terminal bronchiolar epithelium is characterized by single-layered, nearly cuboidal club cells and goblet cells while respiratory bronchiolar epithelium is composed of epithelial cells with cilia. The inner lining of these bronchioles is thin and surrounded by a layer of smooth muscle. In contrast, alveoli consist of an epithelial layer and extracellular matrix surrounded by capillaries. Flat type I and cubic type II alveolar epithelial cells heterogeneously line the alveolar surface. Consequently, there are three classes of cell-cell interfaces: (i) type Itype I cell interface, (ii) type I-type II cell interface and (iii) type II-type II cell interface. In addition, alveoli contain alveolar macrophages, subepithelial connective tissue, fibroblasts, collagen and elastic fibers. Histological sections of human lung tissue were probed for each examined cell junction protein and expression patterns were visualized in four different sections: terminal bronchiolar epithelium, respiratory bronchiolar epithelium, alveolus and a larger blood vessel. To specify and verify the distribution of a junction protein and to characterize the arrangement of two junction proteins to each other, additionally several costainings were conducted.

\subsubsection{VE-cadherin}

The vascular endothelial adhesion molecule VE-cadherin was not expressed in terminal and respiratory bronchiolar epithelium (Figure 3.1a, b). It appeared typically as continuous junctional band along the intercellular junction in 
endothelial cells of capillaries (Figure 3.1c) and larger lung vessels (Figure $3.1 \mathrm{~d})$.

a)

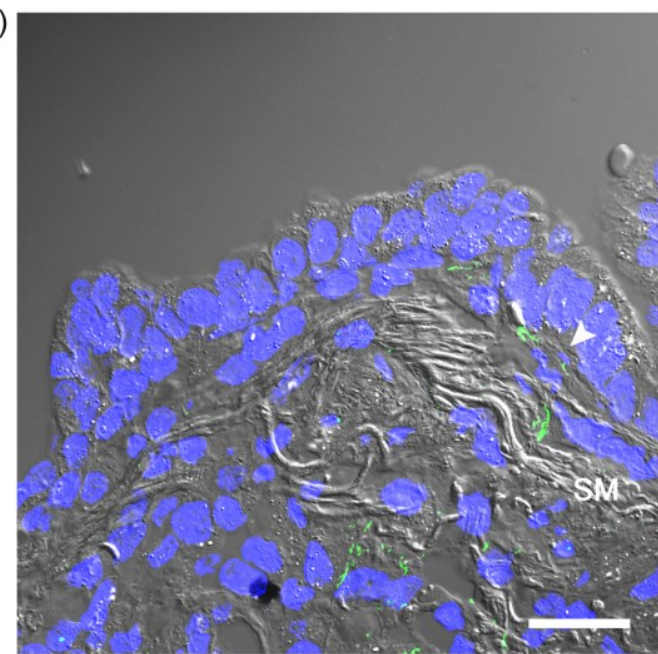

c)
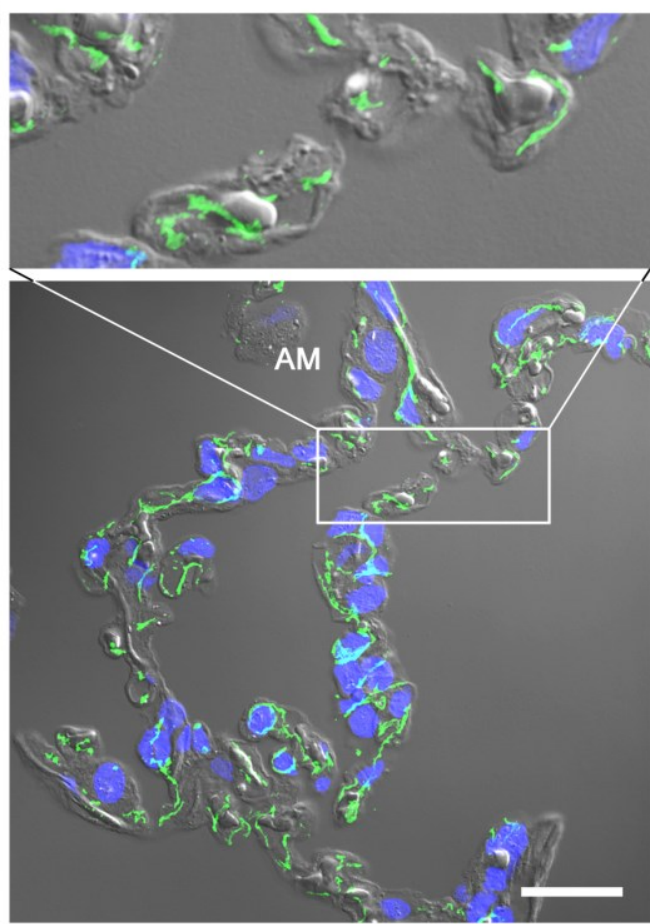

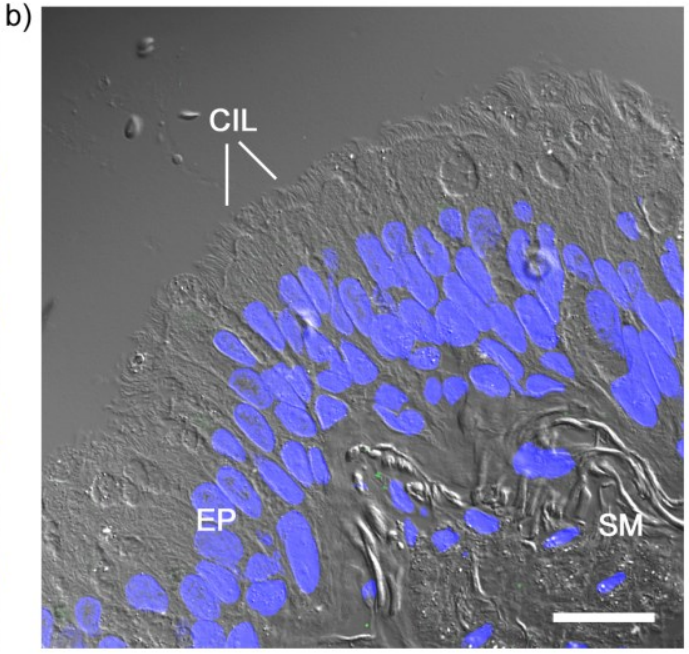

d)

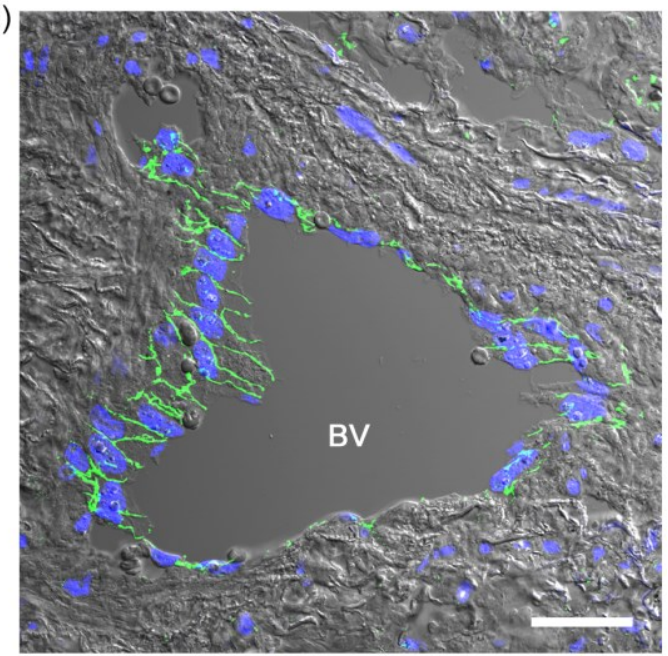

Figure 3.1: VE-cadherin is expressed in capillary endothelial cells and blood vessels. Histological sections of human lung tissue were probed for VE-cadherin (green), nuclei (blue) were counterstained with DAPI and tissue structure was visualized by differential interference contrast. Terminal (a) and respiratory (b) bronchiolar epithelium, an alveolus (c) and a blood vessel (d) are depicted. Abbreviations: AM, alveolar macrophage; BV, blood vessel; CIL, cilia of ciliated columnar cells; EP, epithelium; SM, smooth muscle band. White arrowhead point towards a capillary within human bronchiolar epithelium. Bar represents $20 \mu \mathrm{m}$. 


\subsubsection{Occludin}

Occludin was expressed at the apical borders of the terminal (Figure 3.2a) and respiratory (Figure 3.2b) bronchiolar epithelium. While this two-dimensional assessment of immunofluorescent images obtained from bronchiolar sections of lung tissue revealed a continuous belt-like structure of occludin, this approach is limited in scope as it is restricted to vizualisation of only one section plane. To illustrate human bronchiolar epithelium more detailed, zstacks of an entire $10 \mu \mathrm{m}$ section were surface rendered. A three-dimensional reconstruction illustrated occludin as a grid-like structure covering bronchiolar epithelial cells (Supplementary video 1). Furthermore, occludin was distributed uniformly in the alveolus as well as in endothelial cells of a larger blood vessel (Figure 3.2c, d).

To specify the expression pattern of occludin in the alveolar epithelium, costaining of occludin with the alveolar type II cell marker pro-surfactant protein C (proSP-C) was examined. Simultaneous staining showed a band-like expression of occludin at the type I-type I cell interface as well as at the interface of type II alveolar epithelial cells to adjacent cells (Figure 3.3a, white arrowhead points towards a type I cell and open arrowheads point to type II cells). Furthermore, colocalization of occludin and the endothelial cell marker VE-cadherin verified the presence of occludin also in capillary endothelial cells (Figure 3.3b) and larger blood vessels (Figure 3.3c).

In order to analyze how these two junction proteins are organized and whether they are anchored in the same area along the intercellular junction of endothelial cells or are spatially divided, a three-dimensional reconstruction of occludin and VE-cadherin stained human lung tissue was performed. Firstly, this three-dimensional reconstruction exemplarily visualized the complex architecture of the junctional organization within the human alveolus (Supplementary video 2). Secondly, it demonstrated that both, occludin and VE-cadherin, are lining out the capillary endothelium and are closely localized to each other whereas occludin additionally connected alveolar epithelial cells. 
During the further characterization of expression pattern of other cell junction proteins, costainings with VE-cadherin were conducted to verify or exclude endothelial expression of an analyzed junction protein and occludin was preferred as marker for endo- as well as epithelial cells.

a)

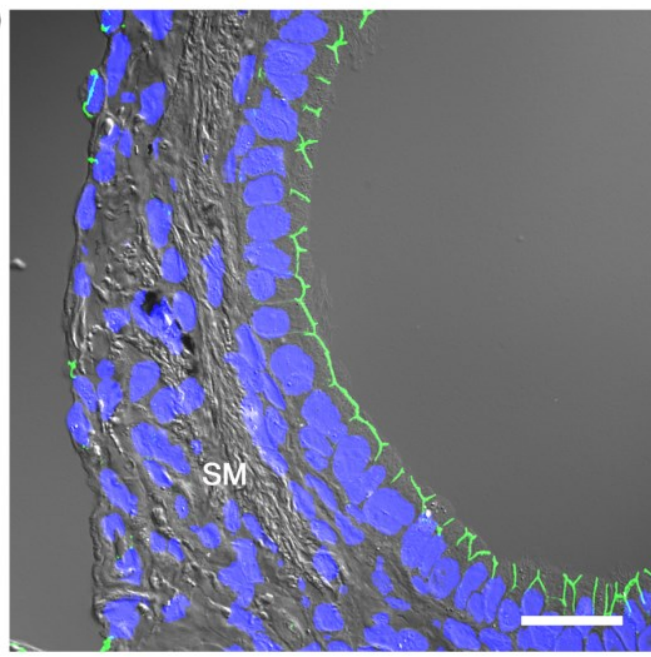

c)

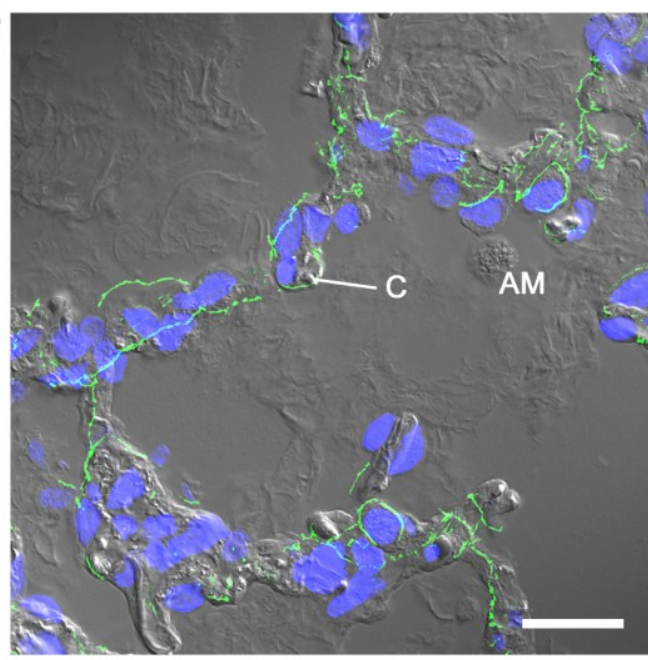

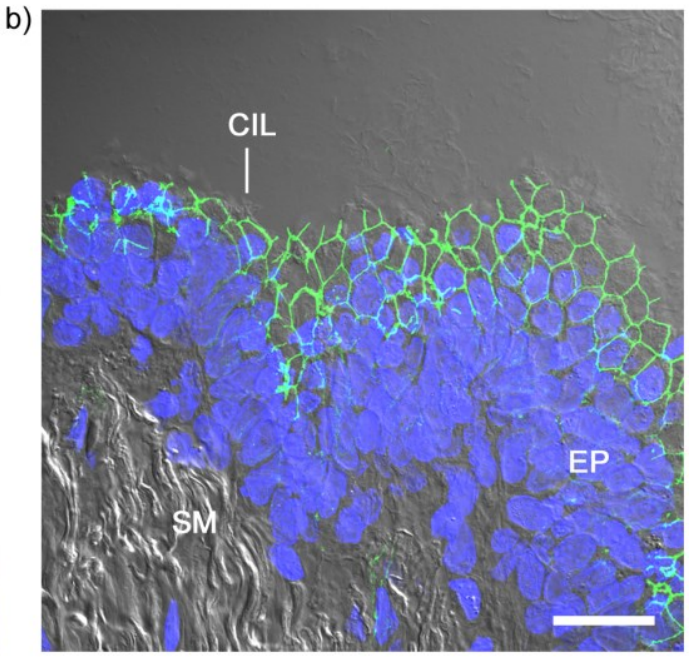

d)

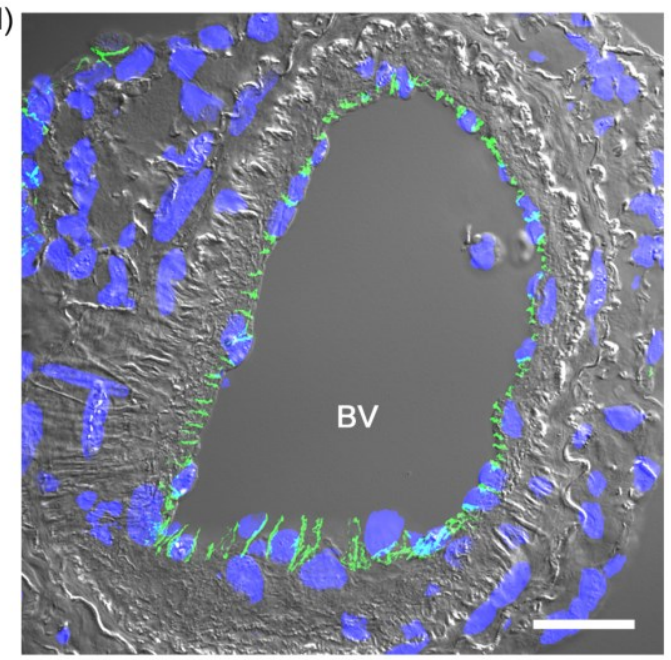

Figure 3.2: Occludin is expressed throughout the bronchiolar and alveolar epithelia and the vascular endothelium. Histological sections of human lung tissue were probed for occludin (green), nuclei (blue) were counterstained with DAPI and tissue structure was visualized by differential interference contrast. Terminal (a) and respiratory (b) bronchiolar epithelium, an alveolus (c) and a blood vessel (d) are depicted. Abbreviations: AM, alveolar macrophage; BV, blood vessel; C, capillary; CIL, cilia of ciliated columnar cells; EP, epithelium; SM, smooth muscle band. Bar represents $20 \mu \mathrm{m}$. 
a)
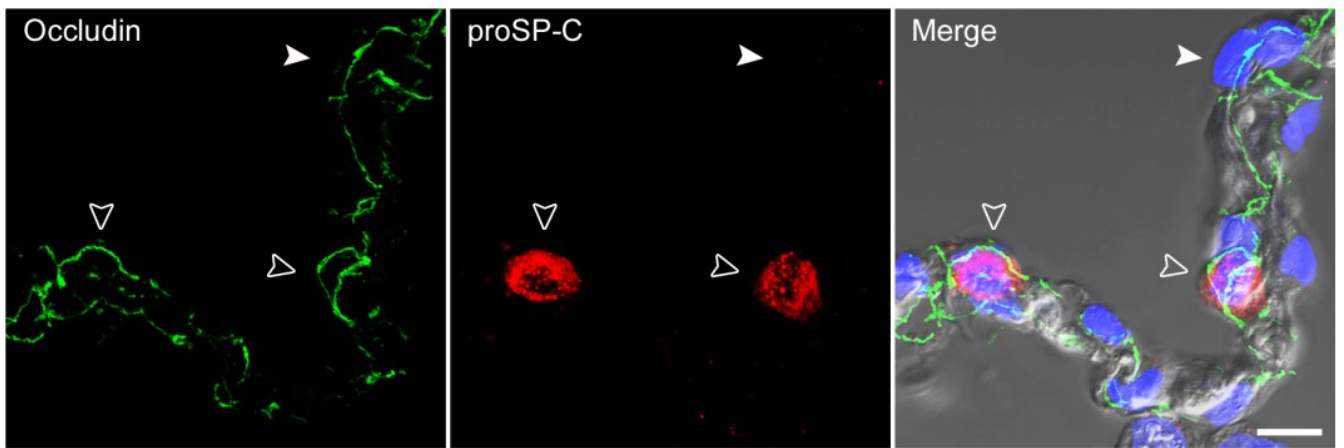

b) Occludin
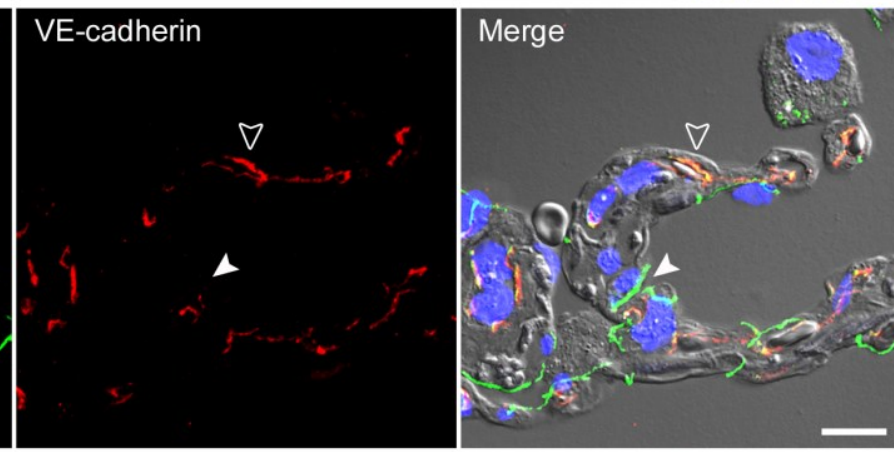

c)
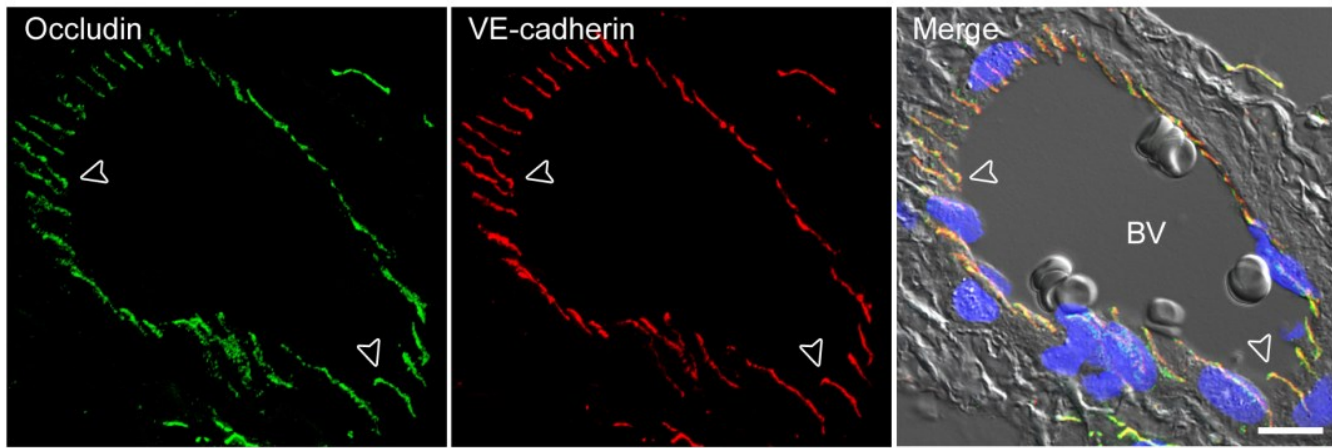

Figure 3.3: Occludin is expressed at the type I-type I cell interface as well as at the interface of type II alveolar epithelial cells to adjacent cells and colocalizes with VEcadherin in endothelial cells. Histological sections of human lung tissue were probed for occludin (green), the cell marker for alveolar type II cells (proSP-C) and VE-cadherin (all red), nuclei (blue) were counterstained with DAPI and tissue structure was visualized by differential interference contrast. Costaining of occludin with proSP-C (a) is depicted. The white arrowhead points towards an alveolar type I cell and open arrowheads point to alveolar type II cells. Costaining of occludin with VE-cadherin in an alveolus (b) and a blood vessel (c) is depicted. The white arrowhead points towards an alveolar epithelial cell and open arrowheads point to endothelial cells. Abbreviation: BV, blood vessel. Bar represents $10 \mu \mathrm{m}$.

\subsubsection{Zonula occludens-1}

In accordance with occludin, ZO-1 formed band-like structures throughout the terminal and respiratory bronchiolar epithelium (Figure 3.4a, b), the alveolus (Figure 3.4c) as well as the vascular endothelium of blood vessels (Figure 3.4d). 
a)

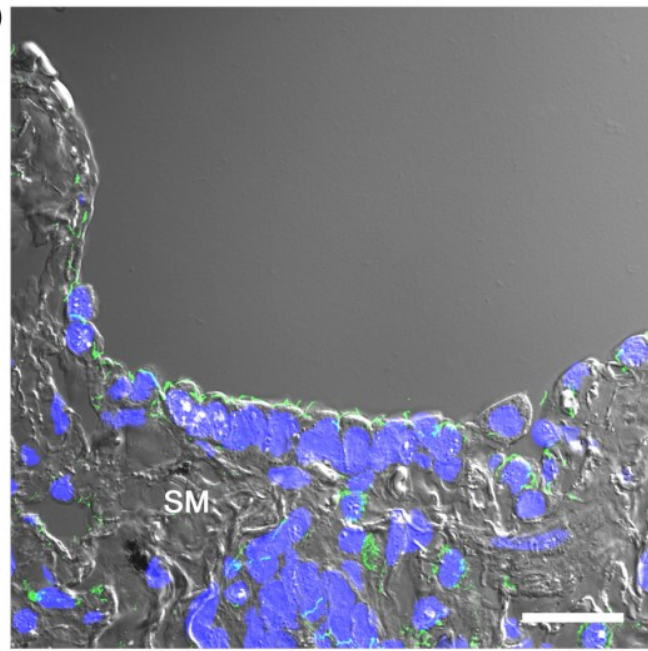

c)

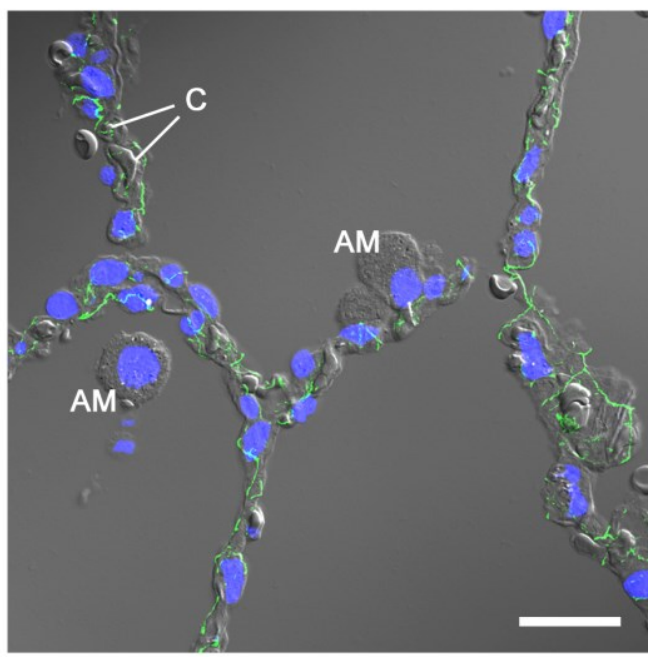

b)

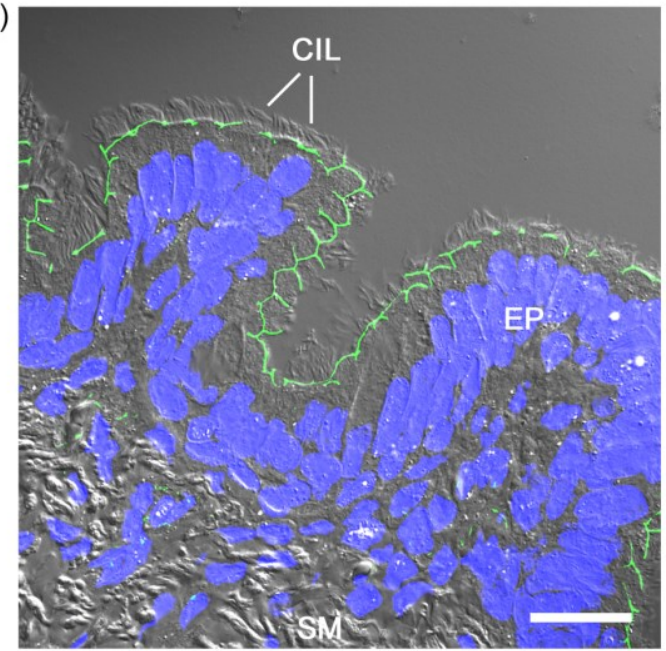

d)

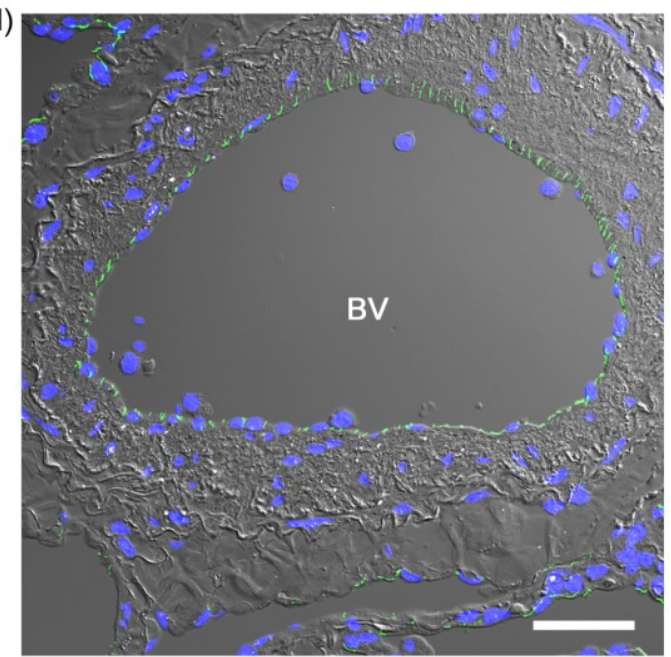

Figure 3.4: ZO-1 is expressed in epithelial and endothelial cells. Histological sections of human lung tissue were probed for ZO-1 (green), nuclei (blue) were counterstained with DAPI and tissue structure was visualized by differential interference contrast. Terminal (a) and respiratory (b) bronchiolar epithelium, an alveolus (c) and a blood vessel (d) are depicted. Abbreviations: AM, alveolar macrophage; BV, blood vessel; C, capillary; CIL, cilia of ciliated columnar cells; EP, epithelium; SM, smooth muscle band. Bar represents $20 \mu \mathrm{m}$.

Costaining of ZO-1 with the alveolar type I cell marker epithelial membrane protein 2 (EMP2) revealed that ZO-1 was expressed at the type I-type I cell interface as well as at the interface of type II alveolar epithelial cells to neighboring cells, as demonstrated by a positive ZO-1 staining in EMP2 positive but also EMP2 negative cells (Figure 3.5a). Furthermore, a high level of colocalization of ZO-1 with occludin in alveolar epithelial cells (Figure 3.5b, white arrowhead) and capillaries (Figure 3.5b, open arrowhead) was recognized. Finally, the colocalization of ZO-1 with the endothelial specific 
marker VE-cadherin in capillaries (Figure 3.5c) verified the expression of ZO-1 also in endothelial cells.
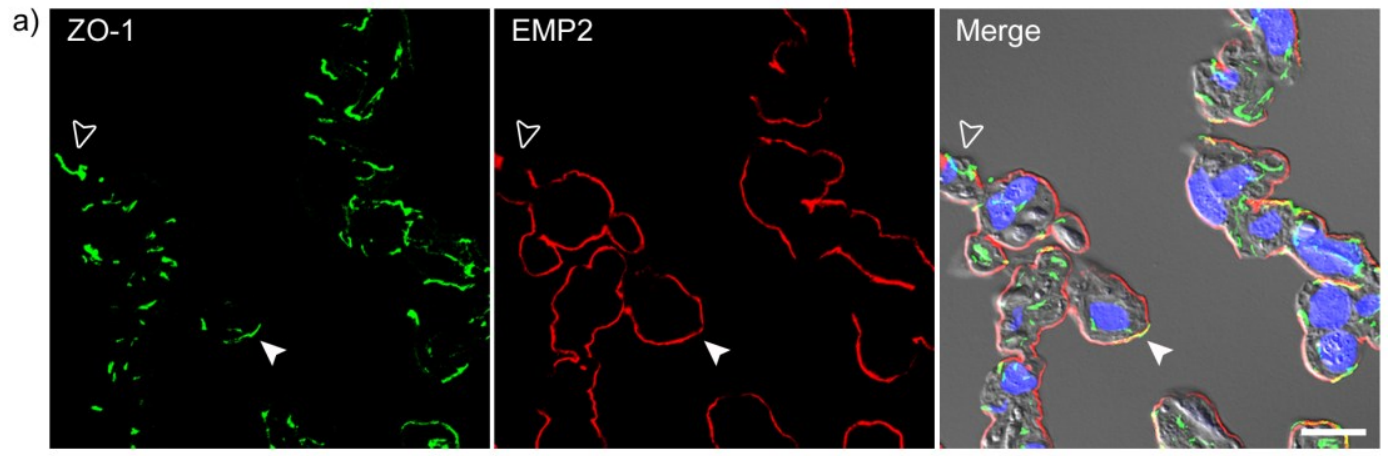

b) ZO-1
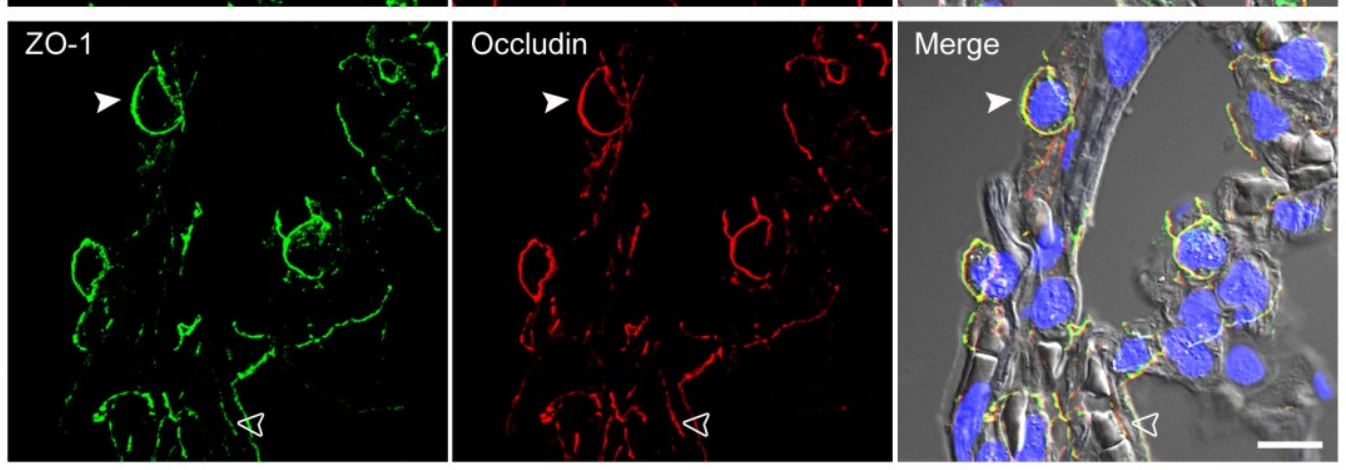

c) $\mathrm{ZO}-1$
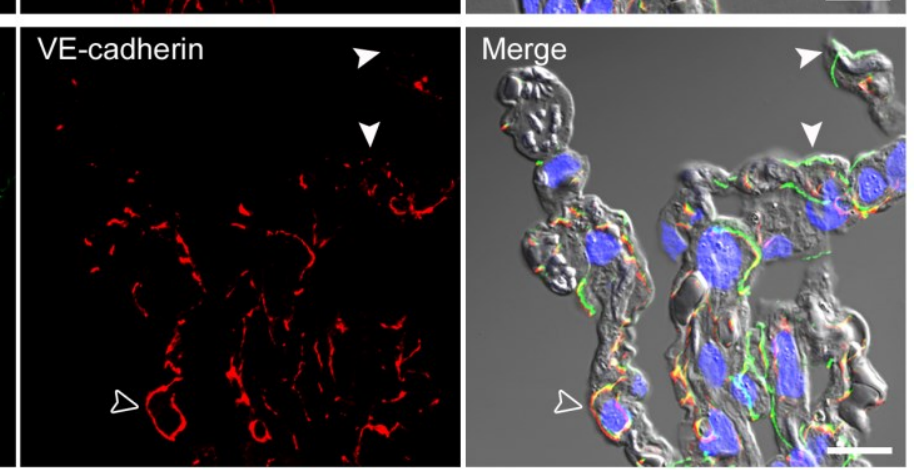

Figure 3.5: ZO-1 is expressed at the type I-type I cell interface as well as at the interface of type II alveolar epithelial cells to adjacent cells and colocalizes with occludin and VE-cadherin. Histological sections of human lung tissue were probed for ZO-1 (green), the cell marker for alveolar type I cells EMP2, VE-cadherin and occludin (all red), nuclei (blue) were counterstained with DAPI and tissue structure was visualized by differential interference contrast. Costaining of ZO-1 with EMP2 is depicted (a). The white arrowhead points towards an alveolar type I cell and the open arrowhead points to an alveolar type II cell. Costainings of ZO-1 with occludin (b) and VE-cadherin (c) are depicted. White arrowheads point to alveolar epithelial cells and open arrowheads point to capillary endothelial cells. Bar represents $10 \mu \mathrm{m}$. 


\subsubsection{Claudin-2}

Next, the expression of several members of the claudin family was investigated. Claudin-2 was strongly expressed in terminal and respiratory bronchiolar epithelium (Figure 3.6a, b) and to a weaker extent also throughout the alveolus (Figure 3.6c) and in a larger lung blood vessel (Figure 3.6d). Notably, in contrast to the typical band-like structures formed by the above mentioned junction proteins VE-cadherin, occludin and ZO-1, a punctate distribution was found for claudin-2.

a)

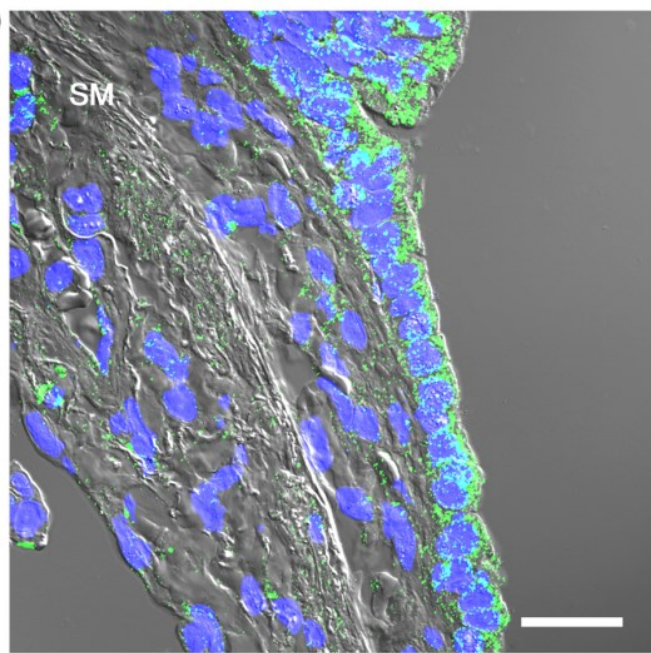

c)

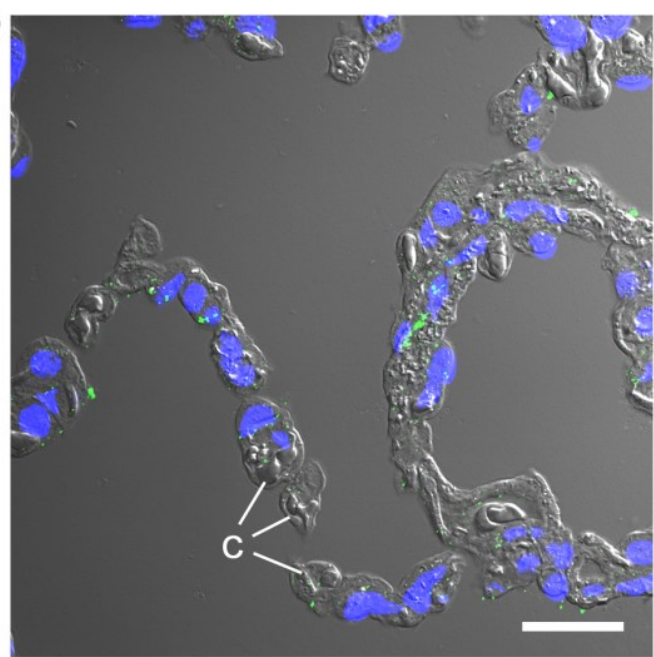

b)

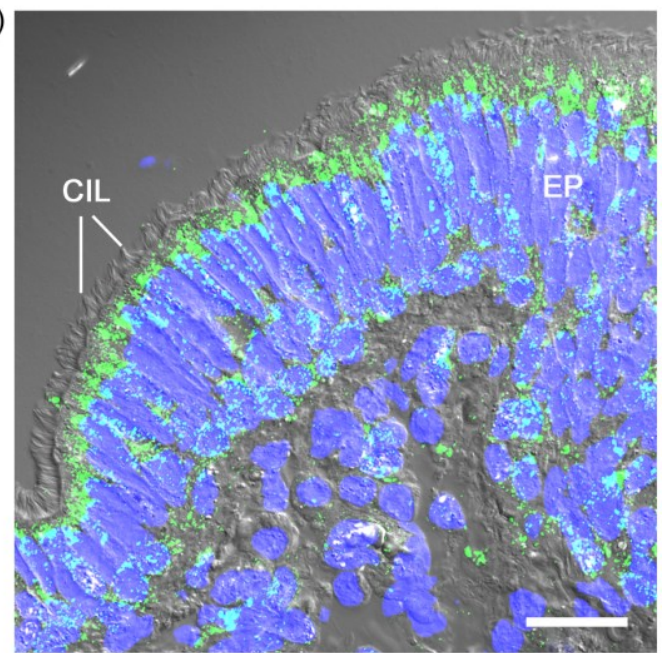

d)

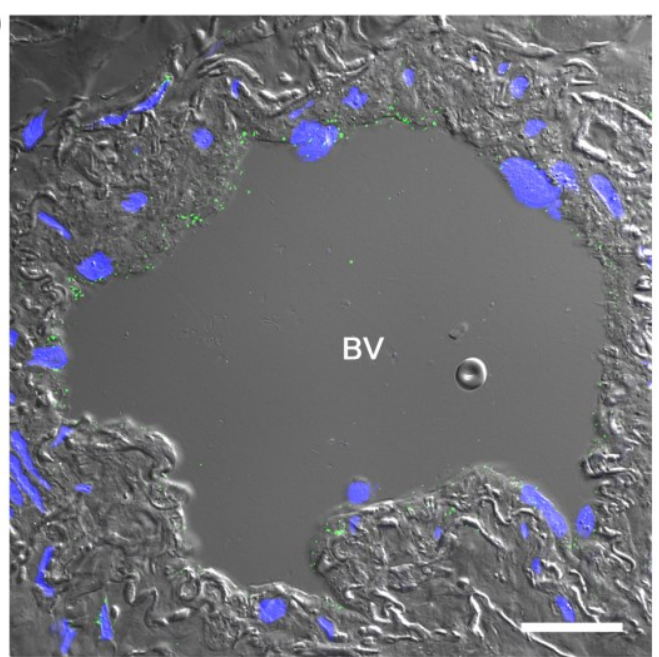

Figure 3.6: Claudin-2 is strongly expressed in bronchiolar epithelia. Histological sections of human lung tissue were probed for claudin-2 (green), nuclei (blue) were counterstained with DAPI and tissue structure was visualized by differential interference contrast. Terminal (a) and respiratory (b) bronchiolar epithelium, an alveolus (c) and a blood vessel (d) are depicted. Abbreviations: BV, blood vessel; C, capillary; CIL, cilia of ciliated columnar cells; EP, epithelium; SM, smooth muscle band. Bar represents $20 \mu \mathrm{m}$. 
Although a punctate positive staining in blood vessels was observed, simultaneous staining of claudin-2 with the endothelial cell marker VE-cadherin showed no colocalization in capillaries (Figure 3.7a) or blood vessels (Figure 3.7b). Therefore, the expression of claudin-2 in endothelial cells was not confirmed. Costaining with epithelial cell marker pan-cytokeratin revealed moreover no colocalization of claudin-2 and pan-cytokeratin (data not shown).
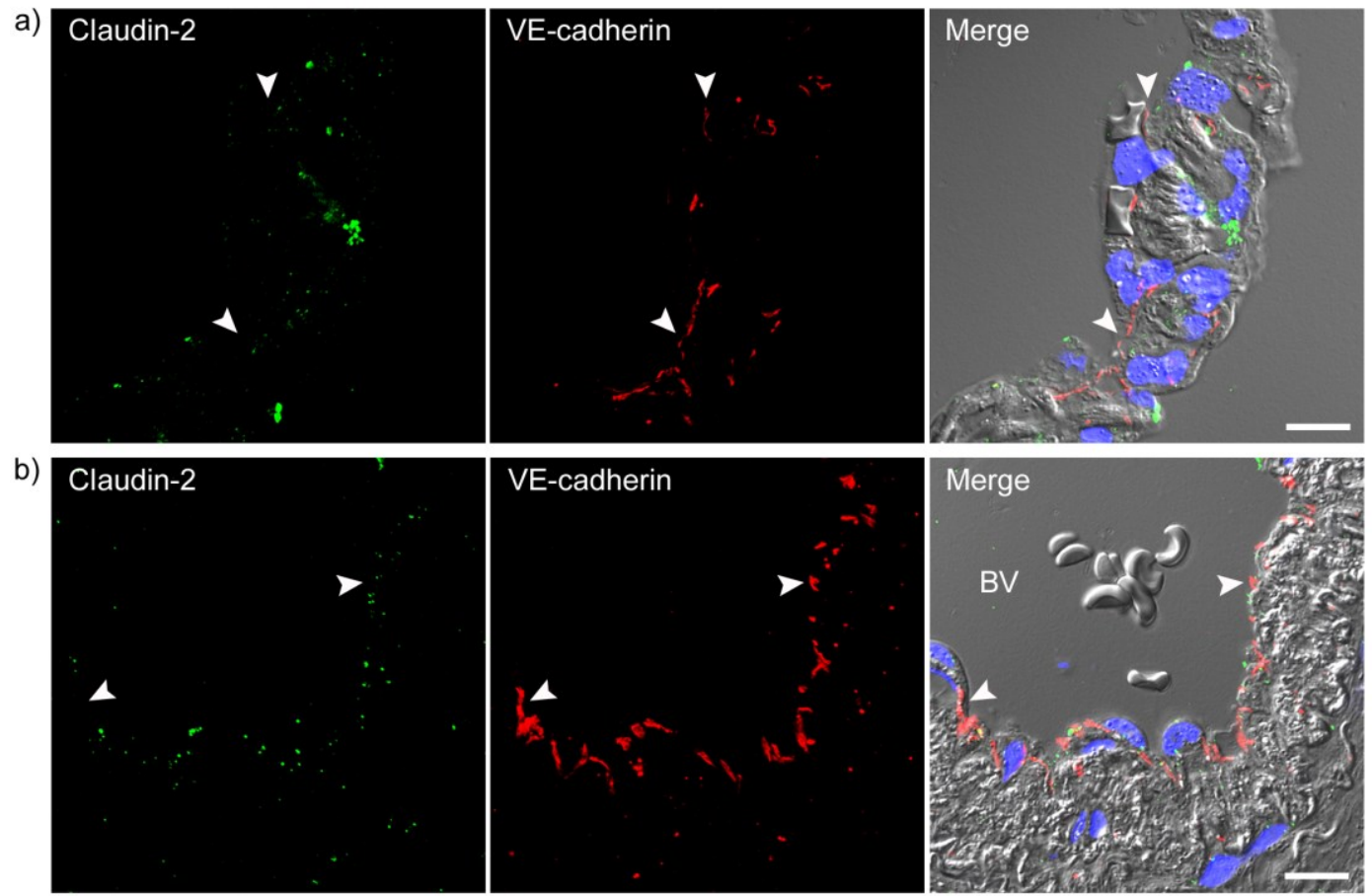

Figure 3.7: Claudin-2 does not colocalize with VE-cadherin. Histological sections of human lung tissue were probed for claudin-2 (green), VE-cadherin (red), nuclei (blue) were counterstained with DAPI and tissue structure was visualized by differential interference contrast. An alveolus (a) and a blood vessel (b) are depicted. White arrowheads point towards capillary endothelial cells. Abbreviation: BV, blood vessel. Bar represents $10 \mu \mathrm{m}$.

\subsubsection{Claudin-3}

Claudin-3 was princpially located in both, terminal and respiratory bronchiolar epithelium (Figure 3.8a, b) as well as in the alveolus (Figure 3.8c). In contrast, blood vessels were not positive for claudin-3 (Figure 3.8d). Costaining with the alveolar type II cell marker proSP-C demonstrated claudin-3 expression at the type I-type II as well as at the type II-type II epithelial cell interface (Figure 3.9a, white arrowheads). In line with this, simultaneous staining with the 
alveolar type I cell marker EMP2 revealed no colocalization of EMP2 and claudin-3 and therefore no expression of claudin-3 at the type I-type I alveolar epithelial cell interface (Figure 3.9b). Costaining of claudin-3 and occludin in epithelial cells of the alveolus showed a band-like colocalization in some but not all areas (Figure 3.9c) indicating a heterogeneous distribution of these two proteins. Although claudin-3 was not expressed in endothelial cells of blood vessels (Fig. 3.8d), sporadic small spots of claudin-3 and the endothelial cell marker VE-cadherin were present in alveolar capillaries (Figure 3.9d, open arrowheads).

a)

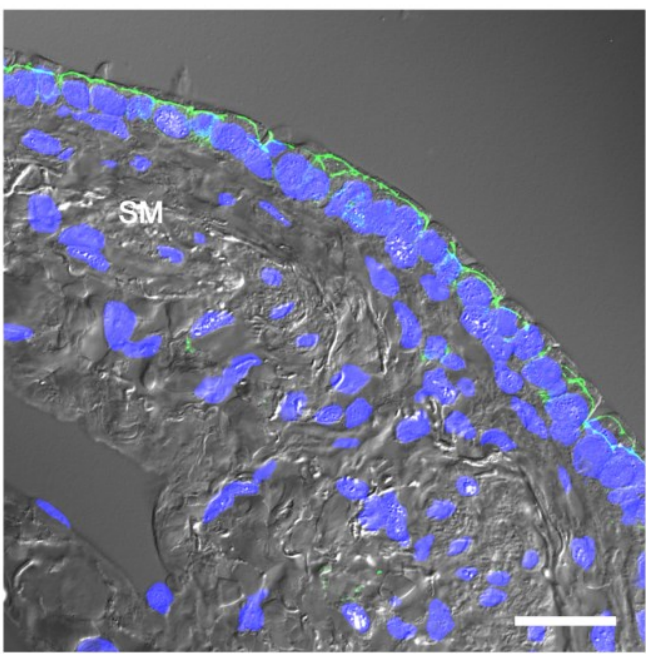

c)

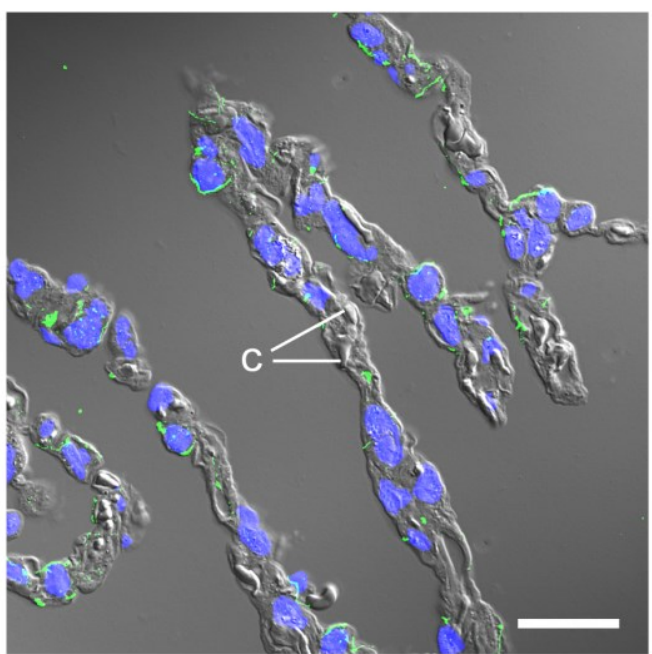

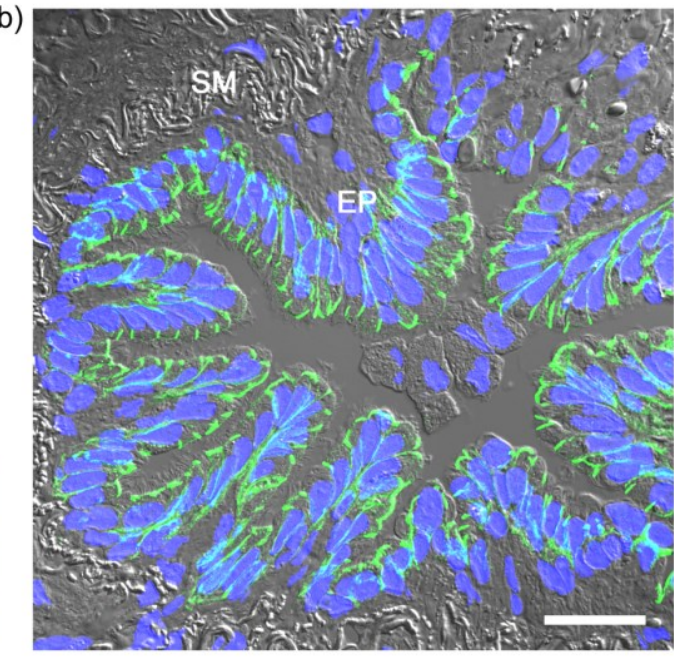

d)

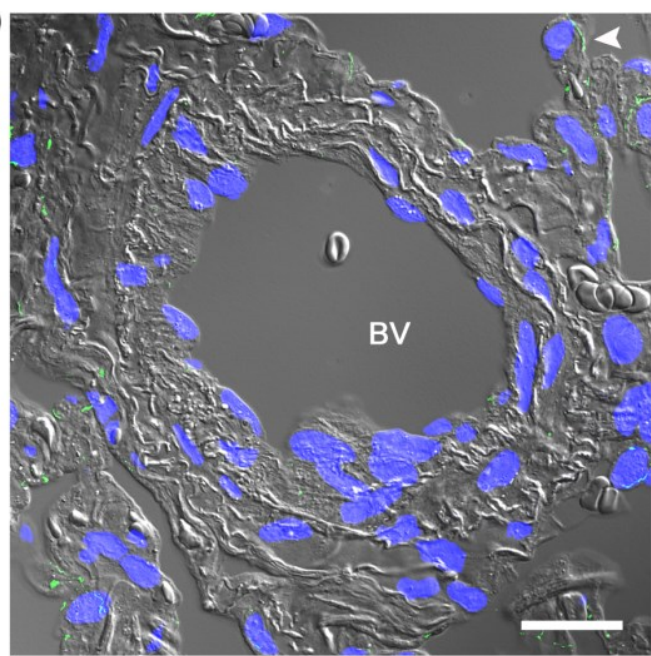

Figure 3.8: Claudin-3 is expressed in bronchiolar and alveolar epithelial cells. Histological sections of human lung tissue were probed for claudin-3 (green), nuclei (blue) were counterstained with DAPI and tissue structure was visualized by differential interference contrast. Terminal (a) and respiratory (b) bronchiolar epithelium, an alveolus (c) and a blood vessel (d) are depicted. Abbreviations: BV, blood vessel; C, capillary; EP, epithelium; SM, smooth muscle band. Bar represents $20 \mu \mathrm{m}$. 
a)
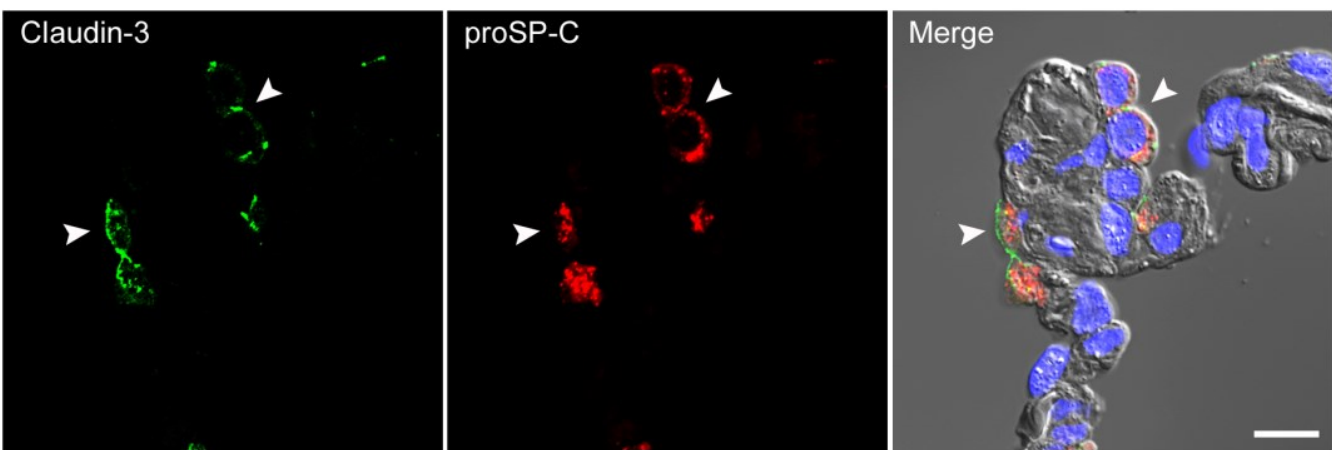

b)
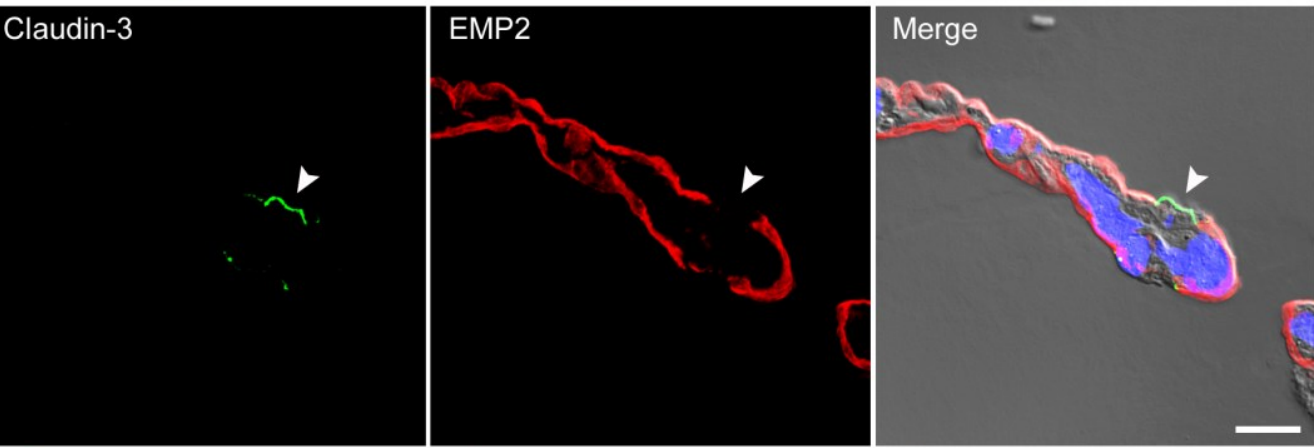

c)
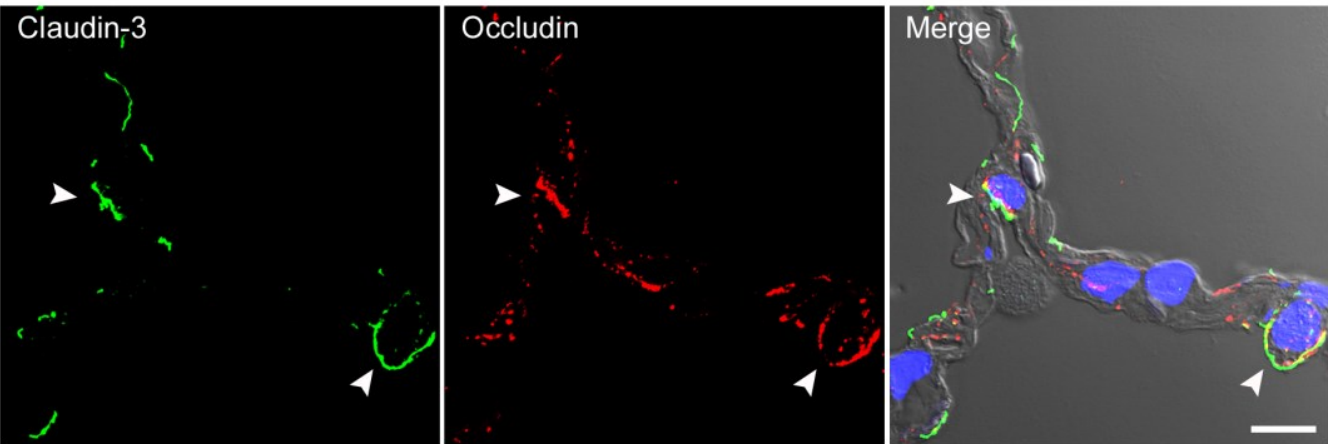

d)
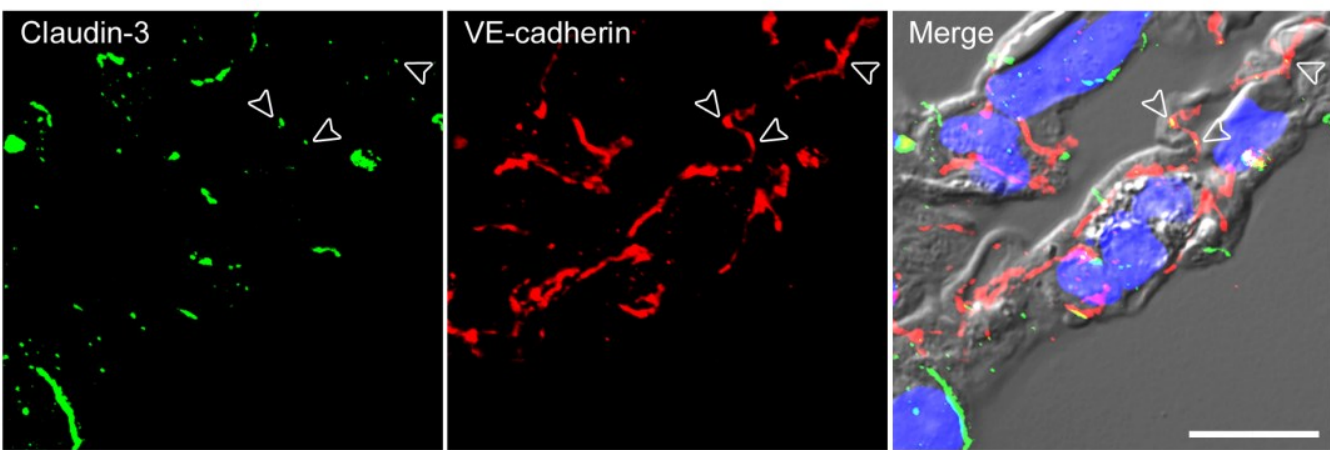

Figure 3.9: Claudin-3 is expressed at the interface of type II alveolar epithelial cells to adjacent cells and in alveolar capillaries. Histological sections of human lung tissue were probed for claudin-3 (green), the cell marker for alveolar type II cells proSP-C, the cell marker for alveolar type I cells EMP2, occludin and VE-cadherin (all red), nuclei (blue) were counterstained with DAPI and tissue structure was visualized by differential interference contrast. White arrowheads point towards type II cells and open arrowheads point to capillary endothelial cells. Bar represents $10 \mu \mathrm{m}$. 


\subsubsection{Claudin-4}

Claudin- 4 was strongly expressed at the apical and lateral borders of the terminal (Figure 3.10a) and respiratory (Figure 3.10b) bronchiolar epithelium. Furthermore, claudin-4 was expressed within the alveolus (Figure 3.10c), whereas larger lung vessels were negativ for claudin-4 (Figure 3.10d). Similar to claudin-2, a punctate distribution was recognized and claudin-4 did not form band-like structures.

a)

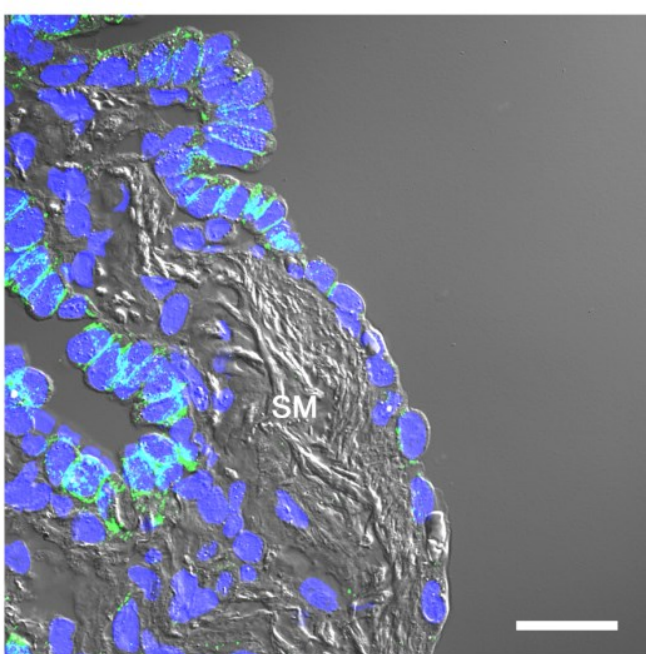

b)

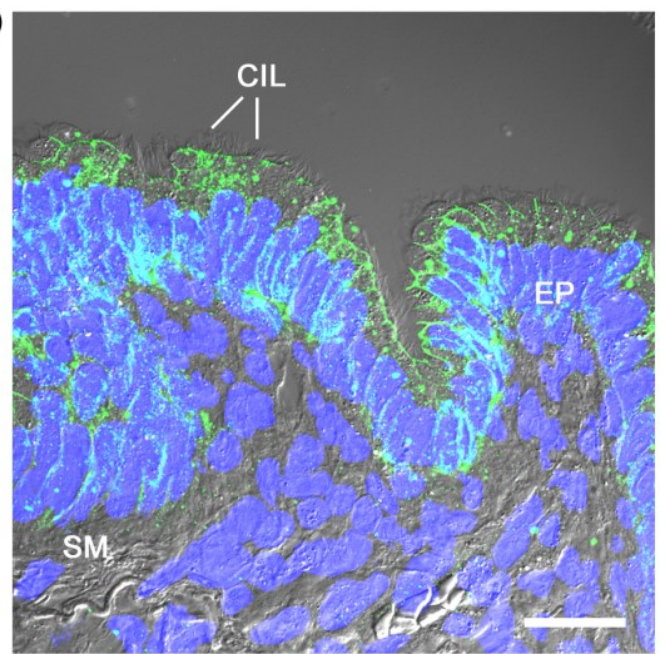

c)

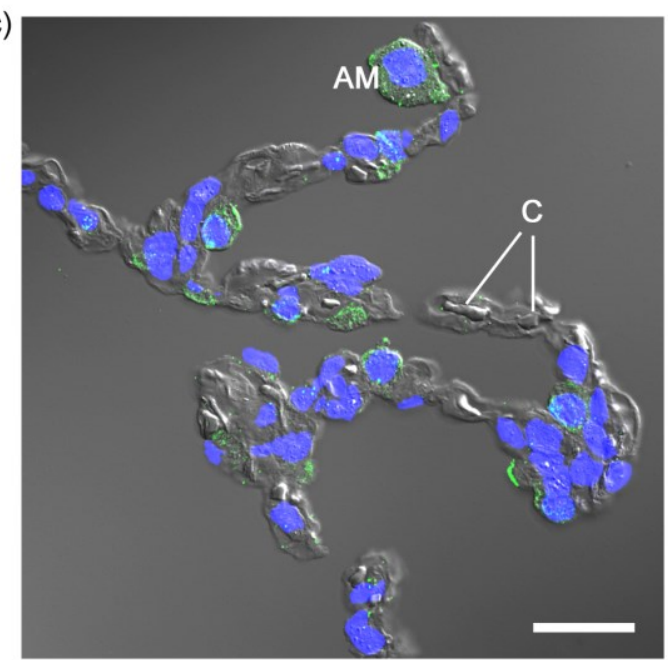

d)

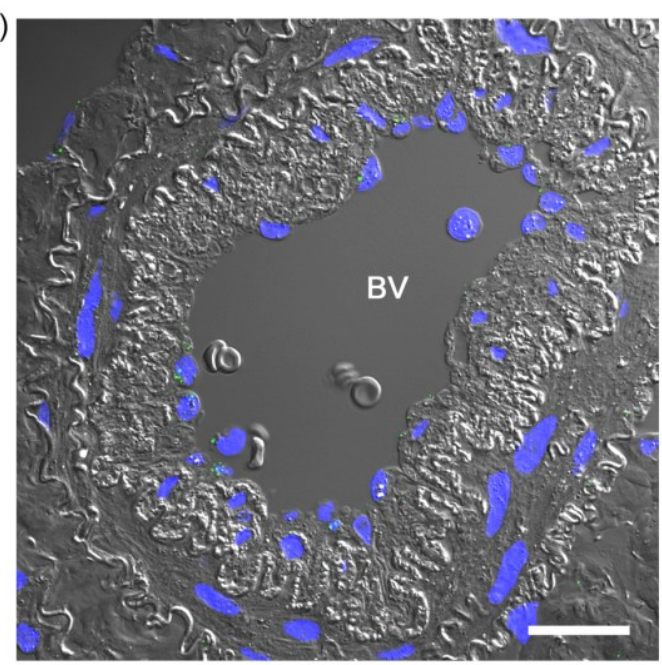

Figure 3.10: Claudin-4 is expressed in bronchiolar and alveolar epithelial cells. Histological sections of human lung tissue were probed for claudin-4 (green), nuclei (blue) were counterstained with DAPI and tissue structure was visualized by differential interference contrast. Terminal (a) and respiratory (b) bronchiolar epithelium, an alveolus (c) and a blood vessel (d) are depicted. Abbreviations: AM, alveolar macrophage; BV, blood vessel; C, capillary; CIL, cilia of ciliated columnar cells; EP, epithelium; SM, smooth muscle band. Bar represents $20 \mu \mathrm{m}$. 
Claudin-4 appeared at the type I-type II as well as at the type II-type II alveolar epithelial cell interface (Figure 3.11a, white arrowheads) and not at the type Itype I cell interface (Figure 3.11b), as indicated by a colocalization with the alveolar typ II cell marker proSP-C but not with the type I cell marker EMP2. Next, claudin-4 and claudin-3, both expressed at the interface of type II cells to neighboring cells, were examined by costaining of these two junction proteins. This revealed a resembling but not equal expression pattern at the interface of type II cells (Figure 3.11c). While claudin-3 formed band-like structures, claudin- 4 was expressed at the borders and in the cytosol of type II alveolar epithelial cells. 


\section{Results}

a)
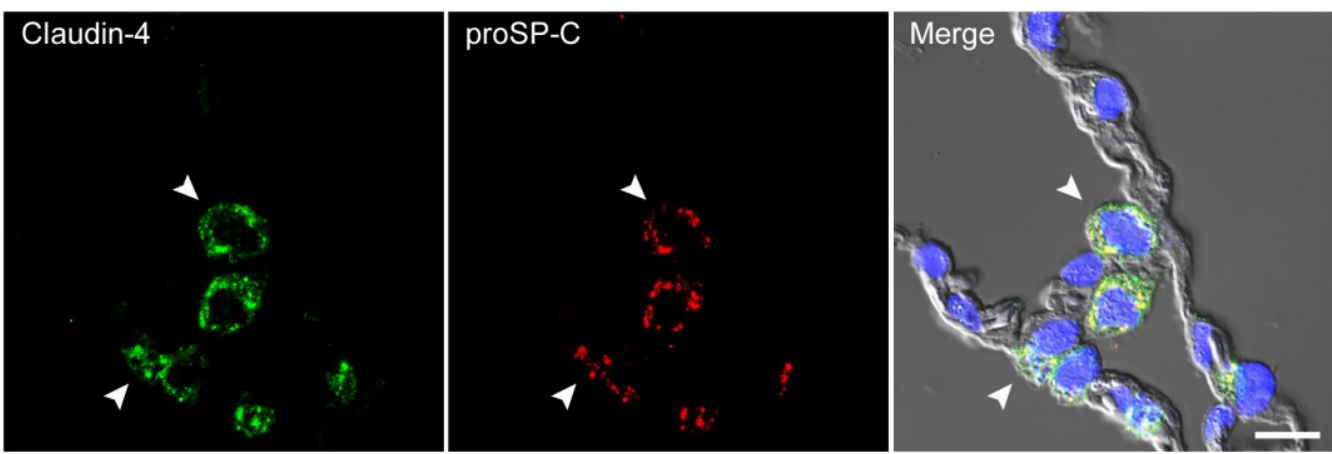

b)
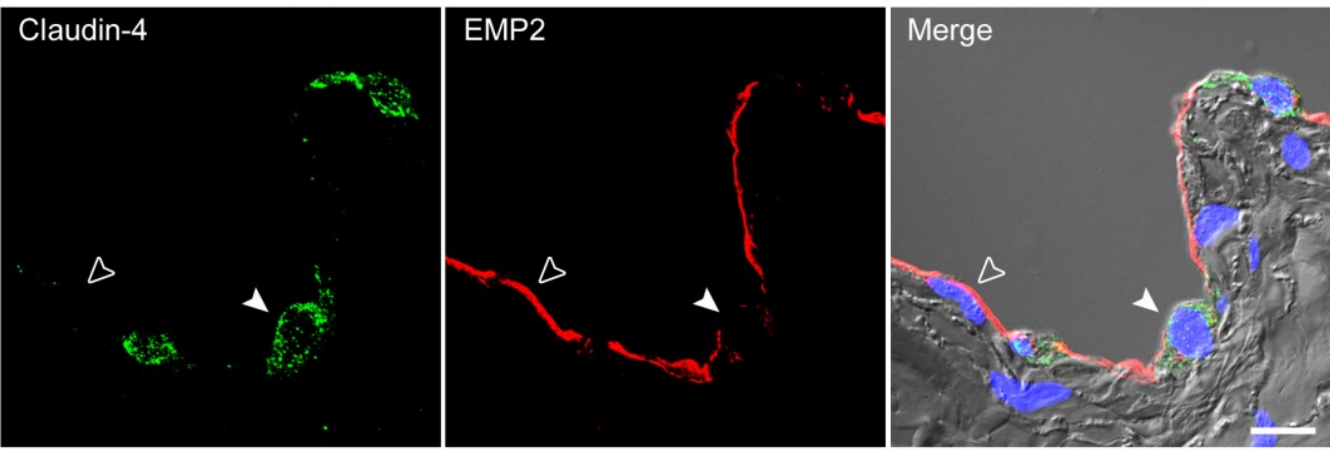

c) Claudin-4
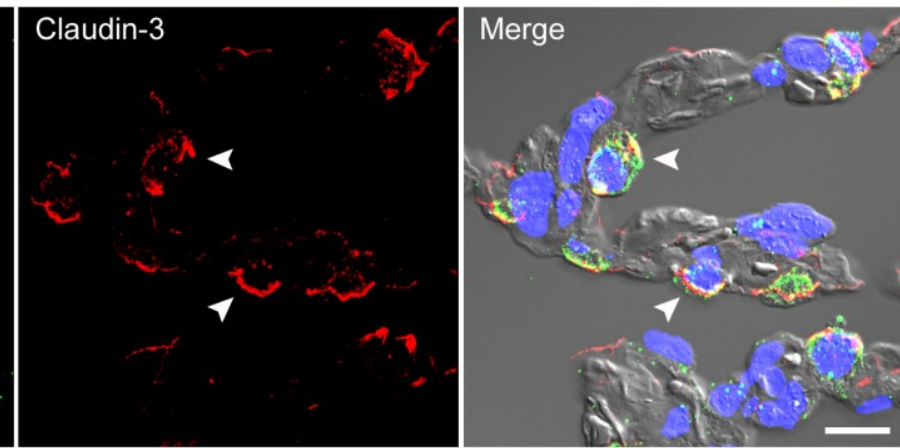

Figure 3.11: Claudin-4 is expressed at the interface of type II alveolar epithelial cells to adjacent cells and colocalizes with claudin-3. Histological sections of human lung tissue were probed for claudin-4 (green), the cell marker for alveolar type II cells proSP-C, the cell marker for alveolar type I cells EMP2 and claudin-3 (all red), nuclei (blue) were counterstained with DAPI and tissue structure was visualized by differential interference contrast. White arrowheads point towards type II cells and open arrowhead points to a type I cell. Bar represents $10 \mu \mathrm{m}$. 


\subsubsection{Claudin-5}

Claudin-5 was expressed in terminal and respiratory bronchiolar epithelium

(Figure $3.12 \mathrm{a}, \mathrm{b}$ ), at cellular boundaries in lung capillaries in the alveolus

(Figure 3.12c) and blood vessels (Figure 3.12d).

a)

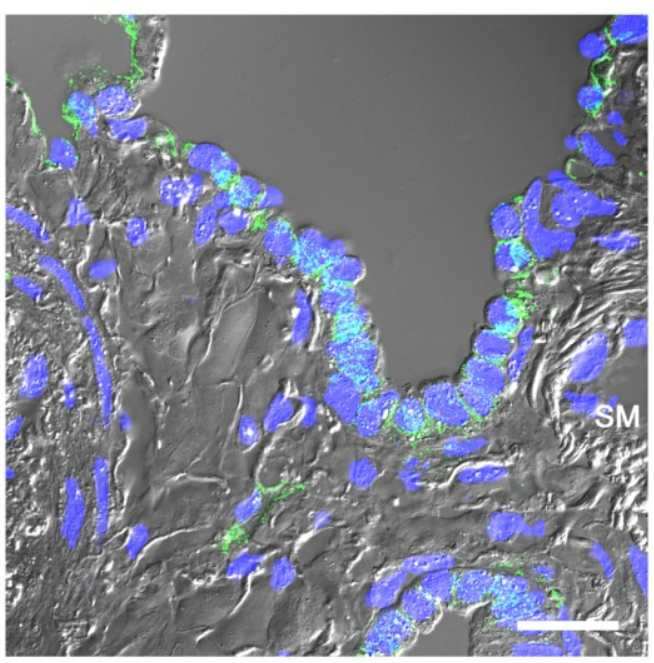

c)

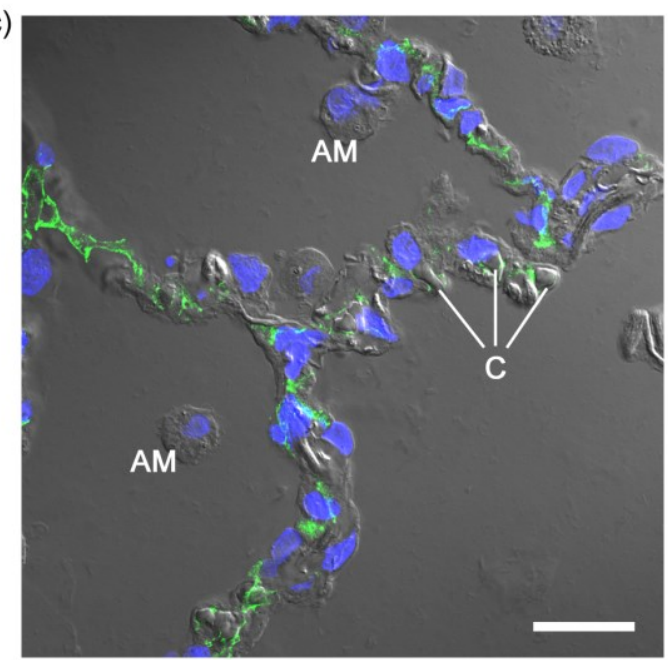

b)

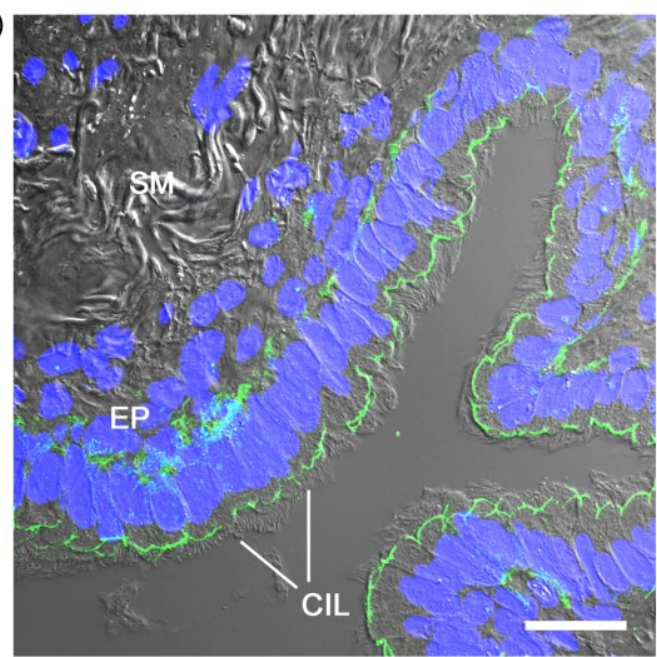

d)

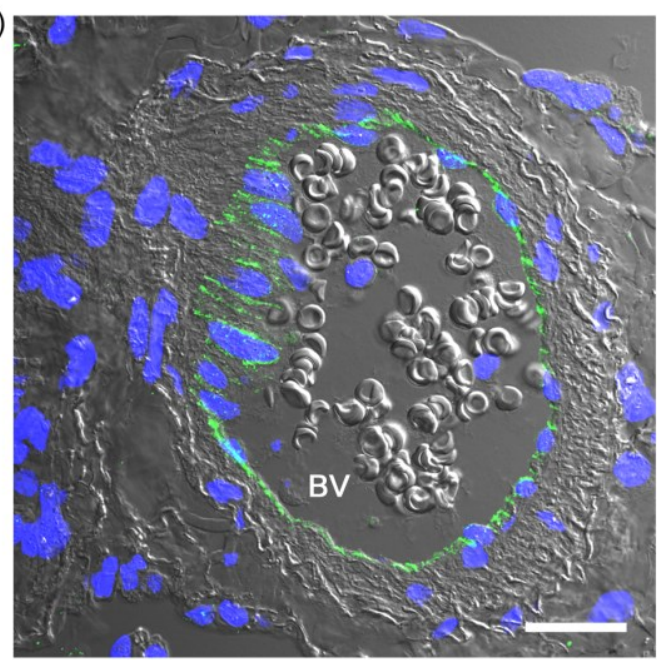

Figure 3.12: Claudin-5 is expressed in bronchiolar epithelial cells and vascular endothelium. Histological sections of human lung tissue were probed for claudin-5 (green), nuclei (blue) were counterstained with DAPI and tissue structure was visualized by differential interference contrast. Terminal (a) and respiratory (b) bronchiolar epithelium, an alveolus (c) and a blood vessel (d) are depicted. Abbreviations: AM, alveolar macrophage; BV, blood vessel; C, capillary; CIL, cilia of ciliated columnar cells; EP, epithelium; SM, smooth muscle band. Bar represents $20 \mu \mathrm{m}$. 
Staining of claudin-5 with the alveolar type I cell marker EMP2 revealed no expression of claudin-5 in alveolar epithelial cells (Figure 3.13a). In contrast, a colocalization with endothelial cell specific VE-cadherin was observed in alveolar capillaries (Figure 3.13b) and blood vessels (Figure 3.13c) validating claudin-5 expression in endothelial cells.

a)

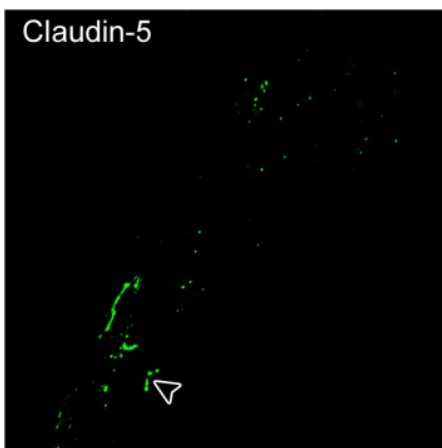

b)

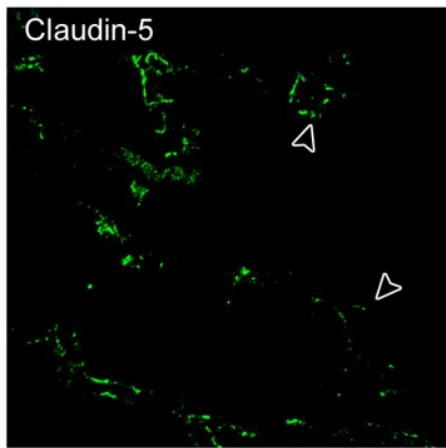

c)

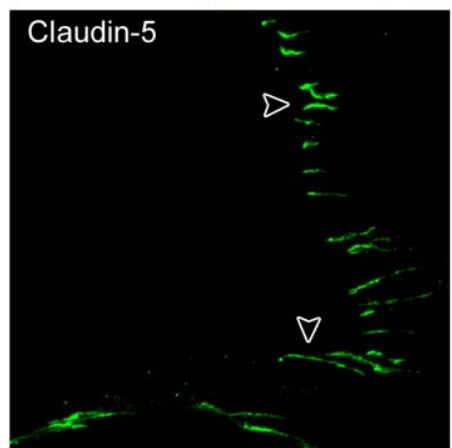

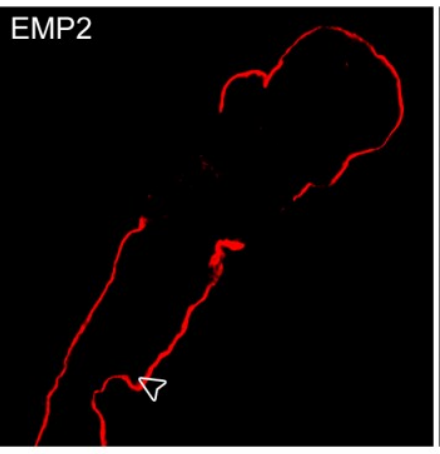
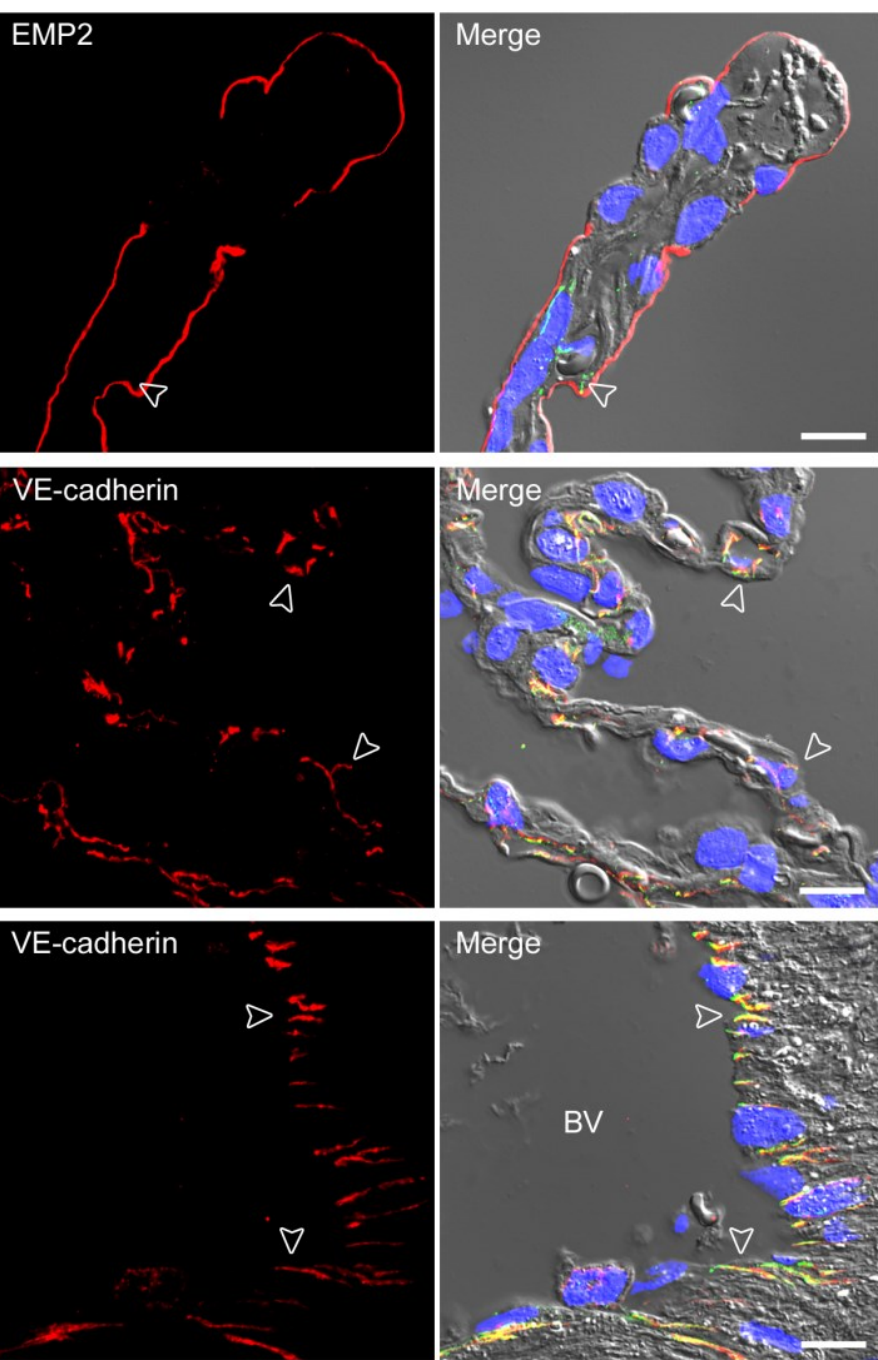

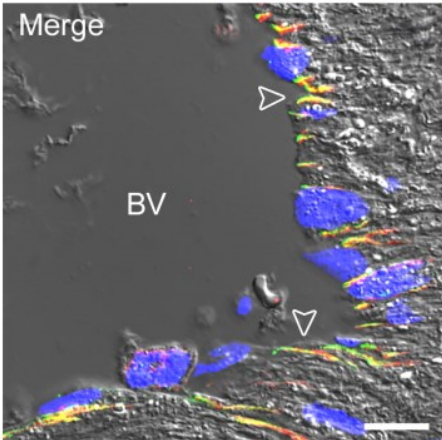

Figure 3.13: Claudin-5 is not expressed in alveolar epithelial cells but colocalizes with VE-cadherin in endothelial cells. Histological sections of human lung tissue were probed for claudin-5 (green), the cell marker for alveolar type I cells EMP2 and VE-cadherin (both red), nuclei (blue) were counterstained with DAPI and tissue structure was visualized by differential interference contrast. Alveoli $(\mathrm{a}, \mathrm{b})$ and a blood vessel $(\mathrm{c})$ are depicted. Open arrowhead point to endothelial cells. Abbreviation: BV, blood vessel. Bar represents $10 \mu \mathrm{m}$. 


\subsubsection{Claudin-18}

Claudin-18 was expressed primarily at the apical borders of the terminal (Figure 3.14a) and respiratory (Figure 3.14b) bronchiolar epithelium as well as throughout the alveolus (Figure 3.14c). Lung blood vessels were negativ for claudin-18 expression (Figure 3.14d).

a)

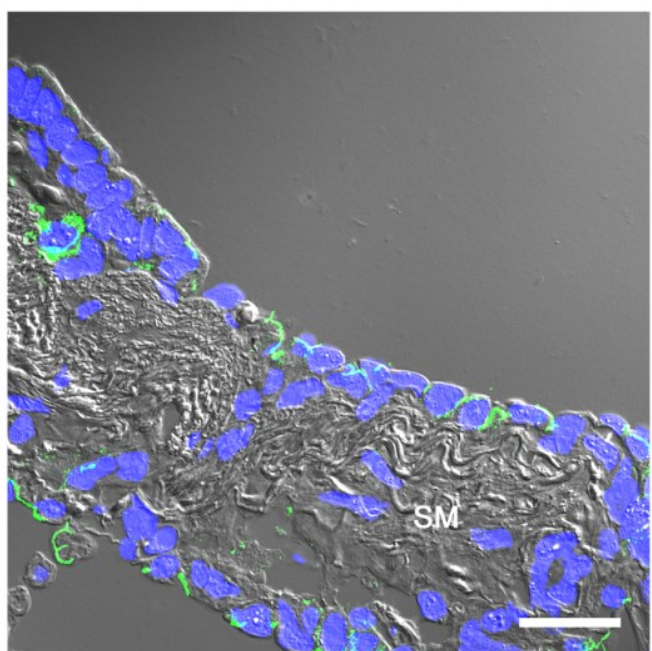

c)

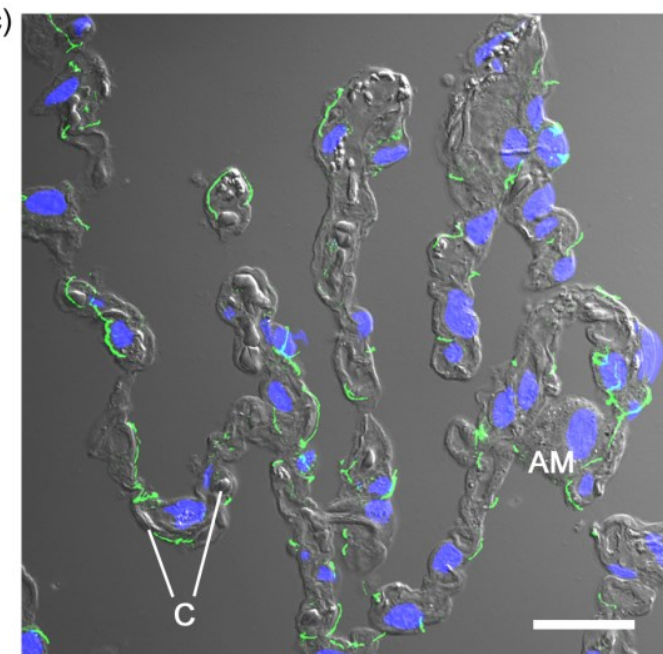

b)

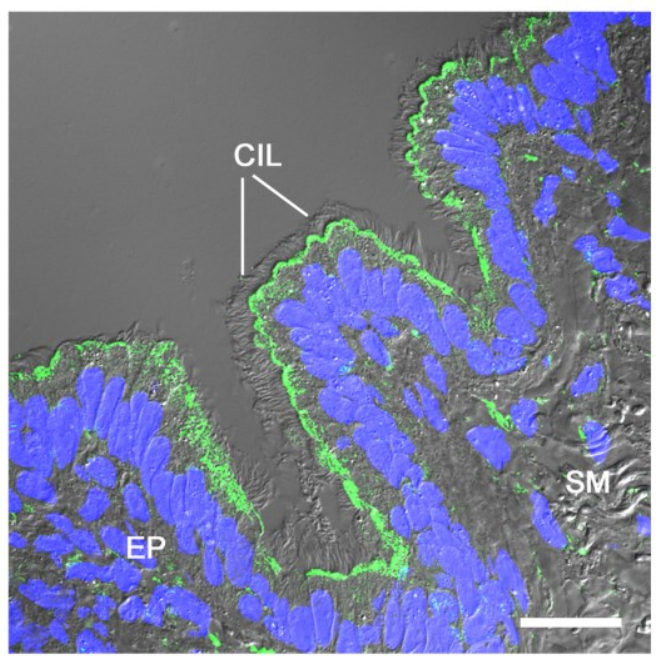

d)

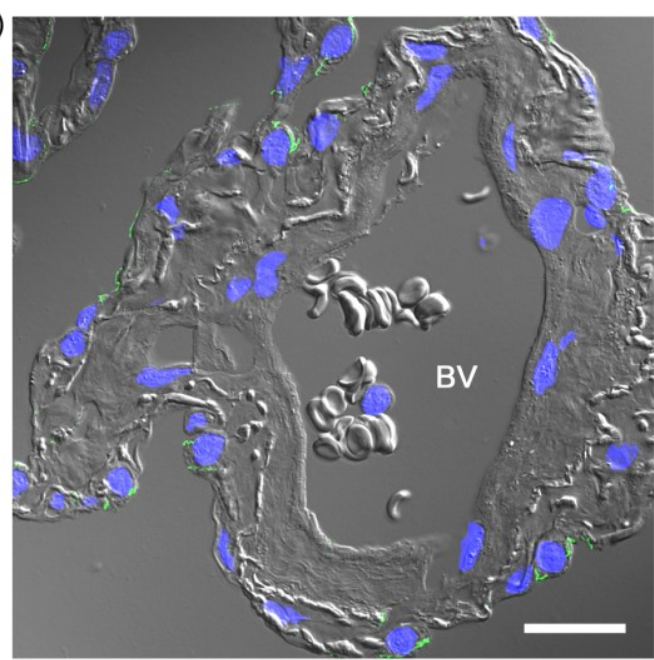

Figure 3.14: Claudin-18 is expressed in bronchiolar and alveolar epithelial cells. Histological sections of human lung tissue were probed for claudin-18 (green), nuclei (blue) were counterstained with DAPI and tissue structure was visualized by differential interference contrast. Terminal (a) and respiratory (b) bronchiolar epithelium, an alveolus (c) and a blood vessel (d) are depicted. Abbreviations: AM, alveolar macrophage; BV, blood vessel; C, capillary; CIL, cilia of ciliated columnar cells; EP, epithelium; SM, smooth muscle band. Bar represents $20 \mu \mathrm{m}$. 
In accordance with claudin-3 and -4 , claudin-18 bands were found at the interface of type II alveolar epithelial cell to adjacent cells as indicated by colocalization with the alveolar type II cell marker proSP-C (Figure 3.15a). Since no colocalization of claudin-18 with the alveolar type I cell marker EMP2 could be observed, claudin-18 seems to be not expressed at the type I-type I cell interface (Figure 3.15b).

a)

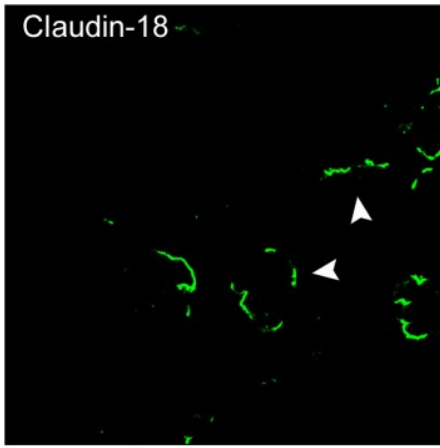

b)

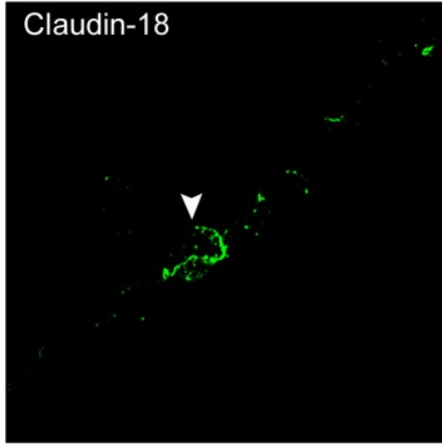

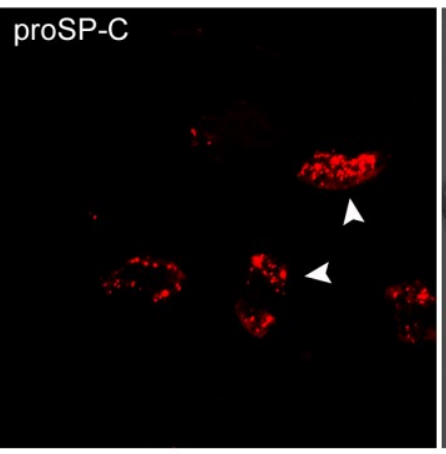

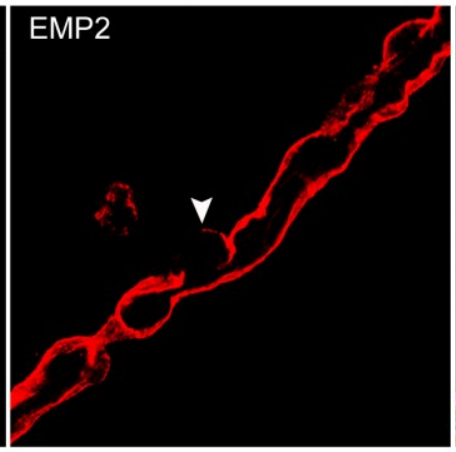

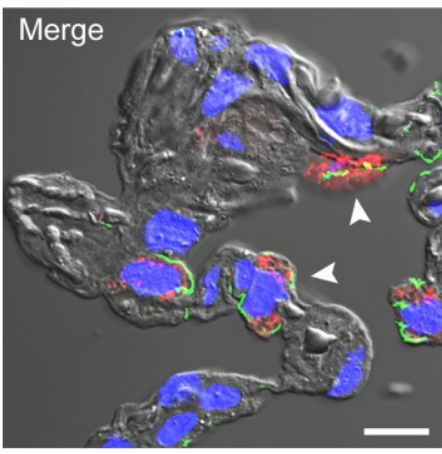

Merge

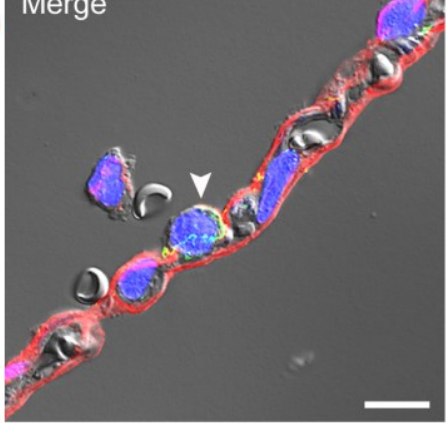

Figure 3.15: Claudin-18 is expressed at the interface of type II alveolar epithelial cells to adjacent cells. Histological sections of human lung tissue were probed for claudin-18 (green), the cell marker for alveolar type II cells proSP-C and the cell marker for alveolar type I cells EMP2 (both red), nuclei (blue) were counterstained with DAPI and tissue structure was visualized by differential interference contrast. White arrowheads point towards type II cells. Bar represents $10 \mu \mathrm{m}$.

\subsubsection{Summary of expression patterns}

Table 3.1 highlights the distinct expression patterns for the analyzed junction proteins expressed in different human lung tissue sections. Since a positive staining of terminal bronchiolar epithelium was always accompanied with a positive staining of respiratory bronchiolar epithelium, both areas were combined and entitled as bronchiolar epithelium. The type II cell interface represents the interface of type II alveolar epithelial cells to type I as well as to type II alveolar epithelial cells. Differences in expression intensities between 
junction proteins were disregarded. In summary, bronchiolar epithelium was tested positive for occludin, ZO-1, claudin-2, $-3,-4,-5$ and -18 . Occludin, ZO-1, claudin-5 and -18 were located merely at apical borders of bronchiolar epithelium and claudin-2, -3 and -4 were detected apical and lateral. Occludin and ZO-1 are expressed at the type I-type I cell interface as well as at the interface of type II alveolar epithelial cells whereas claudin-3, -4 and -18 are exclusively expressed at the interface of type II alveolar epithelial cells to adjacent cells. Cell junctions in lung endothelial cells are formed by VEcadherin, occludin, ZO-1, claudin-3 and claudin-5. The analyzed junction proteins appeared mostly as band-like structures connecting adjacent cells, exept for claudin-2 which showed extensive differences to a typical continuous tight junction morphology. Moreover, claudin-4 was recognized to appear in punctate structures.

Table 3.1: Summary of expression patterns for VE-cadherin, occludin, ZO-1, claudin-2, claudin-3, claudin-4, claudin-5 and claudin-18 in anatomical structures of human lung tissue.

\begin{tabular}{l|c|c|c|c|c}
\hline $\begin{array}{c}\text { Cell } \\
\text { junction }\end{array}$ & $\begin{array}{c}\text { Bronchiolar } \\
\text { epithelium }\end{array}$ & $\begin{array}{c}\text { Alveolar } \\
\text { epithelium }\end{array}$ & \multicolumn{2}{c|}{ Endothelium } \\
& & & $\begin{array}{r}\text { Type I- } \\
\text { type I } \\
\text { cell } \\
\text { interface }\end{array}$ & $\begin{array}{c}\text { Type II } \\
\text { cell } \\
\text { interface }\end{array}$ & \\
\hline VE-cadherin & - & - & - & - & + \\
Occludin & + & + & + & + & + \\
ZO-1 & + & + & + & + & + \\
Claudin-2 & $+*$ & - & - & - & - \\
Claudin-3 & + & + & - & + & + \\
Claudin-4 & $+*$ & $+*$ & - & $+*$ \\
Claudin-5 & + & - & - & - & + \\
Claudin-18 & + & + & - & + & - \\
\hline
\end{tabular}

Abbreviations: -, negative staining; +, positive staining; *, punctate staining;

\#, capillary expression 


\subsection{Ex vivo human lung infection model}

For investigation of cell junction protein expression in response to S. pneumoniae, an ex vivo human lung infection model was used. Human lung tissue explants were obtained from patients undergoing lung resection and originated from the periphery of pulmonary lobes of tumor free lung tissue. After receiving the explants further preparation included cutting and stamping of the tissue in small pieces of similar size and incubating in cell culture medium at $37^{\circ} \mathrm{C}$ and $5 \% \mathrm{CO}_{2}$ overnight. This pre-incubation was performed to remove residual amounts of antibiotics in the tissue and for tissue soothing after acute cell stress caused by resection and preparation of the tissue. Subsequently, lung pieces were infected with $S$. pneumoniae by repeated injection of the bacteria directly into the tissue and samples were processed for further analysis (Figure 3.16).

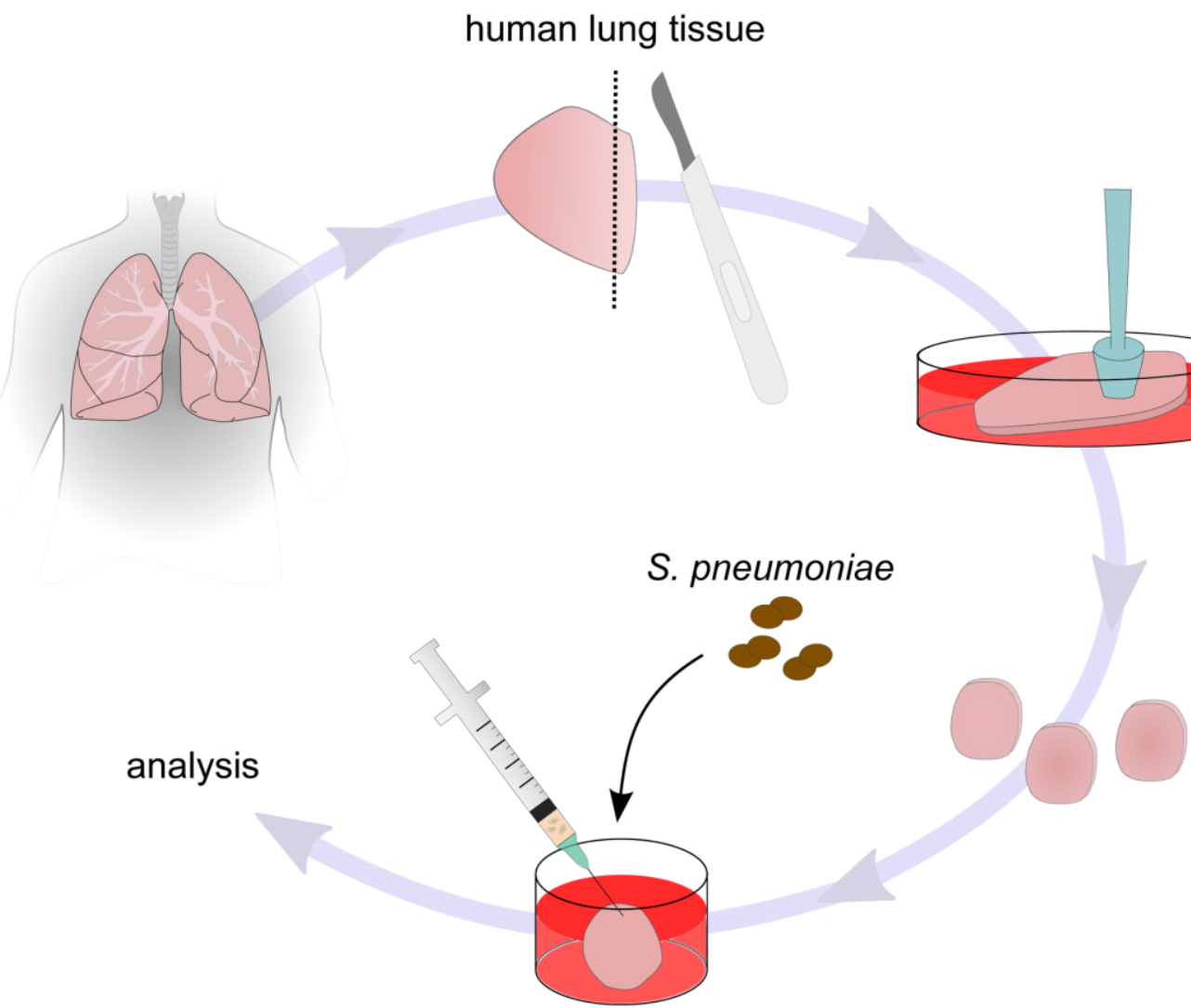

Figure 3.16: Schematic diagram of human lung tissue preparation for ex vivo cultivation and infection. Tumor free human lung tissue was cut with a scalpel into little slices and stamped into small cylinders. Lung pieces were incubated in RPMI 1640 medium at $37^{\circ} \mathrm{C}$ and $5 \% \mathrm{CO}_{2}$ overnight, infected with $S$. pneumoniae and subsequently processed for further analysis. 
An inevitable requirement for infection biology studies using an ex vivo tissue culture model are intact and vital tissue, reproducible pneumococcal infection of the tissue with an inflammatory response and a low cytotoxicity during tissue culture. In order to validate the suitability of the human lung model for the aim of this study, growth of different $S$. pneumoniae strains in the lung tissue, IL-1B release as marker of an inflammatory response and cytotoxicity were analyzed.

Firstly, all S. pneumoniae strains used in the present study were compared for their growth in liquid culture to analyze potential differences between the strains. As expected, deletion mutants S. pneumoniae D39Aply and S. pneumoniae D39 $\Delta s p x B$ exhibited no defects in growth compared to S. pneumoniae D39 wild type (Figure 3.17a), indicating that both virulence factors are not important for bacterial replication in liquid medium. To assure efficient pneumococcal infection of the human lung tissue, bacterial growth was measured over time, demonstrating strong and reproducible bacterial replication of $S$. pneumoniae D39 wild type within 8 and 24 h (Figure 3.17b). The cytokine IL-1B is produced in response to inflammation and was measured here to serve as indicator for an effective bacterial infection. Infection of human lung tissue with $S$. pneumoniae strains showed significant increased IL-1B release (Figure 3.17c). However, IL-1B production upon S. pneumoniae D39 wild type infection was 2 -fold stronger compared to S. pneumoniae D39 $\Delta$ ply and $S$. pneumoniae D39 $\Delta s p x B$ infection. To assess the cytotoxicity in uninfected and infected human lung tissue culture lactate dehydrogenase $(\mathrm{LDH})$ release was determined. Increased levels of the cytosolic localized LDH in the tissue culture supernatant are an indicator for the loss of cell membrane integrity resulting in the release of cytosolic components upon cell death by necrosis or apoptosis. In uninfected human lung tissue, LDH release was about $5-7 \%$ indicating only marginal tissue damage within $24 \mathrm{~h}$ of culture. No significant increase of cytotoxicity $(<10 \%)$ was observed upon pneumococcal infection of human lung tissue (Figure 3.17d). 
a)

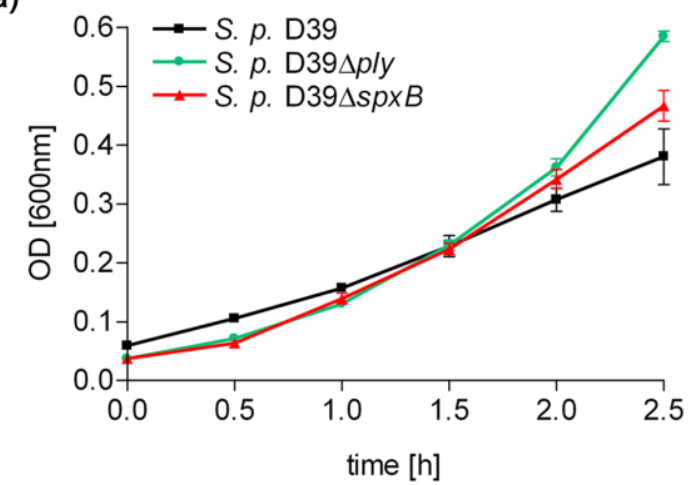

c)

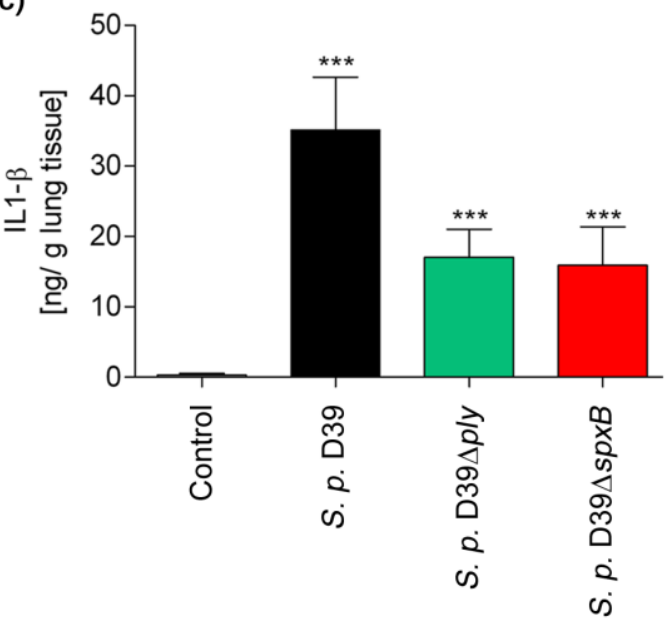

b)

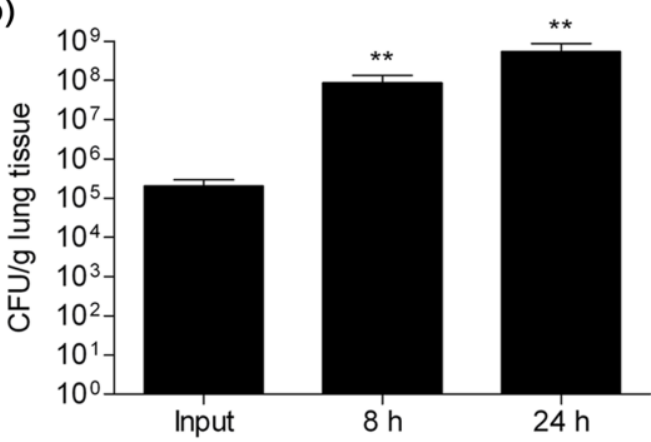

d)

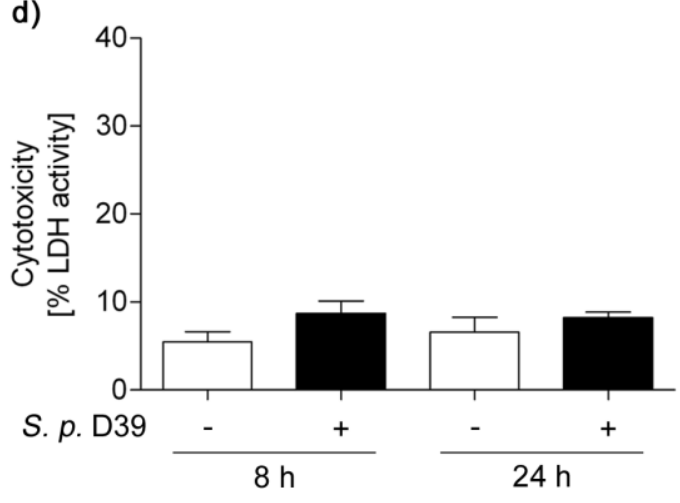

Figure 3.17: Growth of $S$. pneumoniae strains in human lung tissue. S. pneumoniae (S. p.) strains $S . p$. D39 wild type, $S . p$. D39 $\Delta$ ply and $S$. $p$. D39 $\Delta s p x B$ were grown in THY media and OD was measured at $600 \mathrm{~nm}$ (a). Data are means $\pm \mathrm{SEM}$ of four independent experiments. Human lung tissue was infected with $10^{6} \mathrm{CFU} \cdot \mathrm{ml}^{-1} S$. $p$. D39 wild type, S. p. D39 ply and S. $p$. D39 $\Delta p x B$. CFU from $S$. $p$. D39 were determined at 0,8 and $24 \mathrm{~h}$ (b). IL-1B release was quantified at $24 \mathrm{~h}$ (c). Cytotoxicity (\% LDH release) of $S$. $p$. D39 wild type was measured at 8 and $24 \mathrm{~h}(\mathrm{~d})$. Data are means \pm SEM of at least four different patients. ${ }^{* *} p<0.01$ versus input. ${ }^{* * *} p<0.001$ versus control.

In summary, the characterized human lung tissue infection model is appropriate for analyzing cell junction protein expression in response to S. pneumoniae and was therefore used in this study. 


\subsection{S. pneumoniae infection induces alteration of VE-cadherin, occludin, ZO-1 and claudin-5 in human lung tissue}

After systematically visualizing and characterizing constitutive cell-specific expression patterns of junction proteins in uninfected human lung tissue, the alveolar structure and expression in S. pneumoniae infected human lung tissue was investigated. Therefore, human lung tissue was infected with $10^{6} \mathrm{CFU} \cdot \mathrm{ml}^{-1}$ S. pneumoniae D39 wild type for 8 and $24 \mathrm{~h}$ and samples were subjected to immunohistochemistry and western blot.

Infection of human lung tissue with S. pneumoniae D39 wild type induces diminished presence of the adherens junction protein VE-cadherin and the tight junction proteins occludin, ZO-1 and claudin-5. Immunohistochemical analysis of the respective junction proteins and costaining of pneumococci visualized the loss of the continuous junctional bands, appearing in punctate patterns $8 \mathrm{~h}$ post infection (p. i.) (Figure 3.18, middle panel), which was further enhanced 24 h p. i. (Figure 3.18, right panel). Western blot analysis revealed decreased protein levels of VE-cadherin, occludin, ZO-1 and claudin-5 in $S$. pneumoniae D39 wild type infected human lung tissue (Figure 3.19a). To quantify the protein amounts present on western blots densitometric analysis was performed. The intensity of specific bands was measured, normalized to actin and infected samples were correlated to the uninfected samples. Densitometric analysis demonstrated that the amount of VE-cadherin was significantly reduced by $80 \%$, occludin and ZO- 1 by $50 \%$ and claudin- 5 by $30 \%$ 24 h p. i. (Figure $3.19 b)$. 

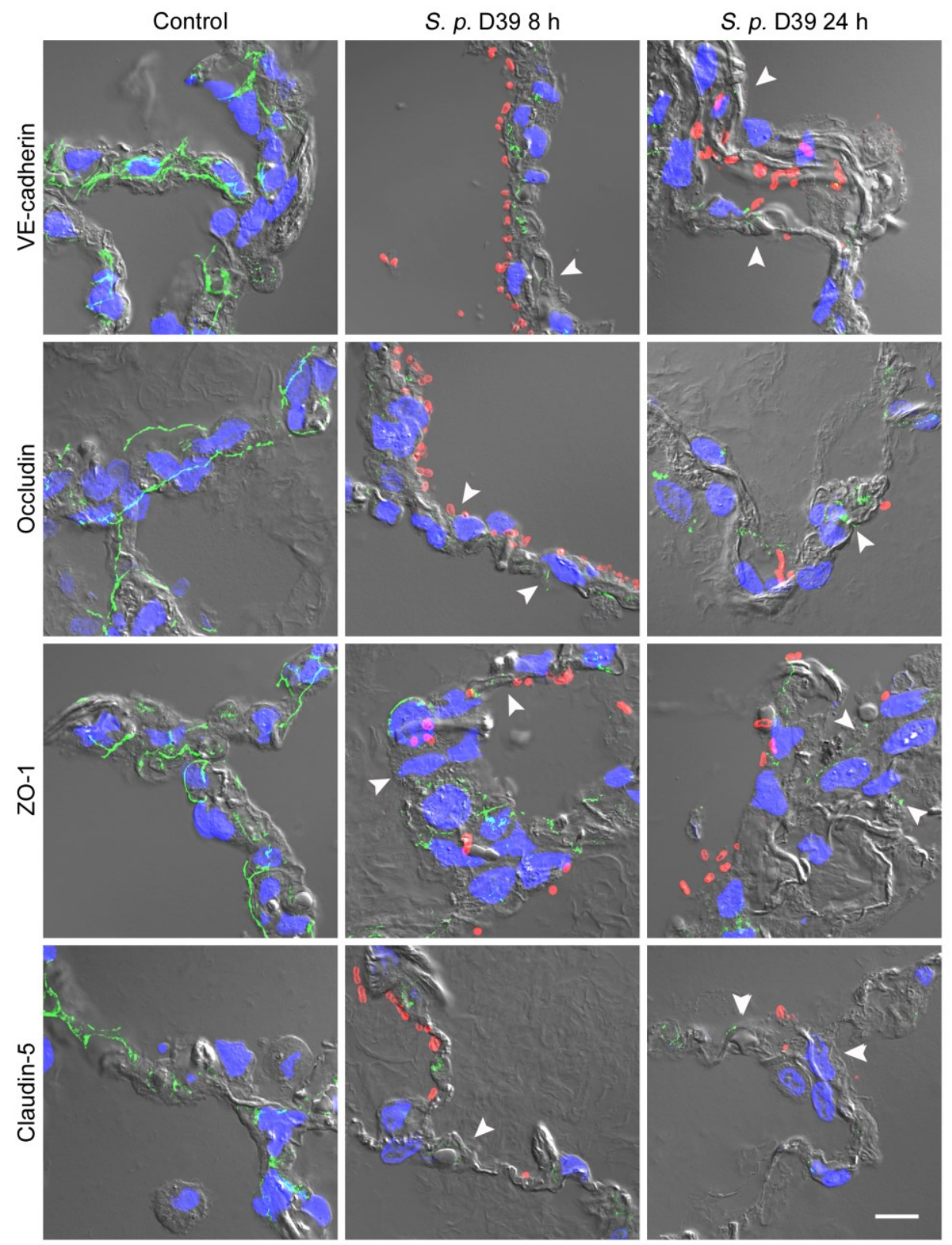

Figure 3.18: Altered structure of VE-cadherin, occludin, ZO-1 and claudin-5 in S. pneumoniae (S. p.) infected human lung tissue. Human lung tissue was infected with $10^{6} \mathrm{CFU} \cdot \mathrm{ml}^{-1}$ S. $p$. D39 for 8 and $24 \mathrm{~h}$. Histological sections were probed for respective cell junction protein (green), S. pneumoniae (red), nuclei (blue) were counterstained with DAPI and tissue structure was visualized by differential interference contrast. Control (left panel), $8 \mathrm{~h}$ infected (middle panel) and $24 \mathrm{~h}$ infected (right panel). White arrowheads point towards broken junction bands. Bar represents $20 \mu \mathrm{m}$. Representative figures of five independent experiments are shown. 
a)

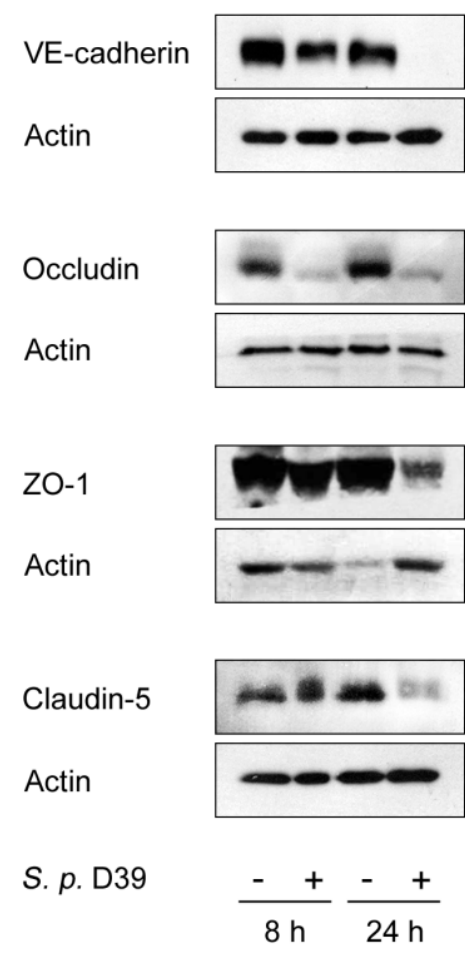

b)

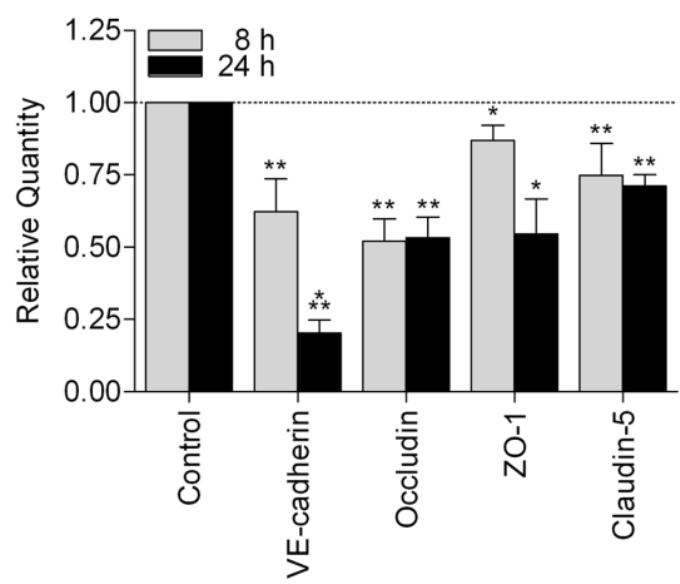

Figure 3.19: Reduced protein levels of VE-cadherin, occludin, ZO-1 and claudin-5 in S. pneumoniae infected human lung tissue. (a) Total tissue lysates were analyzed by western blot. Representative western blots for VE-cadherin, occludin, ZO-1 and claudin-5 are shown. Actin was used as loading control. (b) Densitometric analysis of western blots from at least five independent experiments. Values represent the mean fold change + SEM of each cell junction protein upon infection compared to uninfected control at respective time point, calculated from the band intensity and normalized to actin. ${ }^{*} \mathrm{p}<0.05$ versus control; ${ }^{* *} \mathrm{p}<0.01$ versus control; ${ }^{* * *} \mathrm{p}<0.001$ versus control.

Interestingly, structures of tight junction proteins claudin-2, claudin-3, claudin-4 and claudin-18 remained unchanged in pneumococci infected lung tissue within the tested time frame of 8 and $24 \mathrm{~h}$ (Figure 3.20). This finding was further validated by western blots (Figure 3.21a) and denistometric analyzes (Figure $3.21 \mathrm{~b}$ ).

Cell junction proteins were immunochistochemically analyzed allover the entire lung tissue slice including alveolar and brochiolar epithelium. Interestingly, while several molecules were found to be altered in the alveolar epithelium upon S. pneumoniae infection neither the same, nor other molecules were found to be altered in the bronchiolar epithelium within $24 \mathrm{~h}$ of infection (data not shown). Since not all immunohistochemically analyzed samples 
infected with pneumococci contained bronchiolar epithelium, this finding remains preliminary.
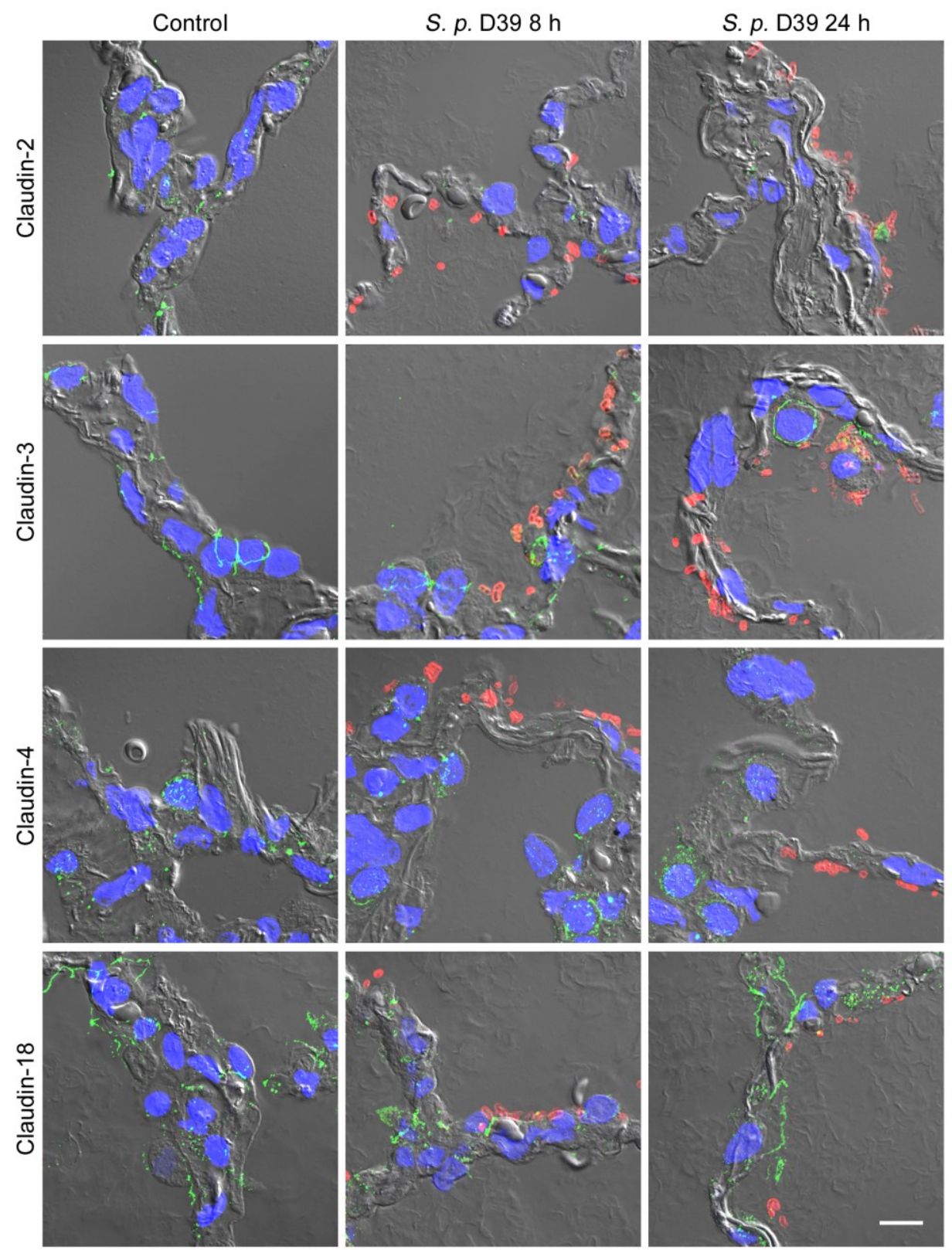

Figure 3.20: No altered structure of claudin-2, claudin-3, claudin-4 and claudin-18 in S. pneumoniae infected human lung tissue. Human lung tissue was infected with $10^{6} \mathrm{CFU} \cdot \mathrm{ml}^{-1}$ S. p. D39 for 8 and $24 \mathrm{~h}$. Histological sections were probed for respective cell junction protein (green), S. pneumoniae (red), nuclei (blue) were counterstained with DAPI and tissue structure was visualized by differential interference contrast. Control (left panel), $8 \mathrm{~h}$ infected (middle panel) and $24 \mathrm{~h}$ infected (right panel). Bar represents $20 \mu \mathrm{m}$. Representative figures of five independent experiments are shown. 
a)

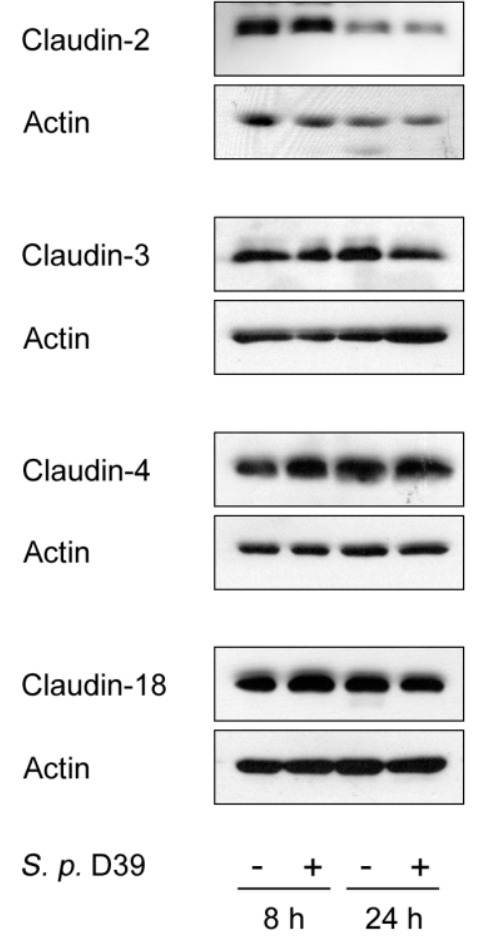

b)

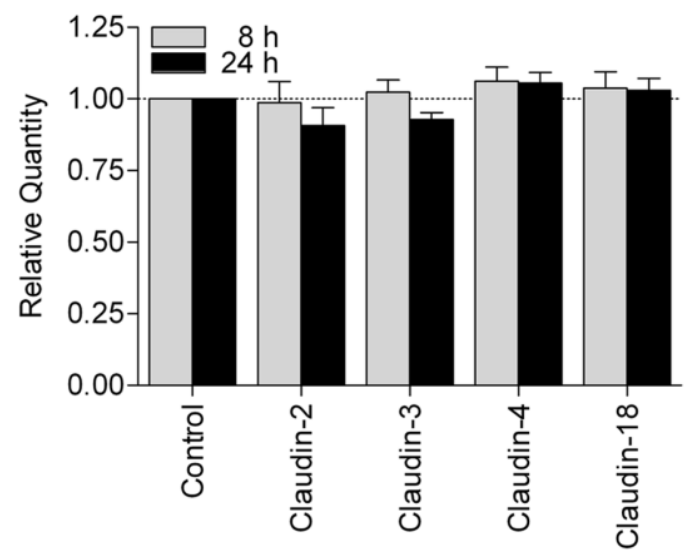

Figure 3.21: Constant protein levels of claudin-2, claudin-3, claudin-4 and claudin-18 in S. pneumoniae infected human lung tissue. (a) Total tissue lysates were analyzed by western blot. Representative western blots for claudin-2, claudin-3, claudin- 4 and claudin-18 are shown. Actin was used as loading control. (b) Densitometric analysis of western blots from at least five independent experiments. Values represent the mean fold change + SEM of each cell junction protein upon infection compared to uninfected control at respective time point, calculated from the band intensity and normalized to actin. Differences were not statistically significant. 


\subsection{The alteration of cell junctions is not transcriptionally regulated}

To examine whether the observed effect of altered cell junction structure and reduced protein levels upon $S$. pneumoniae infection is transcriptionally regulated by the host, mRNA levels were determined by quantitative RT-PCR. Firstly, all samples were tested for pro-IL-1B mRNA level to verify efficient pneumococcal infection of the human lung tissue. As expected, a significant increase of pro-IL-1B mRNA was observed upon $S$. pneumoniae infection (Figure 3.22). Determination of mRNA levels for VE-cadherin, occludin, ZO-1, claudin-3, claudin-4, claudin-5 and claudin-18 showed no significant downregulation overall (Figure 3.22). In contrast to the observation of reduced protein amounts upon infection, VE-cadherin and claudin-5 were slightly upregulated on mRNA level within the first hours of pneumococcal infection. However, claudin-2 mRNA was undetectable in all samples derived from five different patients (data not shown).
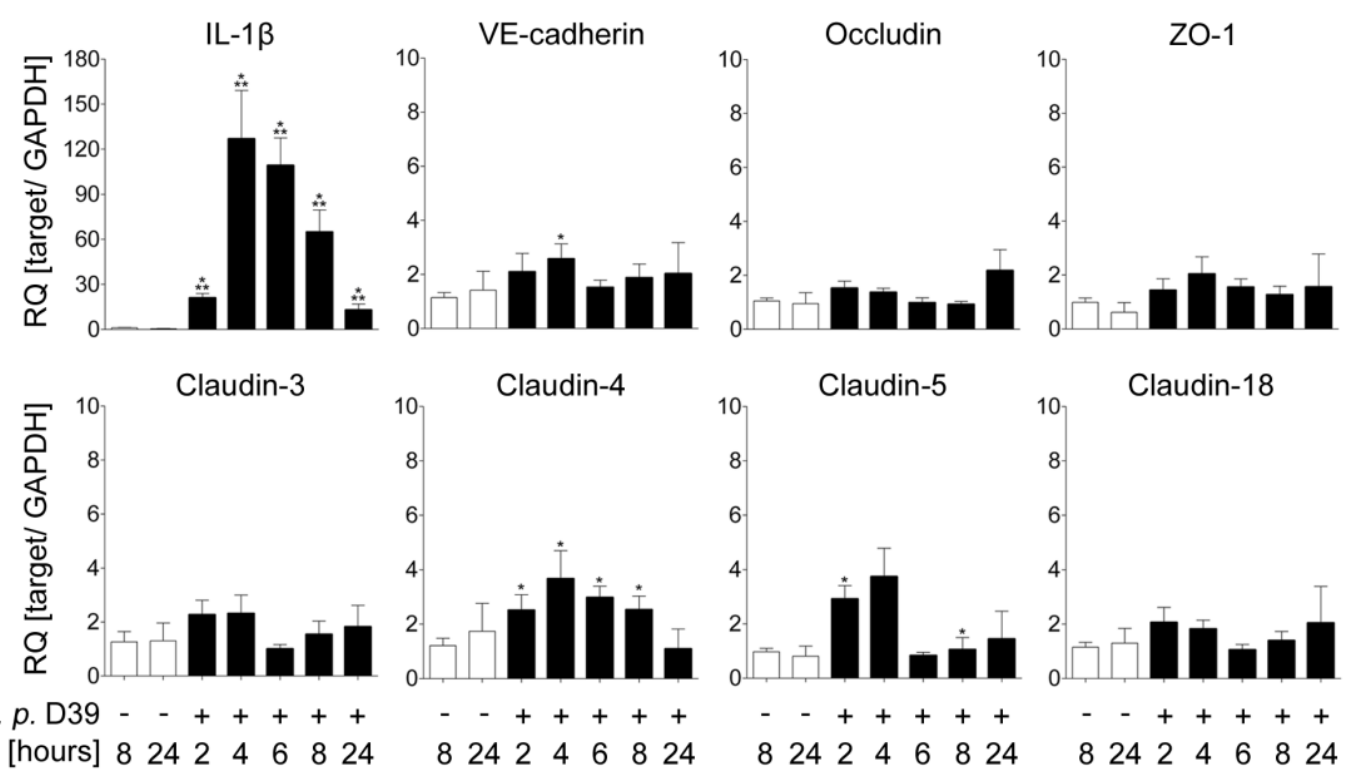

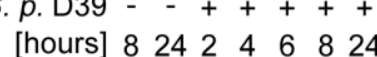

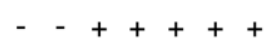

$-++++$

8242446824

Figure 3.22: Alteration of cell junctions is not transcriptionally regulated. Human lung tissue was infected with $10^{6} \mathrm{CFU} \cdot \mathrm{ml}^{-1} \mathrm{~S}$. $p$. D39 for 2, 4, 6, 8 and $24 \mathrm{~h}$. mRNA levels for proIL-1B, VE-cadherin, occludin, ZO-1, claudin-3, claudin-4, claudin-5 and claudin-18 were determined by quantitative RT-PCR. Values represent mean fold change + SEM of five independent experiments carried out in duplicates for each cell junction protein upon infection compared to uninfected control (values of 2, 4, 6 and $8 \mathrm{~h}$ infected samples were correlated to $8 \mathrm{~h}$ control; values of $24 \mathrm{~h}$ infected samples were correlated to $24 \mathrm{~h}$ control). ${ }^{*} \mathrm{p}<0.05$ versus control; ${ }^{* *} \mathrm{p}<0.01$ versus control; ${ }^{* * *} \mathrm{p}<0.001$ versus control. 


\subsection{Pneumolysin is not responsible for the alteration of cell junctions in infected human lung tissue}

Since gene expression of the investigated junction proteins seems to be unaffected by pneumococcal infection, the pneumococci-induced alteration of cell junction proteins is primarily not transcriptionally regulated. Consequently, bacterial virulence factors of $S$. pneumoniae were considered to damage host tissue and attack cell junctions.

The pore forming toxin pneumolysin (PLY) is a central bacterial virulence factor of S. pneumoniae, subsequently its role in ex vivo infection was analyzed. Therefore, human lung tissue was infected with S. pneumoniae D39 wild type or the PLY deficient mutant S. pneumoniae D39Aply for 8 and 24 h. As a positive control purified exogenous PLY was applied. Stimulation with PLY was carried out for only $2 \mathrm{~h}$ since it is immediately effective in contrast to PLY that initially has to be released from pneumococci. Occludin was characterized as junction protein expressed in endothelial and epithelial cells including the interfaces of type I and type II cells. Hence, this particular protein was chosen to further identify causes for pneumococci-induced alteration of cell junctions.

Immunohistochemical analysis revealed a characteristic structure of occludin as continuous junctional band lining the alveolar epithelium as well as endothelial cells of capillaries in untreated samples (Figure 3.23a). In S. pneumoniae D39 wild type as well as S. pneumoniae D39Aply infected human lung tissue the occludin bands were absent (Figure 3.23a, white arrowheads point towards broken junctional bands). This finding was confirmed by western blot and densitometric analysis showing a significant decrease of occludin protein level upon S. pneumoniae D39 wild type and S. pneumoniae D39Aply infection (Figure 3.23b, c). Moreover, stimulation with purified PLY alone affected neither occludin structure nor its protein level within the tested time frame (Figure 3.23a-c). Consequently, PLY seemed to be not responsible for cell junction protein alterations in ex vivo infected lung tissue. 
a)
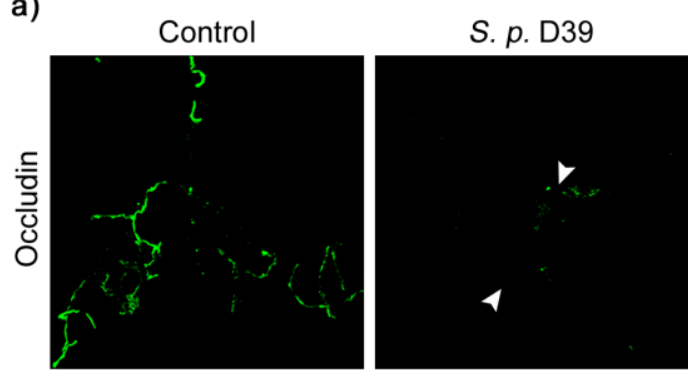

S. p. D39 3 ply
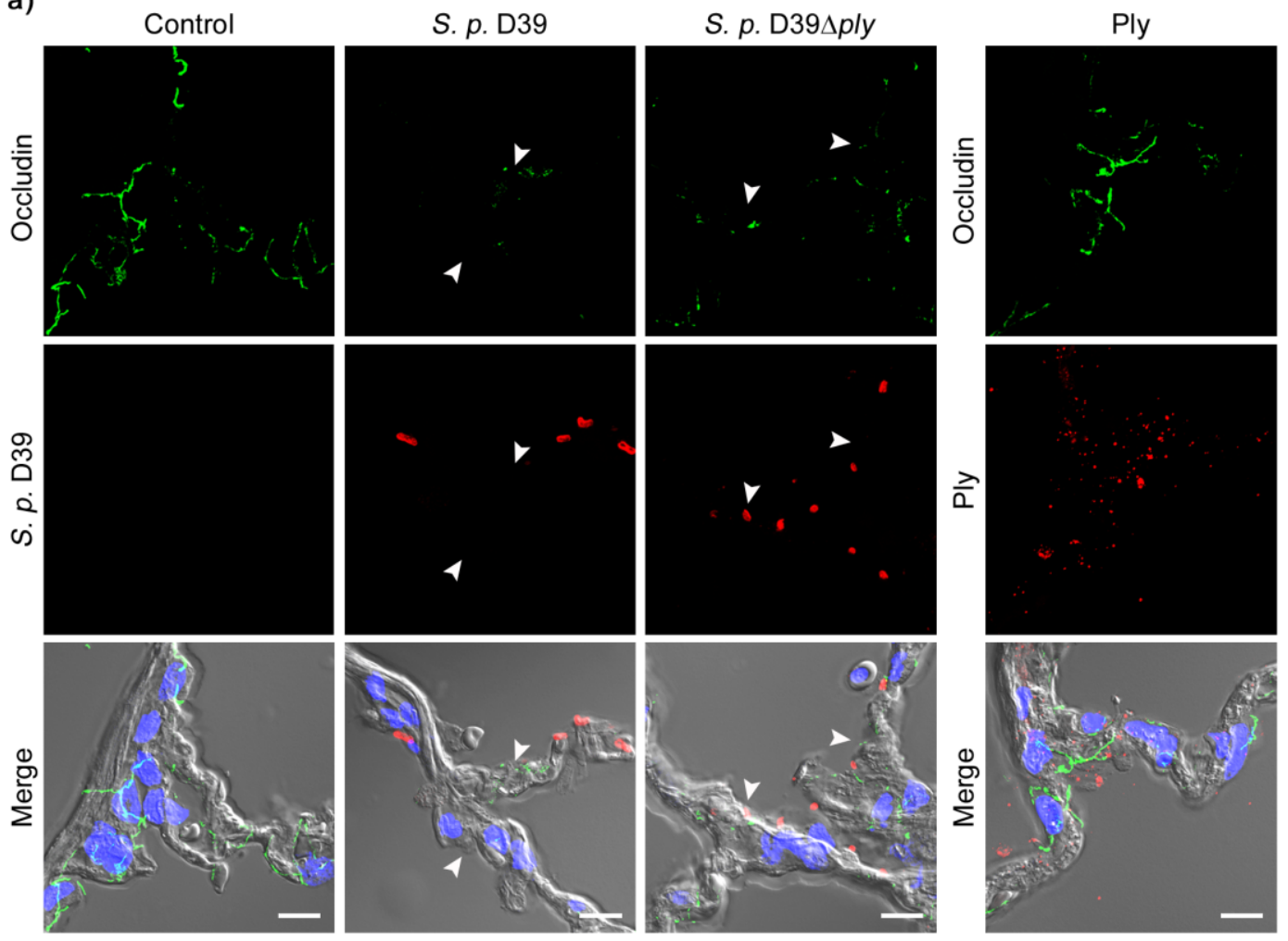

b)

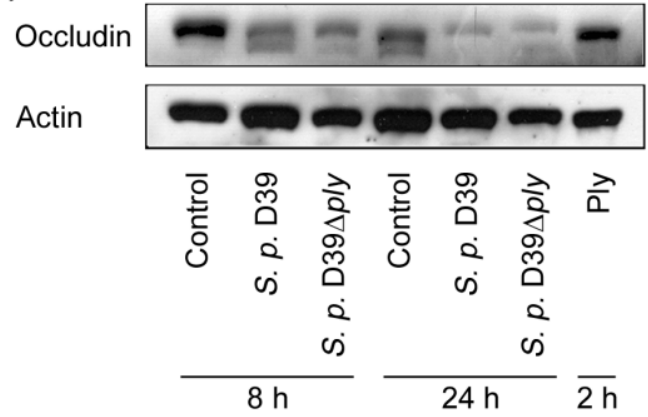

c)

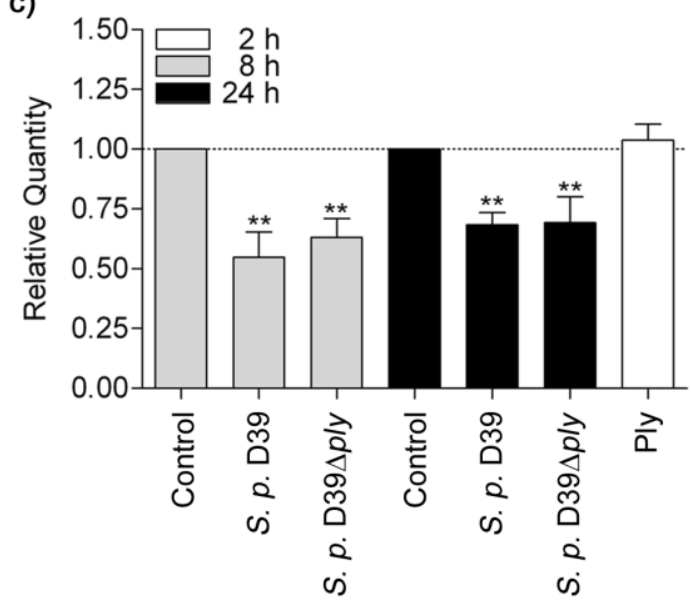

Figure 3.23: Pneumolysin is not responsible for the alteration of occludin. Human lung tissue was infected with $10^{6} \mathrm{CFU} \cdot \mathrm{ml}^{-1} S$. pneumoniae (S. p.) D39 or S. p. D39 $\Delta$ ply for 8 and 24 $\mathrm{h}$ or stimulated with purified PLY for $2 \mathrm{~h}$. (a) Histological sections were probed for occludin (green), S. pneumoniae or PLY (both red), nuclei (blue). Tissue structure was visualized by differential interference contrast. White arrowheads point towards broken junctional bands. Bar represents $10 \mu \mathrm{m}$. Representative figures of five independent experiments are shown. (b) Representative western blot for occludin. Actin was used as loading control. (c) Densitometric analysis of western blots from six independent experiments. Values represent the mean fold change + SEM of occludin upon infection compared to uninfected control at respective time point, calculated from the band intensity and normalized to actin. ${ }^{* *} \mathrm{p}<0.01$ versus control. 


\subsection{Pneumococci impair barrier function independently of the virulence factor pneumolysin in vitro}

In the human lung, disruption of cell junctions is usually associated with an increase in pulmonary permeability and impairment of barrier function. To examine whether $S$. pneumoniae infection induces indeed pulmonary permeability, endothelial and epithelial cells were analyzed for their transcellular electrical resistance during infection. The resistance of a confluent cell monolayer is mainly determined by the three-dimensional shape of the cells and the way they are connected to each other. Morphological changes due to an external stimulus alter the current paths through and around the cell bodies resulting in an increase or decrease of resistance. Transcellular electrical resistance as a measurement of permeability was determined by electric cell-substrate impedance sensing (ECIS). Although PLY is not responsible for occludin alteration, there might be differences in cell permeability upon infection with PLY deficient compared to wild type bacteria. To test this, epithelial and endothelial cells were infected with S. pneumoniae D39Acps as well as the PLY deficient strain S. pneumoniae D39Acps $\Delta$ ply.

Human umbilical vein endothelial cells (HUVECs) as well as epithelial A549 cells showed a significant decrease in transcellular electrical resistance starting at $4 \mathrm{~h}$ after infection. In HUVECs infection with $S$. pneumoniae D39Acps led to an approximately 75\% reduced resistance and PLY deficient $S$. pneumoniae D39 $\Delta$ cps $\Delta$ ply reduced resistance by approximately 50\% compared to baseline resistance after $8 \mathrm{~h}$ infection (Figure 3.24a). In epithelial A549 cells the decrease of transcellular electrical resistance upon infection was overall less pronounced compared to HUVECs as indicated by a drop of approximately $25-40 \%$ (Figure 3.24b). 
a)

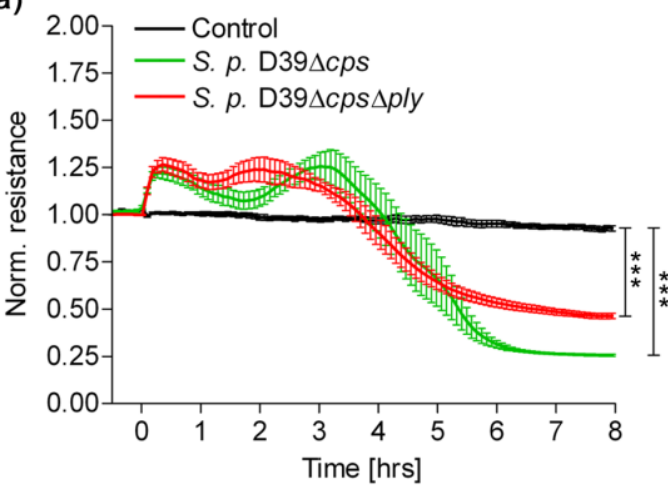

b)

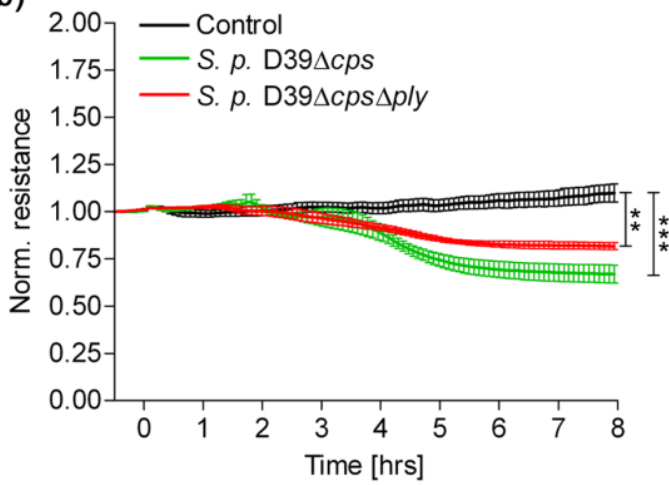

Figure 3.24: S. pneumoniae impairs epithelial and endothelial barrier function independently of pneumolysin. HUVECs (a) and A549 cells (b) were grown on 8W10E ECIS

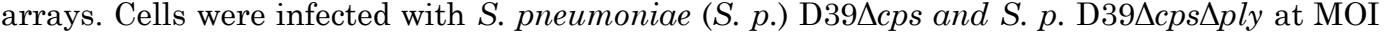
50 for $8 \mathrm{~h}$. Transcellular electrical resistance was continuously monitored and measured resistance normalized to baseline resistance. Values represent the mean fold change \pm SEM of six independent experiments. Statistical significance was tested at time point $8 \mathrm{~h} .{ }^{* *} \mathrm{p}<0.01$ versus control; ${ }^{* * *} \mathrm{p}<0.001$ versus control.

Taken together, S. pneumoniae strongly impaired the epithelial and endothelial barrier function as shown by a significant decrease in transcellular electrical resistance. Since a decreased transcellular electrical resistance results from morphological changes this may indicate a potential formation of gaps within the cell monolayers, which might be due to the disruption of cell junctions. The PLY deficient strain triggered slightly less permeability in epithelial as well as endothelial cells compared to the wild type stain. However, these differences were only marginal and together with the results obtained from the ex vivo lung tissue experiments it seems that PLY is not the major cause of decreased transcellular electrical resistance. 


\subsection{Hydrogen peroxide impairs barrier function and catalase prevents pneumococci-induced gap formation in vitro}

Another important bacterial virulence factor of $S$. pneumoniae is hydrogen peroxide. Hydrogen peroxide is produced by pneumococci mainly through the pyruvate oxidase and it has been reported that its concentrations may exceed $1 \mathrm{mM}$ in the surrounding media [97]. To analyze the effect of hydrogen peroxide in vitro, primary endothelial cells and epithelial A549 cells were stimulated with $0.5 \mathrm{mM}, 1.0 \mathrm{mM}$ and $1.5 \mathrm{mM}$ exogenous hydrogen peroxide $\left(\mathrm{H}_{2} \mathrm{O}_{2}\right)$ and transcellular electrical resistance was measured by ECIS. To investigate the structure of cell monolayer, A549 cells were additionally stained for actin cytoskeleton at $1.5 \mathrm{~h}$ of stimulation with hydrogen peroxide.

HUVECs showed an immediate decrease of transcellular electrical resistance in response to $\mathrm{H}_{2} \mathrm{O}_{2}$. All doses of $\mathrm{H}_{2} \mathrm{O}_{2}$ had a similar effect on HUVECs displayed by decreased resistances of about $75 \%$ after $3.5 \mathrm{~h}$ of incubation (Figure 3.25a). The lowest dose of $0.5 \mathrm{mM} \mathrm{H} \mathrm{H}_{2}$ caused mild and partially reversible reduction of resistance in A549 cells whereas concentrations of $1.0 \mathrm{mM}$ and $1.5 \mathrm{mM}$ led to a significant diminished resistance of about $50 \%$ compared to untreated control (Figure 3.25b). A reduced resistance of epithelial and endothelial cells indicates increased permeability and impairment of barrier function caused by changes in cell morphology. To examine the structure of the epithelial cell layer upon $\mathrm{H}_{2} \mathrm{O}_{2}$ treatment, A549 cells were challenged with different doses of $\mathrm{H}_{2} \mathrm{O}_{2}$ for $1.5 \mathrm{~h}$, a time point when a significant decrease in resistance was measured by ECIS (Figure 3.25b). Staining of the actin filaments showed gap formation and stress fibers already at a concentration of $0.5 \mathrm{mM} \mathrm{H}_{2} \mathrm{O}_{2}$ (Figure $3.25 \mathrm{c}$, white arrowheads) and higher concentrations strengthened this effect even more. Within the cell monolayer gaps increased in number and size and cells rounded up and started to detach in a concentration dependent manner. In summary, hydrogen peroxide impairs and destabilizes endothelial and epithelial barrier function resulting in gap formation and stress fibers in cell monolayers. 

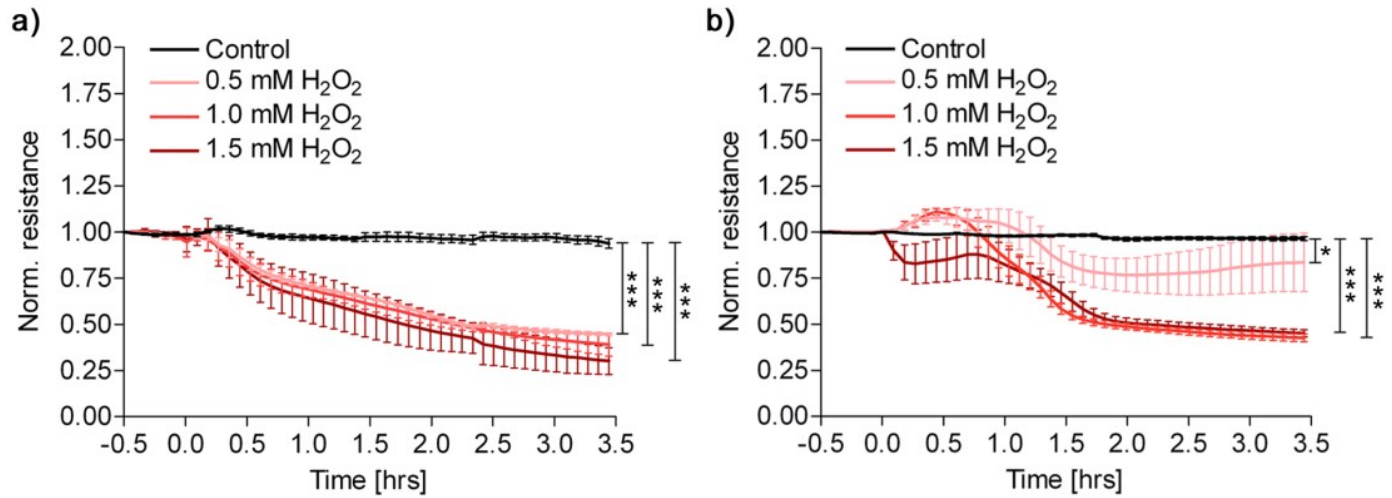

c)
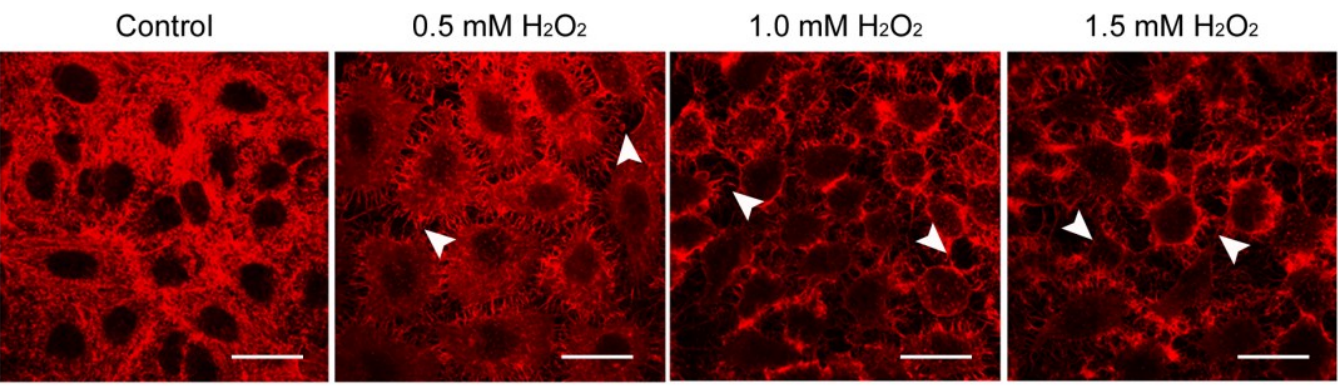

Figure 3.25: Hydrogen peroxide impairs epithelial and endothelial barrier function. HUVECs (a) and A549 cells (b) were grown on 8W10E ECIS arrays. Cells were stimulated with $0.5,1.0$ and $1.5 \mathrm{mM}$ hydrogen peroxide for $3.5 \mathrm{~h}$. Transcellular resistance was continuously monitored and measured resistance normalized to baseline resistance. Values represent the mean fold change \pm SEM of six independent experiments. Statistical significance was tested at time point $3.5 \mathrm{~h}$. ${ }^{*} \mathrm{p}<0.05$ versus control; ${ }^{* * *} \mathrm{p}<0.001$ versus control. (c) A549 cells were grown on glass cover slips and stimulated with $0.5,1.0$ and $1.5 \mathrm{mM}$ hydrogen peroxide for $1.5 \mathrm{~h}$, fixed with paraformaldehyde and stained for actin (red). White arrowheads point to gaps in monolayer. Bars represent $20 \mu \mathrm{m}$. Representative figures of three independent experiments are shown.

Next, it was investigated whether the pneumococci-induced impaired barrier function (compare chapter 3.6) relies on the production of pneumococcal $\mathrm{H}_{2} \mathrm{O}_{2}$. Therefore, HUVECs were infected with S. pneumoniae D39Acps $\Delta$ ply with or without simultaneous application of catalase, an enzyme catalyzing the decomposition of hydrogen peroxide to water and oxygen. HUVECs were chosen here because of their characteristically expression of a continuous occludin band. In contrast, occludin expression in epithelial A549 cells is rather diffuse and potential alterations in cell junction expression are hard to detect. Gap formation is a dynamic process and in order to understand the effects of pneumococci on cell junctions in more detail, live cell imaging was applied. 
Firstly, green fluorescent protein (GFP) fused to the N-terminus of the tight junction protein occludin was adenovirally overexpressed in HUVECs. In line with the results obtained from the ex vivo lung tissue model, confocal microscopy analyzes revealed that GFP-occludin localizes at intercellular connections of endothelial cells (Figure 3.26a, Supplementary video 3). Infection of GFP-occludin overexpressing HUVECs with S. pneumoniae D39Acps $\Delta p l y$ led to a disturbed monolayer as indicated by substantial gap formation after $6 \mathrm{~h}$ (Figure 3.26a, Supplementary video 4). Strikingly, this effect could be rescued by simultaneously application of catalase resulting in an intact monolayer comparable to the untreated control (Figure 3.26a, Supplementary video 5). This indicates that pneumococcal hydrogen peroxide by might be responsible for cell junction alteration. This hypothesis was further strengthened by ECIS experiments measuring cell monolayer integrity.

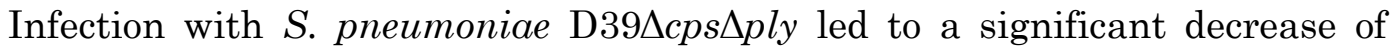
resistance in the HUVEC monolayer (Figure 3.26b), demonstrating an impairment of barrier function. Strikingly, decrease of resistance could again be prevented by application of catalase (Figure 3.26b). 
a)

Control

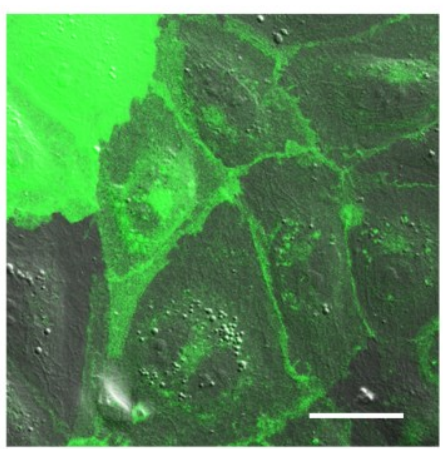

S. p. D39 3 cps $\Delta$ ply

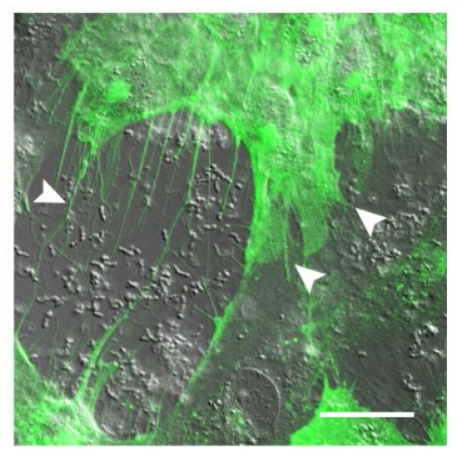

S. p. D39 $\Delta c p s \Delta p l y$

+ catalase

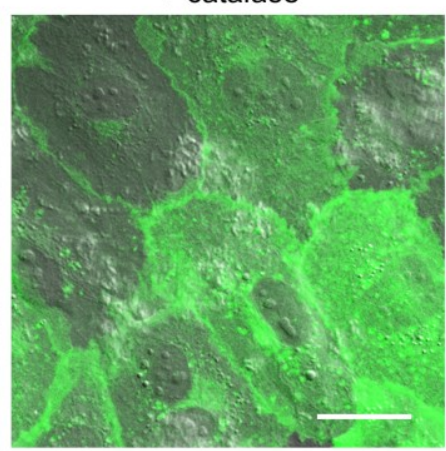

b)

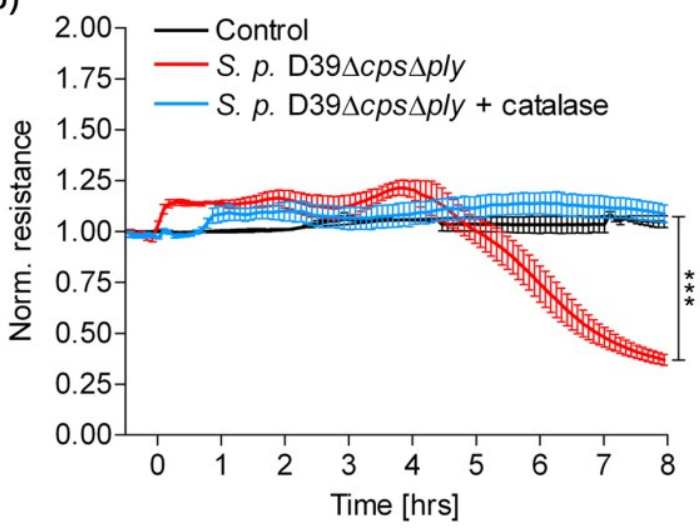

Figure 3.26: Catalase prevents gap formation and impairment of barrier function

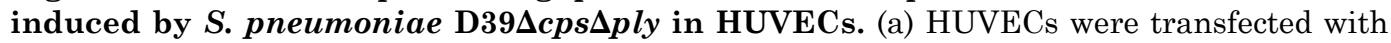
adenoviral GFP-occludin and infected with $S$. pneumoniae (S. p.) D39scps $\Delta$ ply at MOI 50 for $6 \mathrm{~h}$. Simultaneously $192 \mathrm{U}$ catalase was applied. White arrowheads point to gaps in monolayer. Bar represents $20 \mu \mathrm{m}$. Representative figures of three independent experiments are shown.

HUVECs were grown on 8W10E ECIS arrays and infected with $S$. p. D39 $\Delta c p s \Delta p l y$ at MOI 50 for $8 \mathrm{~h}$, where indicated $192 \mathrm{U}$ catalase was added. Transcellular electrical resistance was continuously monitored and measured resistance was normalized to baseline resistance. Values represent the mean fold change \pm SEM of six independent experiments. Statistical significance was tested at time point 8 h. ${ }^{* * *} \mathrm{p}<0.001$ versus control. 


\subsection{The hydrogen peroxide deficient $S$. pneumoniae D39 $\triangle s p x B$ mutant is unable to induce alterations of cell junction proteins in human lung tissue}

Since hydrogen peroxide impairs barrier function and catalase prevents pneumococci-induced gap formation in vitro, these results were consequently transferred to the ex vivo lung infection model hypothesizing that hydrogen peroxide is the major cause of pneumococci-induced alteration of cell junctions in human lungs. Hydrogen peroxide is produced by S. pneumoniae through the enzyme pyruvate oxidase $(\mathrm{spxB})$ under aerobic growth conditions. Thus, human lung tissue was infected with $10^{6} \mathrm{CFU} \cdot \mathrm{ml}^{-1} \mathrm{~S}$. pneumoniae D39 wild type and S. pneumoniae D39 $\Delta s p x B$, a mutant lacking pyruvate oxidase, for $24 \mathrm{~h}$. Immunohistochemical staining of occludin and pneumococci revealed loss of occludin bands in S. pneumoniae D39 wild type infected human lung tissue, whereas S. pneumoniae D39 $\Delta s p B$ infection did not alter occludin structure (Figure 3.27). 

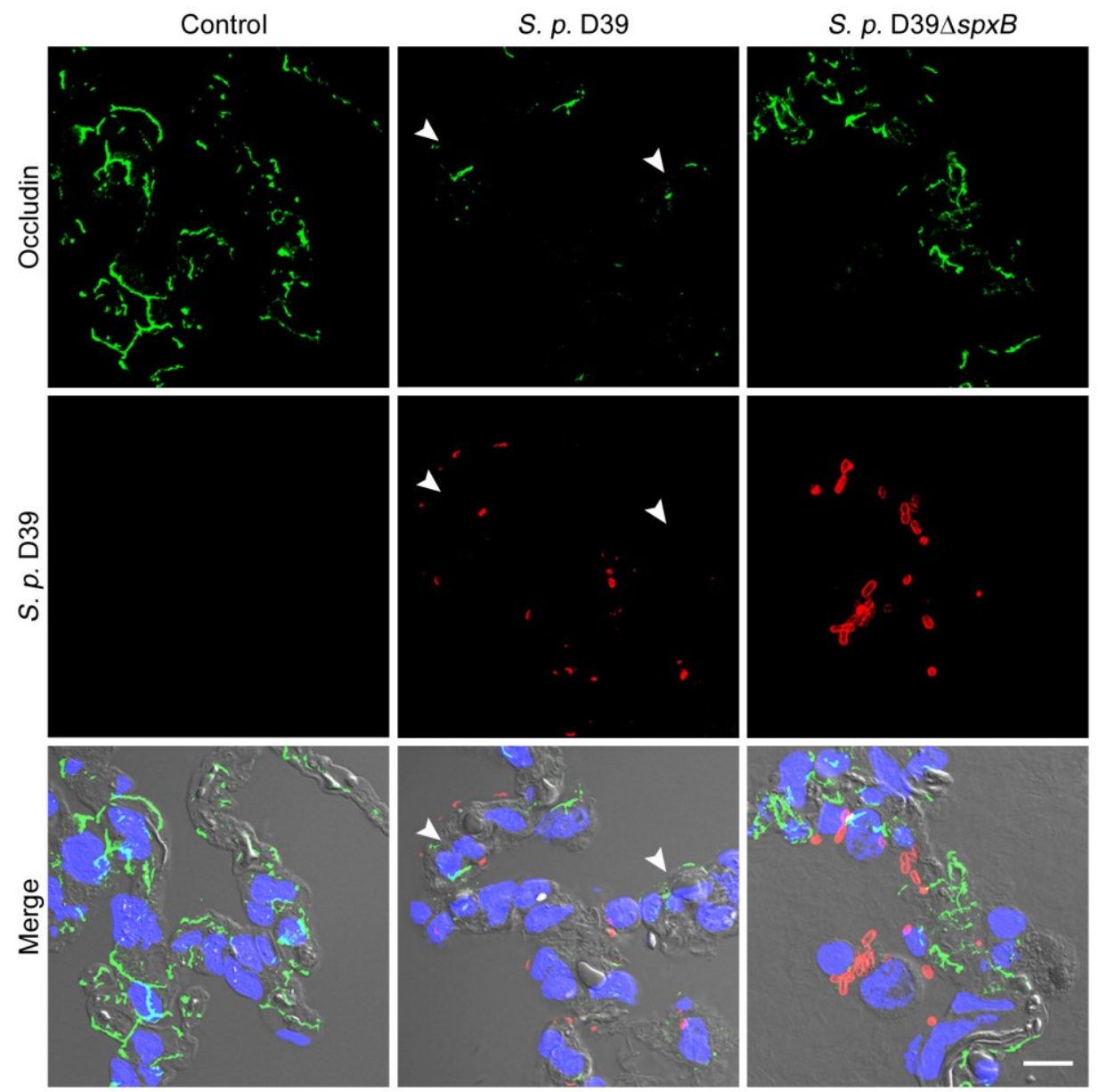

Figure 3.27: S. pneumoniae D39sspxB rescues pneumococci-induced alteration of occludin. Human lung tissue was infected with $10^{6} \mathrm{CFU} \cdot \mathrm{ml}^{-1}$ S. pneumoniae (S. p.) D39 and S. $p$. D $39 \Delta s p x B$ for 24 h. (a) Histological sections were probed for occludin (green), S. pneumoniae (red) and nuclei (blue). White arrowheads point towards broken junctional bands. Representative figures of three independent experiments are shown. Bar represents $10 \mu \mathrm{m}$.

Next, the role of $S$. pneumoniae-derived $\mathrm{H}_{2} \mathrm{O}_{2}$ in pneumococci-induced alteration of cell junction proteins was investigated in a quantitative way. To this end several cell junction proteins were analyzed by western blot in human lung tissue infected with S. pneumoniae D39 wild type with or without simultaneous application of catalase as well as infected with $S$. pneumoniae D39 $\Delta s p x B$ for 24 h. While infection with S. pneumoniae D39 wild type strongly reduced protein levels of VE-cadherin, occludin, ZO-1 and claudin-5 in human lung tissue, simultaneous application of catalase totally protected from protein disappearance. 
Strikingly, the hydrogen peroxide deficient mutant S. pneumoniae D39 $\Delta$ spxB did not cause any changes in protein abundance compared to the uninfected control. (Figure 3.28a, b).

a)

VE-cadherin

Actin

Occludin

Actin

$\mathrm{ZO}-1$

Actin

Claudin-5

Actin
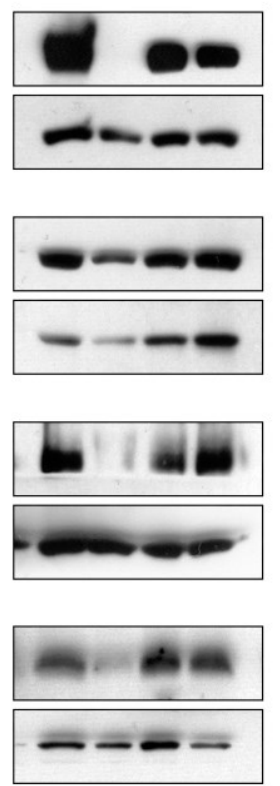

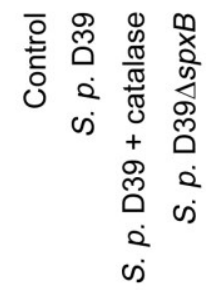

b)

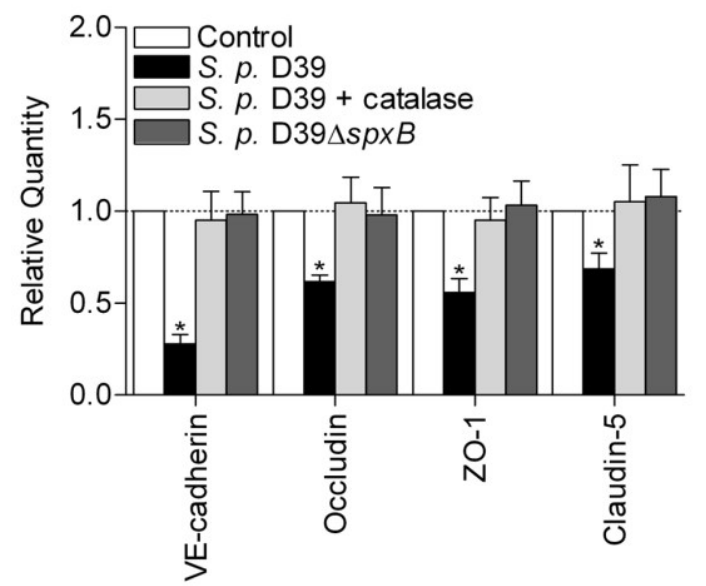

Figure 3.28: S. pneumoniae D39sspxB infection does not reduce protein levels of VE-cadherin, occludin, ZO-1 and claudin-5 in human lung tissue. (a) Representative western blots for VE-cadherin, occludin, ZO-1 and claudin-5. Actin was used as loading control. (b) Densitometric analysis of western blots from three independent experiments. Values represent the mean fold change + SEM of infected samples compared to uninfected control, calculated from the band intensity and normalized to actin. ${ }^{*} \mathrm{p}<0.05$ versus control. 


\section{Discussion}

This study is segmented into two consecutive parts. Initially, the constitutive expression patterns of adherens junction protein VE-cadherin and tight junction proteins occludin, ZO-1 as well as claudin-2, -3, -4, -5 and -18 were characterized in human lung tissue using confocal laser scanning microscopy. Spectral imaging combined with linear unmixing was applied to distinguish between lung tissue autofluorescence and the signals of interest. Bronchiolar epithelium was tested positive for occludin, ZO-1, claudin-2, -3, -4, -5 and -18. However, occludin, ZO-1, claudin-5 and -18 were located merely at apical borders of bronchiolar epithelium and claudin-2, -3 and -4 were detected apical and lateral. Occludin and ZO-1 are expressed at the type I-type I cell interface as well as at the interface of type II alveolar epithelial cells whereas claudin-3, -4 and -18 are exclusively expressed at the interface of type II alveolar epithelial cells. Cell junctions in lung endothelial cells are formed by VE-cadherin, occludin, ZO-1, claudin-3 and claudin-5. The analyzed junction proteins appeared mostly as band-like structures connecting adjacent cells, exept for claudin-2 and claudin-4, which were recognized to appear in punctate structures.

Subsequently, in an ex vivo infection model lung tissue samples were infected with $S$. pneumoniae, the most frequent pathogen of pneumonia. In pneumococci infected human lung tissue the loss of characteristic alveolar structure and significant reduction of protein abundance of VE-cadherin, occludin, ZO-1 as well as claudin-5 were demonstrated. Strikingly, tight junction proteins claudin-2, -3, -4 and -18 remained unchanged within 24 hours post infection. The alteration of junctional proteins and impaired barrier function are primarily not transcriptionally regulated. It is rather dependent on pneumococcal spxB-related hydrogen peroxide production, whereas pneumolysin seemed not to reduce the presence of the investigated cell junction proteins (Figure 4.1). 
Cell-specific expression patterns
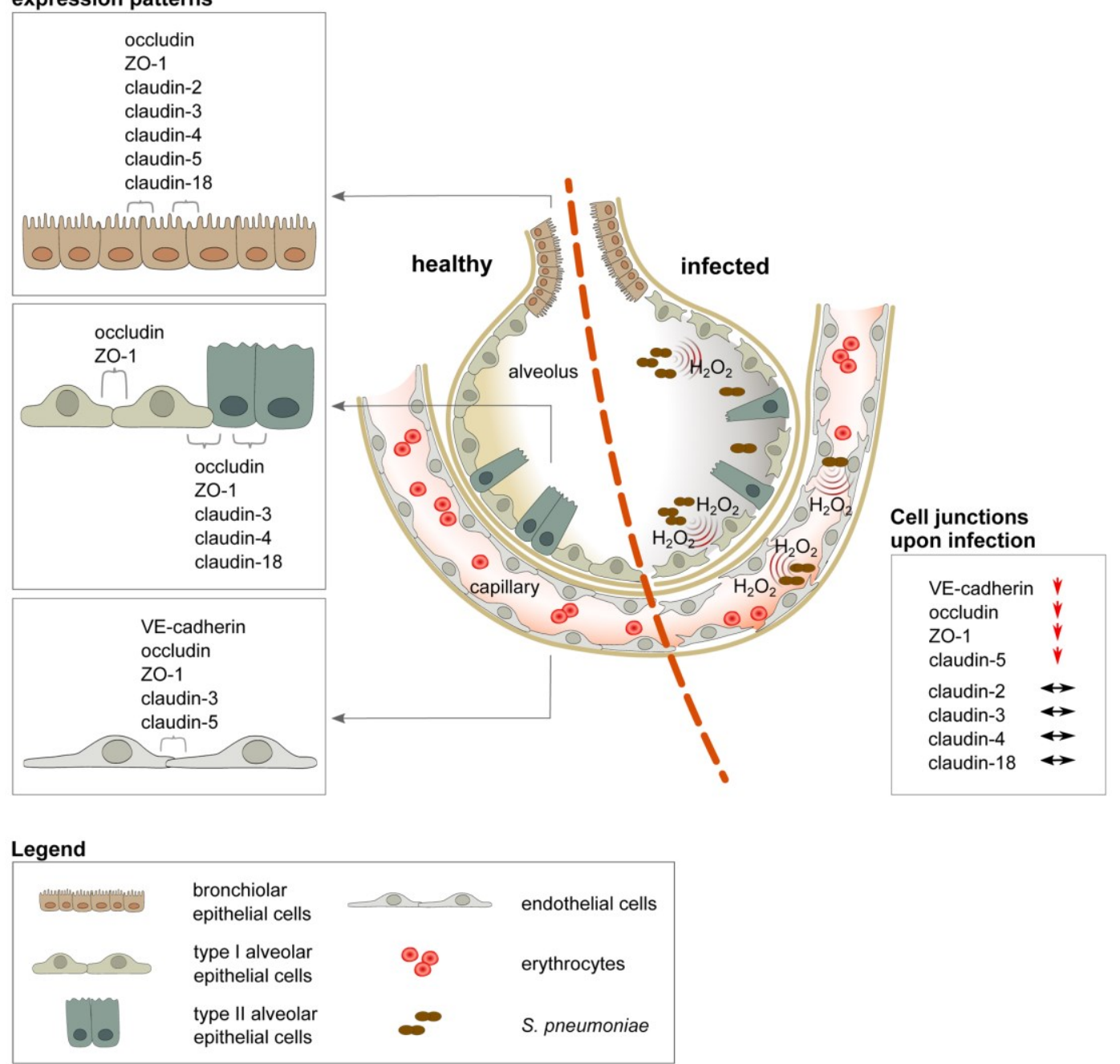

Figure 4.1: Proposed model of cell junctions in healthy and S. pneumoniae infected human lungs. In healthy lungs, heterogeneous expression patterns for VE-cadherin, occludin, ZO-1, claudin-2, $-3,-4,-5$ and -18 are observed in different areas. In infected human lung tissue, S. pneumoniae-derived hydrogen peroxide $\left(\mathrm{H}_{2} \mathrm{O}_{2}\right)$ causes reduction of VE-cadherin, occludin, ZO-1 as well as claudin-5 whereas claudin-2, $-3,-4$ and -18 remained unchanged within 24 hours post infection. In vitro experiments indicate that alteration of cell junction proteins involves destabilization of endothelial and epithelial barrier function resulting in gap formation.

\subsection{Ex vivo cultivated human lung tissue explants as an infection model}

Most studies on pathophysiologic mechanisms of lung diseases are based on cultured cell lines and animal models. These models represent an integral part of current pneumonia research, but their obvious limitations should be considered [256, 257]. Immortalized pulmonary cell lines such as A549 cells often originate from cancer cells, thereby strongly differ from primary cells. 


\section{Discussion}

Cell passaging and adding of growth factors or fetal calf serum in cell culture can lead to dedifferentiation and mutation of cells resulting in the loss of cellspecific characteristics [257]. Human pneumonia is modeled with experimental infection of mammals, most frequently mice. Mice and humans differ in many important issues relevant to lung infection, e.g. differences in structural anatomy and cellular composition of the murine respiratory tract [258, 259]. Whereas mouse lungs exhibit only 13-17 generations of respiratory bronchioles, the human respiratory tree branches over 23 generations. Additionally, mouse lungs have a relatively large airway lumen compared to humans [260]. Discrepancies in mouse and human innate immunity have also been reported, e.g. whereas neutrophils are a rich source of leukocyte-derived defensins in humans, no defensins are expressed by neutrophils in mice [261]. Another important aspect is the use of inbred mouse strains in research. The choice of a specific genetic background has long been known to influence the observed phenotype. On the other hand, in studies using human material the genetic diversity is reflected by the donor patients [262]. Therefore, principal investigation or the validation of results obtained from cell culture or animal models should be performed in original human material.

One of the benefits of the human lung tissue model is the preservation of the complex threedimensional structure reflecting the different cell types of the human respiratory tract. In explant culture, cells are sourrounded by their extracellular matrix and their natural arrangement within the tissue correspond to in vivo conditions. Therefore, the interaction between different cell types, e.g. type I and type II alveolar epithelial cells, can be investigated whereas cell lines are composed of phenotypically identical cells. Nevertheless, the human lung infection model also has limitations. Since the recruitment of immune cells from the bloodstream can not be simulated, this model is not suitable for immunological issues. Furthermore, the nutritive nourishment and cleansing of the isolated tissue is severely restricted. The alveoli are neither ventilated nor are capillaries perfused. As a result, processes such as apoptosis or necrosis can be triggered that may influence the inflammatory response. However, analysis of $24 \mathrm{~h}$ cultivated naive human lung tissue showed 
a slight increase of LDH release indicating only a marginal tissue damage (Figure 3.17d).

The human lung explants in this study were received from patients undergoing lung resection. Although the lung tissue itself was tumor free, it originated most frequent from cancer patients that were by tendency elderly, prevalently exposed to cigarette smoke and/ or suffering from chronic obstructive pulmonary disease (COPD). Certain characteristics of human lung tissue may depend on clinical indicators and the medical condition of the patients. Although the influence of potential patient-customized factors on experiments cannot be excluded, statistically solid and reproducible results were obtained. Furthermore, the infection route in this model is only limited comparable to the human body. The pathogens enter the alveoli initially via the upper respiratory tract, the trachea and bronchioles. In contrast, in this model the bacteria are injected directly into the lung tissue. The bacteria reach the tissue structures and host cells from all sides, similarly as in the setup of a cell culture infection experiment. To provide evidence that the human lung tissue model supports $S$. pneumoniae replication and is able to identify mutants, growth kinetics of wild type as well as pneumolysin- and spxB-deficient $S$. pneumoniae strains were determined in tissue samples demonstrating strong bacterial replication within 8 and $24 \mathrm{~h}$ post infection (Figure $3.17 \mathrm{~b}$ and data not shown).

The human lung model used in this study with its variety of cell types and extracellular components facilitates the characterization of cell junction proteins during S. pneumoniae infection and constitutes a valuable model for the investigation of host-pathogen interactions within the human lung tissue. Particular aspects of infections with the pneumonia causing pathogens L. pneumophila [263], C. pneumoniae [264], H. influenzae [265], S. pneumoniae [266] as well as influenza A virus [267] and Middle East respiratory syndrome coronavirus (MERS-CoV) [268] have been analyzed in comparable systems. Nevertheless, studies involving human lung tissue explants remain the minority in pneumonia research. 


\subsection{Tissue autofluorescence - a soluble problem?}

The basic composition and three-dimensional structure of cell junction proteins in the human lung is widely unknown and studies addressing their alteration in inflamed human lung tissue are rare. Besides the restricted availability of vital human lung tissue for such research purposes, its high autofluorescence has previously hampered a detailed study of junctional organization by fluorescence-based microscopic methods. Autofluorescence is the natural light emission by certain cellular components and structures such as the extracellular matrix, lipopigments and mitochondria [269]. It poses substantial problems in fluorescence microscopy by interfering or even overpowering the signal from exogenous fluorophores used to stain specific proteins and areas in the tissue. Besides the prevalent autofluorescence of normal lung tissue, the intensity of its unique fluorescence spectra differs significant from diseased lung tissue [270, 271]. An additional problem is the fluorescent crosstalk due to the wide emission range of fluorophores [272]. Crosstalk or bleed-through occurs when two or more fluorescent markers are excited and imaged resulting in an overlap of their significant spectral profiles. To evade this problem, most studies providing histopathologic and immunohistological information on human lung tissue structure utilize labels such as alkaline phosphatase and horseradish peroxidase for protein detection. Subsequent analyzes are restricted to light or electron microscopy and a two-dimensional illustration [273-275].

Therefore, in this study spectral imaging and linear unmixing were applied to discriminate between lung tissue autofluorescence and specific signals of the added artificial fluorophores. Initially, a three-dimensional data set is created that contains a collection of images of the same view field captured at different wavelengths. This spectral image stack (or lambda stack) gathered by the LSM 780 microscope is the basis for the accompanying computational process performed with ZEN 2012 software. Thereby the mixed fluorophore spectra are separated into individual spectra. The individual fluorophore spectra, including the lung tissue autofluorescence, are then subtracted from the signal of interest. This approach has been performed for every added artificial 
fluorophore to the histological section and the single unmixed images were finally merged. This technique allows multichannel fluorescence imaging in lung tissue e.g. simultaneous staining of a cell junction protein and a cellspecific marker. For the first time, it was possible to determine and illustrate heterogeneous cell-specific expression patterns of cell junctions in the complex three-dimensional alveolar compartments by fluorescence microscopy.

The discrimination between lung tissue autofluorescence and specific signals using spectral imaging and linear unmixing has recently successfully been applied to identify type II alveolar epithelial cells as principal target cell type of avian, porcine and human influenza A viruses [276, 277] and it revealed extensive alveolar infection of bronchiolar epithelial cells, type I as well as type II alveolar epithelial cells by MERS-CoV [278].

\subsection{Heterogeneous expression patterns of cell junction proteins in normal human lung tissue}

The investigation of cell junction proteins VE-cadherin, occludin, ZO-1 as well as claudin-2, claudin-3, claudin-4, claudin-5 and claudin-18 revealed heterogeneous expression patterns in various sections of the human lung. The analyzed distribution and structure were categorized in terminal and respiratory bronchiolar epithelium, alveolar epithelium and endothelium including larger blood vessels and capillaries.

\section{Expression patterns in the bronchioles}

Terminal as well as respiratory bronchiolar epithelium were tested positive for tight junction proteins occludin, ZO-1, claudin-2, $-3,-4,-5$ and -18 . Furthermore, the expression patterns of these cell junction proteins differed within the distinct areas of the bronchiolar epithelium. Whereas occludin, ZO-1, claudin-5 and -18 were located at apical borders of bronchiolar epithelium, claudin-2, -3 and -4 were detected both in the apical and lateral region of cells. 
ZO-1 and occludin were, in line with this study, previously outlined at apical borders of the bronchiolar epithelium in human lung tissue [273, 274, 279], but non of these studies revealed their appearance as junctional bands. They were rather described as dots or a short line. Only in primary human bronchiolar epithelial cells or cell lines a continuous band-like structure of ZO-1 as well as occludin was shown [280, 281]. In this study, the images are maximum intensity projections of a $\mathrm{z}$-stack representing the entire $10 \mu \mathrm{m}$ section of a histological slide. The merged 2D image of successive slices enables additional information about lung structure. Further processing to a three-dimensional reconstruction displays the complex grid-like structure of occludin covering bronchiolar epithelial cells maintaining its gate and fence function (Supplementary video 1). Studies comparing immunohistochemical claudin expression of normal and usual interstitial pneumonia or pulmonary fibrosis lungs from patients showed bronchiolar epithelial expression of claudin-1, $-2,-3,-4,-5$ and -7 in normal human lung tissue $[282,283]$. To this date bronchiolar epithelial expression of claudin-18 was only found in mice or detected on mRNA level in human lung [206, 284].

The herewith defined strong expression patterns of almost all of the investigated cell junctions (the only exception is endothelial specific VE-cadherin) at the apicolateral border of the bronchiolar epithelium may be associated with its barrier function. The bronchiolar epithelium primary functions as physical barrier defending the airways against the invasion of noxious substances [285]. Three essential components contribute to the barrier function of the bronchiolar epithelium: (i) the mucociliary escalators which trap and remove inhaled small particels and pathogens from the airways, (ii) secreted antimicrobial products that provide protection against a wide range of inhaled pathogens and (iii) intercellular tight and adherens junctions that regulate paracellular permeability $[285,286]$. Maintaining the integrity of the bronchiolar epithelium could therefore be the principal reason for a strong and diverse expression of intercellular junctions as shown in this study. 


\section{Discussion}

\section{Expression patterns in the alveoli}

Cell junctions in lung endothelial cells are formed by VE-cadherin, occludin, ZO-1, claudin-3 and claudin-5. Cell-specific costainings of the alveolar epithelial compartment revealed the expression of occludin and ZO-1 at the type I-type I cell interface as well as at the interface of type II alveolar epithelial cells whereas claudin-3, -4 and -18 are exclusively expressed at the interface of type II alveolar epithelial cells to neighboring cells.

VE-cadherin is known to be strictly located at intercellular junctions of all types of endothelium [287], which could be verified also for human lungs in this study. Consequently, VE-cadherin was chosen as endothelial marker for the cell-specific expression analysis of further cell junction proteins. No differences in expression patterns for VE-cadherin were found between pulmonary blood vessels and capillaries in this study. In contrast, a heterogeneous vessel typespecific expression pattern for VE-cadherin in human lungs was reported demonstrating a strong endothelial expression of VE-cadherin in arteries, arterioles, and capillaries but almost no expression in veins and venules [288]. Transmembrane occludin links via ZO-1 to the actin cytoskeleton thereby contributing to tight junction assembly and regulation [230]. The high level of colocalisation between occludin and ZO-1 observed in this study indicates that their known direct association [289] also exists in human lungs. Both, the illustration of the occludin-ZO-1 complex as well as the three-dimensional reconstruction of VE-cadherin and occludin expression (Supplementary video 2) suggest that these cell junction proteins comprise a critical basic structural element of the complex alveolar architecture within the human alveolus.

The analyzed junction proteins formed mostly characteristic continuous junctional bands between adjacent cells. In contrast to that, a punctate distribution was found for claudin-2. The reports about claudin-2 expression in the lung are controversial. Claudin-2 is expressed in lung-derived cell lines and mouse lungs [290, 291], whereas some studies stated the absence of claudin-2 in the alveolar compartment of normal human lung tissue [282, 283]. In this study the positive staining for claudin-2 in the alveolar epithelium and vascular endothelium was found to be of weak extent. Although it was found 
at intercellular junctions, claudin-2 colocalized neither with the epithelial cell marker pan-cytokeratin (data not shown) nor with endothelial specific VEcadherin. Therefore, additional methods are needed to precisely define claudin-2 expression in the alveolus, e.g. by using superresolution structured illumination microscopy. Claudin-2 is deemed as an integral component of a tight junction pore pathway, permitting the transport of cations and small solutes [292]. However, evidence is provided that claudin-2 contributes to the regulation of epithelial sodium flux in the gut [293] and the kidney [209], but its role in lung homeostasis is still unknown. Claudin-3, -4 and -18 are exclusively found at the interface of type II alveolar epithelial cells to adjacent cells which is consistent with previous studies delineating junctional expression differences in healthy lung and lung diseases [282, 283]. Futhermore, a study investigating the protective effect of keratinocyte growth factor (KGF) on alveolar epithelial barrier found that primary rat alveolar epithelial cells express claudin-3, -4 and -18 and that enhanced alveolar barrier function does not require a change in claudin expression [294]. Claudin-5 connects endothelial cells lining out the interior surface of capillaries and blood vessels, but it is not expressed in alveolar epithelium. It is classically thought to be an integral component of the vessel sealing cell junctions [295] including the lung [296] but its epithelial expression has also been observed in tumor cells [274].

\subsection{Alteration of cell junction proteins in pneumococci- infected human lung tissue}

Cell junctions function especially as barrier for pathogens and other exogenous components preventing their invasion into interstitial tissues and are therefore crucial for lung defense. A plethora of clinical studies has shown that pathogenesis of ARDS and sepsis include the influx of protein-rich fluid into the air spaces as a consequence of increased permeability of the pulmonary barrier leading to fatal lung edema formation [40, 297-299]. Experimental studies in animals and cultured cells strengthened the hypothesis that junctional disruption of the lung barrier significantly contributes to a 


\section{Discussion}

deleterious outcome [44-46]. So far, direct data addressing the effects on cell junction expression upon pneumococcal infection are missing [300].

In S. pneumoniae infected human lung tissue loss of characteristic alveolar structure and significant reduction of protein levels of VE-cadherin, occludin, ZO-1 as well as claudin-5 were noted. In vitro studies and animal models have shown that disruption of VE-cadherin at endothelial cell junctions leads to a reduced endothelial barrier integrity and an increase of vascular permeability allowing the migration of inflammatory cells [301-304]. A recent study with human patient samples demonstrated a statistically significant reduction in VE-cadherin expression in ARDS-altered lungs compared to control tissue [305]. Notably, targeting claudin-5 dysregulation in HIV-induced interstitial pneumonitis and lung vascular injury by peroxisome proliferator-activated receptor-y ligands suggested claudin-5 as an important marker for endothelial and microvascular barrier integrity [306]. VE-cadherin and claudin-5 represent major components of endothelial barriers and are of primary importance for the stability of endothelial junctions. The reduced presence of VE-cadherin and claudin-5 in pneumococci-infected human lungs in conjugation with a diminished transcellular electrical resistance in primary endothelial cells, as shown in this study, may be considered as a major pathophysiological mechanism of increased vascular permeability in lung diseases such as pneumonia and their frequent complications sepsis, septic shock and ARDS.

Since ZO-1 directly interacts with occludin, it can be speculated that the pneumococci-induced alteration of either of them leads to a dissociation of the occludin-ZO-1 complex and their subsequent detachment from the actin cytoskeleton. So far, a dissociation of the occludin-ZO-1 complex has been shown only in vitro. It was reported that oxidative stress-induced tyrosine phosphorylation of the occludin-ZO-1 complex results in cellular redistribution of the occludin-ZO-1 complex [307, 308]. Considered as a clinical risk factor for the development of ALI and ARDS, chronic alcohol ingestion leads to a decreased expression of occludin and ZO-1 in alveolar epithelial cells [309, 310]. Changes to tight junction protein expression in both epithelial and endothelial 
cells result in a compromised ability to form completely functional tight junctions and thus impair the alveolar barrier.

Tight junction proteins claudin-3, -4 and -18 , which are exclusively expressed at the interface of type II alveolar epithelial cells, as well as claudin-2 remained unchanged at 8 and 24 hours post infection. Since other time points have not been analyzed, it can be speculated whether the expression of these cell junction proteins might also be affected e.g. 48 hours post infection. In usual interstitial pneumonia and sarcoidosis expression levels of claudin-1, -2, -3, -4, -5, -7 in metaplastic alveolar epithelium were strongly elevated compared to healthy lungs [282]. Immunhistochemical analyses of junction proteins in pulmonary fibrosis and normal human lungs revealed increased accumulation of claudin proteins, predominantly claudin- 1 and -3 , in the regenerative alveolar epithelium of pulmonary fibrosis lungs [283]. In the same study, enhanced mRNA levels of $\mathrm{N}$-cadherin, B-catenin and E-cadherin were detected in diseased lungs compared to healthy control lungs. In accordance with its prominent junctional localization, in vitro studies support a barrier regulating role for claudin-3 [311], but lung-specific, conclusive studies are still lacking. Interestingly, although claudin-4 deficient mice displayed a normal physiological phenotype, they showed increased susceptibility to lung injury caused by hyperoxia or ventilator-induced lung injury [312]. Increased claudin-4 expression was suggested as a barrierprotective response in ALI in mice [313], and its expression levels were positively correlated with the rate of alveolar fluid clearance in a model of ex vivo perfused human lungs [314]. Claudin-18 deficient mice display alveolar barrier dysfunction and impaired alveologenesis indicating an essential role in lung physiology and development [220, 221]. Although no alterations of claudin-2, -3, -4 and -18 in infected lung tissue were observed, further studies are needed to investigate if e.g. the functionality of claudin-4 with respect to alveolar fluid clearance is impaired in infected lungs. It could also be interesting whether other pneumonia causing pathogens such as L. pneumophila or influenza virus can also cause alterations of cell junctions 


\section{Discussion}

in a hydrogen peroxide independent mechanism or whether distinct cell junctions would also remain unaffected by other pathogens.

Another interesting finding that was apparent during immunohistochemical analysis in this study is that pneumococci did not affect any of the investigated cell junctions at the terminal and respiratory bronchiolar epithelium within 24 hours of infection. Since not all analyzed samples that were infected with pneumococci contained bronchiolar epithelium, this finding remains preliminary. Similarly, the expression of claudin-2, $-3,-4$ and -5 in bronchiolar epithelium remained steady in idiopathic pulmonary fibrosis lungs [283]. The bronchiolar epithelium is a multiple stratified structure composed of a large variety of cells including ciliated, nonciliated, club cells as well as mucoussecreting cells. The strong and diverse expression of intercellular junctions in bronchiolar epithelial cells as shown in this study could be the basis for maintaining the integrity of the bronchiolar epithelium and the robustness as a solid physical barrier that may defend pneumococcal attacks more effectively than the single-layered alveolar epithelium. Interestingly, no decreased mRNA levels for the analyzed cell junctions were found in infected samples arguing against a transcriptional down-regulation. Since in this model no invading inflammatory cells are present, the data presented here indicate that pneumococci per se may cause cell junction disassembly thereby paving the way for deleterious barrier dysfunction. However, in models studying the bloodbrain barrier alterations in gene expression of cell junctions have been shown. In a model of bacterial meningitis, infection with group B Streptococcus led to decreased transcript as well as protein abundance of occludin, ZO-1 and claudin-5 in human brain microvascular endothelial cells in a Snail1dependent mechanism contributing to blood-brain barrier disruption [315]. Furthermore, in an in vivo study rats were made acutely hypertensive by aortic constriction above the renal arteries. Investigating the mRNA expression of claudin-3, -5 as well as claudin-12 demonstrated significantly diminished levels of these claudins in response to hypertension suggesting that gene transcription alteration of tight junction proteins is the main mechanism leading to blood-brain barrier breakdown [316]. 


\subsection{Hydrogen peroxide - a key factor for junctional disruption during pneumococcal infection}

S. pneumoniae possesses a wide variety of virulence factors and among those the pore forming toxin pneumolysin (PLY) and hydrogen peroxide are considered as important for the induction of severe pneumonia and lung barrier failure [84, 317].

PLY causes severe pro-inflammatory activation of lung cells and is required for the development of severe pneumonia and bacterial survival in the blood [318, 319]. Furthermore, several reports in animal and cell culture models suggest an important role of PLY for lung barrier disruption [83, 84]. In human lungs, PLY-deficient pneumococci were still able to cause loss of occludin and purified exogenous PLY alone did neither affect occludin structure nor its protein level. Although the biological activity of PLY was not tested here, both mentioned findings (no effect of PLY alone and loss of occludin upon infection with PLYdeficient pneumococci) strongly argue against a relevant role of PLY in this setting. In addition, pneumococci impair epithelial as well as endothelial barrier function as evidenced by significant decreased transcellular electrical resistances independently of PLY in vitro. Overall, these data indicate that, at least with respect to occludin, PLY seems not to be the predominant factor causing junctional disruption in the human lung.

Strikingly, hydrogen peroxide was identified as a key factor for cell junction disruption and impaired barrier function during pneumococcal infection. In vitro experiments revealed that exogenous hydrogen peroxide impairs barrier function in endothelial as well as epithelial cells and catalase prevents pneumococci-induced gap formation in endothelial cells. In ex vivo cultivated human lung tissue, pneumococci deficient for hydrogen peroxide production failed to induce the loss of junctional proteins VE-cadherin, occludin, ZO-1 as well as claudin-5 and catalase protects junctional architecture when infected with wild type pneumococci. In line with this, previous studies reported redox sensitivity of occludin [320-322] including the dissociation of occludin from ZO-1 [307]. Hydrogen peroxide has been shown to increase the phosphorylation 
of occludin serine residues mediated by activation of p38 and ERK-1/-2 signaling pathways [321, 322]. Additionally, oxidative stress induces disruption of tight junctions and a decrease in transepithelial electrical resistance resulting from tyrosine phosphorylation of occludin and ZO-1 [307, 308]. It was moreover demonstrated that tyrosine phosphorylation of occludin reduces its ability to bind ZO-1 [323]. It can be speculated if the pneumococciinduced alteration of cell junctions in this study is induced or caused by cell junction phosphorylation as well. Interestingly, a hydrogen peroxide-induced rearrangement of occludin and ZO-1 accompanied by formation of actin stress fibers has also been shown in bovine brain microvascular endothelial cells [324].

The pyruvate oxidase $(\mathrm{spxB})$ is responsible for the endogenous hydrogen peroxide production by the pneumococcus [96]. Notably, spxB-defective mutants showed reduced virulence in animal models for nasopharyngeal colonization, pneumonia and sepsis [96]. It was reported that intratracheally challenge of mice with spxB-deficient pneumococci resulted in significant reduced outgrowth in the blood and less lung damage compared to mice infected with wild type bacteria suggesting that hydrogen peroxide production by pneumococci promotes barrier dysfunction in vivo [318]. A recent study supports these findings showing that spxB-deficient pneumococci were significantly less toxic compared to wild type bacteria in vivo proposing a key role for S. pneumoniae-derived hydrogen peroxide in pneumonia pathogenesis [325]. In vitro studies, in accordance with this study, showed that disruption of junctional occludin expression due to hydrogen peroxide exposure was reversed by catalase [326]. Furthermore, superoxide dismutase 1 mutations reduced the levels of occludin, ZO-1 and claudin-5 between endothelial cells in mice [327]. Besides this oxidative stress in lungs which is directly attributable to the pneumococci [317], the massive recruitment of polymorphonuclear leukocytes in pneumococcal pneumonia and subsequent respiratory burst of these cells may further impact on junctional dysfunction in vivo [328].

The data obtained in this study support these studies generally and augment the findings for ex vivo cultivated human lung explants. Although the 
mechanism leading to the alteration of cell junctions by hydrogen peroxide remains unclear, possible explanations are discussed. In general, hydrogen peroxide is a reactive oxygen species which can mediate the oxidation of amino acids in proteins. The investigated cell junctions, except for $\mathrm{ZO}-1$, are transmembrane proteins with two extracellular loops that are accessible to nucleophilic attacks. Therefore, hydrogen peroxide could oxidize redox sensitive cell junctions directly or may influence different redox sensitive signal transduction pathways that modify the expression and localization of cell junctions [329]. Subsequently, the damaged cell junction proteins may be internalized and degraded within the host cell as shown before for VE-cadherin particularly [330, 331]. This hypothesis could be tested for the human lung infection model using proteasome inhibitors in further studies. An in vitro study showed that inhibition of the proteasome with lactacystin and MG132 stabilizes junctional proteins and prevents cell-cell dissociation [332]. The endocytosis and recycling of internalized tight junctions as a result of inflammation [333, 334] seems rather be unlikely as a potential mechanism followed by junction alteration in this study. The recycling of internalized cell junctions would not lead to diminished protein levels of the respective cell junctions as shown here.

\subsection{Conclusions and further outlook}

This study highlights the complex nature of alveolar junctional organization and points out that pneumococci attack these structures by hydrogen peroxide potentially to drive invasion. Hydrogen peroxide might therefore be therapeutically targetable in pneumococcal pneumonia to prevent septic dissemination.

The airway epithelium naturally possesses an effective antioxidant defense system including gluthathione, vitamins, uric acid, B-carotene and enzymatic antioxidants such as superoxide dismutase and catalase [335]. Antioxidants counteract the deleterious consequences of reactive oxygen species such as hydrogen peroxide on cell junctions to maintain their barrier functions. The antioxidant glutathione is present in lower airway fluid and detoxificates 
reactive oxygen species such as hydrogen peroxide [336, 337]. In addition to a conventional treatment with antibiotics, an adjunctive therapy with gluthathione may reduce the pathogenesis from simple community-acquired pneumonia to severe pneumonia with a deleterious barrier malfunction. Griese et al. showed that, using a new inhalation device with high efficacy, basically glutathione treatment of the lower airways is feasible in patients [338]. Resveratrol is an antioxidant which has been shown to induce intracellular gluthathione synthesis in lung epithelial cells [339] and is able to prevent pneumococci-related oxidative stress induction in airway epithelial cells [317]. Therefore, resveratrol might be a second adjuvant treatment option for improving clinical outcomes from pneumococcal pneumonia. Both antioxidants, glutathione and resveratrol, are already commercially available and randomly used in dietary supplements.

Additionally, the feasibility of targeting certain cell junctions to improve barrier function and prevent fatal pulmonary edema has to be examined to identify additional suitable targets. Overall, this study contributes to the characterization of cell junctions in the human lung. The effects on cell junctions during $S$. pneumoniae infection will prove to be an essential pathophysiologic mechanism leading to impairment of alveolar barrier function and therefore provides an important foundation for understanding the pathogenesis of lung diseases. 


\section{REFERENCES}

1. Stanfield CL. Principles of Human Physiology. Postgrad. Med. J. Pearson Education; 1962.

2. Ochs M, Nyengaard JR, Jung A, Knudsen L, Voigt M, Wahlers T, Richter J, Gundersen HJG. The number of alveoli in the human lung. Am. J. Respir. Crit. Care Med. 2004; 169: 120-124.

3. Rhoades RA, Bell, DR. Medical Physiology: Principles for Clinical Medicine. Vasa Lippincott Williams \& Wilkins 2009.

4. Sun S, Schiller JH, Gazdar AF. Lung cancer in never smokers--a different disease. Nat. Rev. Cancer 2007; 7: 778-790.

5. Kim YS, Ho SB. Intestinal goblet cells and mucins in health and disease: Recent insights and progress. Curr. Gastroenterol. Rep. 2010; 12: 319330 .

6. BéruBé K, Prytherch Z, Job C, Hughes T. Human primary bronchial lung cell constructs: The new respiratory models. Toxicology 2010; 278: $311-318$.

7. Smith P, Heath D, Moosavi H. The Clara cell. Thorax 1974; 29: 147-163.

8. King RJ. Pulmonary surfactant. J. Appl. Physiol. 1982; 53: 1-8.

9. Griese M. Pulmonary surfactant in health and human lung diseases: state of the art. Eur. Respir. J. Off. J. Eur. Soc. Clin. Respir. Physiol. 1999; 13: 1455-1476.

10. Mason RJ. Biology of alveolar type II cells. Respirology 2006; 11: S12S15.

11. Simionescu M. Cellular components of the air-blood barrier. J. Cell. Mol. Med. 2001; 5: 320-321.

12. Althaus M, Clauss WG, Fronius M. Amiloride-sensitive sodium channels and pulmonary edema. Pulm. Med. 2011; 2011: 830320.

13. Hsia CCW, Raskin P. The diabetic lung: Relevance of alveolar microangiopathy for the use of inhaled insulin. Am. J. Med. 2005; 118: 205-211. 
14. Proctor DF, Lundqvist G. Clearance of inhaled particles from the human nose. Arch. Intern. Med. 1973; 131: 132-139.

15. Mygind N, Dahl R. Anatomy, physiology and function of the nasal cavities in health and disease. Adv. Drug Deliv. Rev. 1998; 29: 3-12.

16. Ritter L. Anatomy and physiology of the upper airways. Soins. Chir. 1981. p. 3-7.

17. Sleigh M a, Blake JR, Liron N. The propulsion of mucus by cilia. Am. Rev. Respir. Dis. 1988; 137: 726-741.

18. Knowles MR, Boucher RC. Mucus clearance as a primary innate defense mechanism for mammalian airways. J. Clin. Invest. 2002; 109: 571-577.

19. Randell SH, Boucher RC. Effective mucus clearance is essential for respiratory health. Am. J. Respir. Cell Mol. Biol. 2006; 35: 20-28.

20. Beck JM, Young VB, Huffnagle GB. The microbiome of the lung. Transl. Res. 2012; 160: 258-266.

21. Nguyen LDN, Viscogliosi E, Delhaes L. The lung mycobiome: an emerging field of the human respiratory microbiome. Front. Microbiol. 2015; 6: 89.

22. Liu. P, Dasaraju V, Liu C. Infections of the Respiratory System. Med. Microbiol. 1996.

23. Howie J. Respiratory infections. Br. J. Gen. Pract. 2009.

24. Rydén IC, Cobbs CG. Respiratory infections. Med. Times 1981.

25. Wardlaw TMP, Johansson EW, Hodge M. Pneumonia The Forgotten Killer of Children. World Health Organization 2006.

26. WHO | World Health Statistics 2014. World Health Organization 2014.

27. Welte T, Torres A, Nathwani D. Clinical and economic burden of community-acquired pneumonia among adults in Europe. Thorax 2012; 67: 71-79.

28. Ruuskanen O, Lahti E, Jennings LC, Murdoch DR. Viral pneumonia. Lancet 2011; 377: 1264-1275.

29. Skolnik NS, Menichello GM. Community-Acquired Pneumonia. Fam. Pract. News Springer Science \& Business Media 2007. 
30. Rom WN, Weiden M, Garcia R, Yie TA, Vathesatogkit P, Tse DB, McGuinness G, Roggli V, Prezant D. Acute eosinophilic pneumonia in a New York City firefighter exposed to World Trade Center dust. Am. J. Respir. Crit. Care Med. 2002; 166: 797-800.

31. Farr BM, Bartlett CL, Wadsworth J, Miller DL. Risk factors for community-acquired pneumonia diagnosed upon hospital admission. British Thoracic Society Pneumonia Study Group. Respir. Med. 2000; 94: 954-963.

32. Taniguchi T, Ko M, Seko S, Nishida O, Inoue F, Kobayashi H, Saiga T, Okamoto M, Fukuse T. Interstitial pneumonia associated with autoimmune pancreatitis. Gut 2004; 53: 770-771.

33. Longo DL, Musher DM, Thorner AR, Debakey ME. CommunityAcquired Pneumonia. N Engl J Med 2014; 17371: 1619-1628.

34. Nicod LP. Lung defences: An overview. Eur. Respir. Rev. 2005; 14: 4550 .

35. Whitsett J a, Alenghat T. IMMUNOLOGY OF THE LUNG Respiratory epithelial cells orchestrate pulmonary innate immunity. Nat. Publ. Gr. 2015; 16: 27-35.

36. Boyton RJ, Openshaw PJ. Pulmonary defences to acute respiratory infection. Br. Med. Bull. 2002; 61: 1-12.

37. Matthay MA, Ware LB, Zimmerman GA. The acute respiratory distress syndrome. J. Clin. Invest. 2012; 122: 2731-2740.

38. Matthay $\mathrm{M}$ a, Zemans RL. The acute respiratory distress syndrome: pathogenesis and treatment. Annu. Rev. Pathol. 2011; 6: 147-163.

39. Braune S, Kluge S. Akutes Lungenversagen - ein Update. DMW - Dtsch. Medizinische Wochenschrift 2013; 138: 1019-1022.

40. Berkowitz DM, Danai P a, Eaton S, Moss M, Martin GS. Accurate characterization of extravascular lung water in acute respiratory distress syndrome. Crit. Care Med. 2008; 36: 1803-1809.

41. Pesakhov S, Benisty R, Sikron N, Cohen Z, Gomelsky P, KhozinGoldberg I, Dagan R, Porat N. Effect of hydrogen peroxide production and the Fenton reaction on membrane composition of Streptococcus pneumoniae. Biochim. Biophys. Acta 2007; 1768: 590-597.

42. Goldenberg NM, Steinberg BE, Slutsky AS, Lee WL. Broken barriers: a new take on sepsis pathogenesis. Sci. Transl. Med. 2011; 3: 88ps25. 
43. Ware LB, Matthay MA. The acute respiratory distress syndrome. $N$. Engl. J. Med. 2000; 342: 1334-1349.

44. Lucas R, Verin AD, Black SM, Catravas JD. Regulators of endothelial and epithelial barrier integrity and function in acute lung injury. Biochem. Pharmacol. 2009; 77: 1763-1772.

45. Herold S, Gabrielli NM, Vadász I. Novel concepts of acute lung injury and alveolar-capillary barrier dysfunction. Am J Physiol Lung Cell Mol Physiol 2013; 305: L665-L681.

46. Müller-Redetzky HC, Will D, Hellwig K, Kummer W, Tschernig T, Pfeil U, Paddenberg R, Menger MD, Kershaw O, Gruber AD, Weissmann N, Hippenstiel S, Suttorp N, Witzenrath M. Mechanical ventilation drives pneumococcal pneumonia into lung injury and sepsis in mice: protection by adrenomedullin. Crit. Care 2014; 18: R73.

47. Kohlhammer Y, Raspe H, Marre R, Suttorp N, Welte T, Schäfer T. Antibiotic treatment of community acquired pneumonia varies widely across Germany. J. Infect. 2007; 54: 446-453.

48. Niederman MS, Mandell LA, Anzueto A, Bass JB, Broughton WA, Campbell GD, Dean N, File T, Fine MJ, Gross PA, Martinez F, Marrie TJ, Plouffe JF, Ramirez J, Sarosi GA, Torres A, Wilson R, Yu VL. Guidelines for the management of adults with community-acquired pneumonia diagnosis, assessment of severity, antimicrobial therapy, and prevention. Am. J. Respir. Crit. Care Med. 2001; 163: 1730-1754.

49. Heffelfinger JD, Dowell SF, Jorgensen JH, Klugman KP, Mabry LR, Musher DM, Plouffe JF, Rakowsky A, Schuchat A, Whitney CG. Management of community-acquired pneumonia in the era of pneumococcal resistance: a report from the Drug-Resistant Streptococcus pneumoniae Therapeutic Working Group. Arch. Intern. Med. 2000; 160: 1399-1408.

50. Van der Poll T, Opal SM. Pathogenesis, treatment, and prevention of pneumococcal pneumonia. Lancet 2009; 374: 1543-1556.

51. Bogaert D, De Groot R, Hermans PWM. Streptococcus pneumoniae colonisation: The key to pneumococcal disease. Lancet Infect. Dis. 2004; 4: 144-154.

52. Jauneikaite E, Tocheva AS, Jefferies JMC, Gladstone RA, Faust SN, Christodoulides M, Hibberd ML, Clarke SC. Current methods for capsular typing of Streptococcus pneumoniae. J. Microbiol. Methods 2015; 113: 41-49. 
53. Weinberger DM, Trzcinski K, Lu YJ, Bogaert D, Brandes A, Galagan J, Anderson PW, Malley R, Lipsitch M. Pneumococcal capsular polysaccharide structure predicts serotype prevalence. PLoS Pathog. 2009; 5: e1000476.

54. Kadioglu A, Weiser JN, Paton JC, Andrew PW. The role of Streptococcus pneumoniae virulence factors in host respiratory colonization and disease. Nat. Rev. Microbiol. 2008; 6: 288-301.

55. Caya CA, Boikos C, Desai S, Quach C. Dosing regimen of the 23-valent pneumococcal vaccination: A systematic review. Vaccine 2015; 33: 13021312 .

56. Fletcher M a, Balmer P, Bonnet E, Dartois N. PCVs in individuals at increased risk of pneumococcal disease: a literature review. Expert Rev. Vaccines 2015; 14: 975-1030.

57. Neuhauser H. Epidemiologisches Bulletin. Robert Koch Inst. 2013; 105114.

58. Pletz MW, Maus U, Krug N, Welte T, Lode H. Pneumococcal vaccines: mechanism of action, impact on epidemiology and adaption of the species. Int. J. Antimicrob. Agents 2008; 32: 199-206.

59. Direct and indirect effects of routine vaccination of children with 7valent pneumococcal conjugate vaccine on incidence of invasive pneumococcal disease--United States, 1998-2003. MMWR. Morb. Mortal. Wkly. Rep. 2005; 54: 893-897.

60. Whitney CG, Farley MM, Hadler J, Harrison LH, Bennett NM, Lynfield R, Reingold A, Cieslak PR, Pilishvili T, Jackson D, Facklam RR, Jorgensen JH, Schuchat A. Decline in invasive pneumococcal disease after the introduction of protein-polysaccharide conjugate vaccine. $N$. Engl. J. Med. 2003; 348: 1737-1746.

61. Pilishvili T, Lexau C, Farley MM, Hadler J, Harrison LH, Bennett NM, Reingold A, Thomas A, Schaffner W, Craig AS, Smith PJ, Beall BW, Whitney CG, Moore MR. Sustained reductions in invasive pneumococcal disease in the era of conjugate vaccine. J. Infect. Dis. 2010; 201: 32-41.

62. Bogaert D, Hermans PWM, Adrian P V., Rümke HC, De Groot R. Pneumococcal vaccines: An update on current strategies. Vaccine 2004; 22: $2209-2220$.

63. Briles DE, Hollingshead SK, Nabors GS, Paton JC, Brooks-Walter A. The potential for using protein vaccines to protect against otitis media caused by Streptococcus pneumoniae. Vaccine 2000; 19 Suppl 1: S87S95. 
64. Nabors GS, Braun PA, Herrmann DJ, Heise ML, Pyle DJ, Gravenstein S, Schilling M, Ferguson LM, Hollingshead SK, Briles DE, Becker RS. Immunization of healthy adults with a single recombinant pneumococcal surface protein A (PspA) variant stimulates broadly cross-reactive antibodies to heterologous PspA molecules. Vaccine 2000; 18: 17431754.

65. Seo J-Y, Seong SY, Ahn B-Y, Kwon IC, Chung H, Jeong SY. Crossprotective immunity of mice induced by oral immunization with pneumococcal surface adhesin a encapsulated in microspheres. Infect. Immun. 2002; 70: 1143-1149.

66. DeVelasco AE, Verheul AF, Verhoef J, Snippe H. Streptococcus pneumoniae: virulence factors, pathogenesis, and vaccines. Microbiol. Rev. 1995; 59: 591-603.

67. Sorensen UBS, Henrichsen J, Chen HC, Szu SC. Covalent linkage between the capsular polysaccharide and the cell wall peptidoglycan of streptococcus pneumoniae revealed by immunochemical methods. Microb. Pathog. 1990; 8: 325-334.

68. Brown J. Streptococcus Pneumoniae: Molecular Mechanisms of HostPathogen Interactions. Academic Press Inc. 2015.

69. Watson DA., Musher DM. Interruption of capsule production in Streptococcus pneumoniae serotype 3 by insertion of transposon Tn916. Infect. Immun. 1990; 58: 3135-3138.

70. Nelson AL, Roche AM, Gould JM, Chim K, Ratner AJ, Weiser JN. Capsule enhances pneumococcal colonization by limiting mucusmediated clearance. Infect. Immun. 2007; 75: 83-90.

71. Hyams C, Camberlein E, Cohen JM, Bax K, Brown JS. The Streptococcus pneumoniae capsule inhibits complement activity and neutrophil phagocytosis by multiple mechanisms. Infect. Immun. 2010; 78: 704-715.

72. Abeyta M, Hardy GG, Yother J. Genetic alteration of capsule type but not PspA type affects accessibility of surface-bound complement and surface antigens of Streptococcus pneumoniae. Infect. Immun. 2003; 71: $218-225$.

73. Mitchell A. M, Mitchell TJ. Streptococcus pneumoniae: Virulence factors and variation. Clin. Microbiol. Infect. 2010; 16: 411-418.

74. Guiral S, Mitchell TJ, Martin B, Claverys J-P. Competence-programmed predation of noncompetent cells in the human pathogen Streptococcus 
pneumoniae: genetic requirements. Proc. Natl. Acad. Sci. U. S. A. 2005; 102: 8710-8715.

75. Balachandran P, Hollingshead SK, Paton JC, Briles DE. The autolytic enzyme lytA of Streptococcus pneumoniae is not responsible for releasing pneumolysin. J. Bacteriol. 2001; 183: 3108-3116.

76. Price KE, Camilli A. Pneumolysin localizes to the cell wall of Streptococcus pneumoniae. J. Bacteriol. 2009; 191: 2163-2168.

77. Tilley SJ, Orlova E V, Gilbert RJC, Andrew PW, Saibil HR. Structural basis of pore formation by the bacterial toxin pneumolysin. Cell 2005; 121: $247-256$.

78. Mitchell TJ, Dalziel CE. The biology of pneumolysin. Subcell. Biochem. 2014; 80: 145-160.

79. Jefferies JMC, Johnston CHG, Kirkham L-AS, Cowan GJM, Ross KS, Smith A, Clarke SC, Brueggemann AB, George RC, Pichon B, Pluschke G, Pfluger V, Mitchell TJ. Presence of nonhemolytic pneumolysin in serotypes of Streptococcus pneumoniae associated with disease outbreaks. J. Infect. Dis. 2007; 196: 936-944.

80. Kirkham LAS, Jefferies JMC, Kerr AR, Jing Y, Clarke SC, Smith A, Mitchell TJ. Identification of invasive serotype 1 pneumococcal isolates that express nonhemolytic pneumolysin. J. Clin. Microbiol. 2006; 44: $151-159$.

81. Lock R a, Zhang QY, Berry a M, Paton JC. Sequence variation in the Streptococcus pneumoniae pneumolysin gene affecting haemolytic activity and electrophoretic mobility of the toxin. Microb. Pathog. 1996; 21: 71-83.

82. Rubins JB, Duane PG, Charboneau D, Janoff EN. Toxicity of pneumolysin to pulmonary endothelial cells in vitro. Infect. Immun. 1992; 60: 1740-1746.

83. Rubins JB, Duane PG, Clawson D, Charboneau D, Young J, Niewoehner DE. Toxicity of pneumolysin to pulmonary alveolar epithelial cells. Infect. Immun. 1993; 61: 1352-1358.

84. Witzenrath M, Gutbier B, Hocke AC, Schmeck B, Hippenstiel S, Berger K, Mitchell TJ, de los Toyos JR, Rosseau S, Suttorp N, Schütte H. Role of pneumolysin for the development of acute lung injury in pneumococcal pneumonia. Crit. Care Med. 2006; 34: 1947-1954.

85. Rubins JB, Charboneau D, Fasching C, Berry AM, Paton JC, Alexander JE, Andrew PW, Mitchell TJ, Janoff EN. Distinct roles for pneumolysin's 
cytotoxic and complement activities in the pathogenesis of pneumococcal pneumonia. Am. J. Respir. Crit. Care Med. 1996; 153: 1339-1346.

86. Rayner CFJ, Jackson AD, Rutman A, Dewar A, Mitchell TJ, Andrew PW, Cole PJ, Wilson R. Interaction of pneumolysin-sufficient and -deficient isogenic variants of Streptococcus pneumoniae with human respiratory mucosa. Infect. Immun. 1995; 63: 442-447.

87. Steinfort C, Wilson R, Mitchell T, Feldman C, Rutman A, Todd H, Sykes D, Walker J, Saunders K, Andrew PW, Boulnois GJ, Cole PJ. Effect of Streptococcus pneumoniae on human respiratory epithelium in vitro. Infect. Immun. 1989; 57: 2006-2013.

88. Rubins JB, Charboneau D, Paton JC, Mitchell TJ, Andrew PW, Janoff EN. Dual function of pneumolysin in the early pathogenesis of murine pneumococcal pneumonia. J. Clin. Invest. 1995; 95: 142-150.

89. Boulnois GJ, Paton JC, Mitchell TJ, Andrew PW. Structure and function of pneumolysin, the multifunctional, thio-activated toxin of Streptococcus pneumoniae. Mol. Microbiol. 1991; 5: 2611-2616.

90. Mitchell TJ, Andrew PW, Saunders FK, Smith a N, Boulnois GJ. Complement activation and antibody binding by pneumolysin via a region of the toxin homologous to a human acute-phase protein. Mol. Microbiol. 1991; 5: 1883-1888.

91. Houldsworth S, Andrew PW, Mitchell TJ. Pneumolysin stimulates production of tumor necrosis factor alpha and interleukin-1 beta by human mononuclear phagocytes. Infect. Immun. 1994; 62: 1501-1503.

92. Paton JC, Ferrante A. Inhibition of human polymorphonuclear leukocyte respiratory burst, bactericidal activity, and migration by pneumolysin. Infect. Immun. 1983; 41: 1212-1216.

93. Moreland JG, Bailey G. Neutrophil transendothelial migration in vitro to Streptococcus pneumoniae is pneumolysin dependent. Am. J. Physiol. Lung Cell. Mol. Physiol. 2006; 290: L833-L840.

94. Malley R, Henneke P, Morse SC, Cieslewicz MJ, Lipsitch M, Thompson CM, Kurt-Jones E, Paton JC, Wessels MR, Golenbock DT. Recognition of pneumolysin by Toll-like receptor 4 confers resistance to pneumococcal infection. Proc. Natl. Acad. Sci. U. S. A. 2003; 100: 19661971.

95. McNeela EA., Burke Á, Neill DR, Baxter C, Fernandes VE, Ferreira D, Smeaton S, El-Rachkidy R, McLoughlin RM, Mori A, Moran B, Fitzgerald KA, Tschopp J, Pétrilli V, Andrew PW, Kadioglu A, Lavelle EC. Pneumolysin activates the NLRP3 inflammasome and promotes 
proinflammatory cytokines independently of TLR4. PLoS Pathog. 2010; 6: e1001191.

96. Spellerberg B, Cundell DR, Sandros J, Pearce BJ, Idanpaan-Heikkila I, Rosenow C, Masure HR. Pyruvate oxidase, as a determinant of virulence in Streptococcus pneumoniae. Mol. Microbiol. 1996; 19: 803-813.

97. Pericone CD, Park S, Imlay JA, Weiser JN. Factors Contributing to Hydrogen Peroxide Resistance in Streptococcus pneumoniae Include Pyruvate Oxidase (SpxB) and Avoidance of the Toxic Effects of the Fenton Reaction. J. Bacteriol. 2003; 185: 6815-6825.

98. Chandra J, Samali A, Orrenius S. Triggering and modulation of apoptosis by oxidative stress. Free Radic. Biol. Med. 2000; 29: 323-333.

99. Cochrane CG. Cellular injury by oxidants. Am. J. Med. 1991; 91: 23S 30 S.

100. Spencer JP, Jenner A, Aruoma OI, Cross CE, Wu R, Halliwell B. Oxidative DNA damage in human respiratory tract epithelial cells. Time course in relation to DNA strand breakage. Biochem. Biophys. Res. Commun. 1996; 224: 17-22.

101. Duane PG, Rubins JB, Weisel HR, Janoff EN. Identification of hydrogen peroxide as a Streptococcus pneumoniae toxin for rat alveolar epithelial cells. Infect. Immun. 1993; 61: 4392-4397.

102. Braun JS, Sublett JE, Freyer D, Mitchell TJ, Cleveland JL, Tuomanen EI, Weber JR. Pneumococcal pneumolysin and H 2 O 2 mediate brain cell apoptosis during meningitis. J. Clin. Invest. 2002; 109: 19-27.

103. Okahashi N, Nakata M, Sumitomo T, Terao Y, Kawabata S. Hydrogen Peroxide Produced by Oral Streptococci Induces Macrophage Cell Death. PLoS One 2013; 8: e62563.

104. Hirst RA., Sikand KS, Rutman A, Mitchell TJ, Andrew PW, O\&apos;Callaghan C. Relative roles of pneumolysin and hydrogen peroxide from Streptococcus pneumoniae in inhibition of ependymal ciliary beat frequency. Infect. Immun. 2000; 68: 1557-1562.

105. Kobayashi K, Salathé M, Pratt MM, Cartagena NJ, Soloni F, Seybold Z V., Wanner A. Mechanism of hydrogen peroxide-induced inhibition of sheep airway cilia. Am. J. Respir. Cell Mol. Biol. 1992; 6: 667-673.

106. Feldman C, Anderson R, Cockeran R, Mitchell T, Cole P, Wilson R. The effects of pneumolysin and hydrogen peroxide, alone and in combination, on human ciliated epithelium in vitro. Respir. Med. 2002; 96: 580-585. 
107. Pericone CD, Overweg K, Hermans PW, Weiser JN. Inhibitory and bactericidal effects of hydrogen peroxide production by Streptococcus pneumoniae on other inhabitants of the upper respiratory tract. Infect. Immun. 2000; 68: 3990-3997.

108. Jedrzejas MJ. Pneumococcal virulence factors: structure and function. Microbiol. Mol. Biol. Rev. 2001; 65: 187-207.

109. Anderson JM, Van Itallie CM. Physiology and function of the tight junction. Cold Spring Harb. Perspect. Biol. 2009; 1: a002584.

110. Tsukita S, Furuse M. Overcoming barriers in the study of tight junction functions: From occludin to claudin. Genes to Cells 1998; 3: 569-573.

111. Cavey M, Lecuit T. Molecular bases of cell-cell junctions stability and dynamics. Cold Spring Harb. Perspect. Biol. 2009; 1: a002998.

112. Meng W, Takeichi M. Adherens junction: molecular architecture and regulation. Cold Spring Harb. Perspect. Biol. 2009; 1: a002899.

113. Goodenough DA., Paul DL. Gap junctions. Cold Spring Harb. Perspect. Biol. 2009; 1: a002576.

114. Ohno S. Intercellular junctions and cellular polarity: The PAR-aPKC complex, a conserved core cassette playing fundamental roles in cell polarity. Curr. Opin. Cell Biol. 2001; 13: 641-648.

115. González-Mariscal L, Tapia R, Chamorro D. Crosstalk of tight junction components with signaling pathways. Biochim. Biophys. Acta Biomembr. 2008; 1778: 729-756.

116. Citi S, Spadaro D, Schneider Y, Stutz J, Pulimeno P. Regulation of small GTPases at epithelial cell-cell junctions. Mol. Membr. Biol. 2011; 28: 427-444.

117. Niessen CM, Gottardi CJ. Molecular components of the adherens junction. Biochim. Biophys. Acta 2008; 1778: 562-571.

118. Gamble JR, Drew J, Trezise L, Underwood A, Parsons M, Kasminkas L, Rudge J, Yancopoulos G, Vadas MA. Cell Junctions. Circ. Res. 2000. p. 603-607.

119. Bazzoni G, Dejana E. Endothelial cell-to-cell junctions: molecular organization and role in vascular homeostasis. Physiol. Rev. 2004; 84: 869-901.

120. Tsukita S, Furuse M, Itoh M. Multifunctional strands in tight junctions. Nat. Rev. Mol. Cell Biol. 2001; 2: 285-293. 
121. Kumar NM, Gilula NB. The gap junction communication channel. Cell 1996; 84: 381-388.

122. Perkins G, Goodenough D, Sosinsky G. Three-dimensional structure of the gap junction connexon. Biophys. J. 1997; 72: 533-544.

123. Meşe G, Richard G, White TW. Gap junctions: basic structure and function. J. Invest. Dermatol. 2007; 127: 2516-2524.

124. Hussain MU. Connexins: The Gap Junction Proteins. Springer; 2014.

125. Hoh JH, Sosinsky GE, Revel JP, Hansma PK. Structure of the extracellular surface of the gap junction by atomic force microscopy. Biophys. J. 1993; 65: 149-163.

126. Goodenough DA. Bulk isolation of mouse hepatocyte gap junctions. Characterization of the principal protein, connexin. J. Cell Biol. 1974; 61: 557-563.

127. Beblo DA, Veenstra RD. Monovalent cation permeation through the connexin40 gap junction channel. $\mathrm{Cs}, \mathrm{Rb}, \mathrm{K}, \mathrm{Na}, \mathrm{Li}$, TEA, TMA, TBA, and effects of anions $\mathrm{Br}, \mathrm{Cl}, \mathrm{F}$, acetate, aspartate, glutamate, and NO3. J. Gen. Physiol. 1997; 109: 509-522.

128. Kanaporis G, Mese G, Valiuniene L, White TW, Brink PR, Valiunas V. Gap junction channels exhibit connexin-specific permeability to cyclic nucleotides. J. Gen. Physiol. 2008; 131: 293-305.

129. Bedner P, Niessen H, Odermatt B, Kretz M, Willecke K, Harz H. Selective permeability of different connexin channels to the second messenger cyclic AMP. J. Biol. Chem. 2006; 281: 6673-6681.

130. Valiunas V, Polosina YY, Miller H, Potapova IA, Valiuniene L, Doronin S, Mathias RT, Robinson RB, Rosen MR, Cohen IS, Brink PR. Connexinspecific cell-to-cell transfer of short interfering RNA by gap junctions. $J$. Physiol. 2005; 568: 459-468.

131. Franke WW. Discovering the molecular components of intercellular junctions--a historical view. Cold Spring Harb. Perspect. Biol. 2009; 1: a003061.

132. Cras P. Glial neurobiology. Spinal Cord 2008.

133. Kardami E, Doble BW. Cardiomyocyte gap junctions: A target of growthpromoting signaling. Trends Cardiovasc. Med. 1998; 8: 180-187.

134. Rohr S. Role of gap junctions in the propagation of the cardiac action potential. Cardiovasc. Res. 2004; 62: 309-322. 
135. Johnson JL, Najor NA., Green KJ. Desmosomes: Regulators of Cellular Signaling and Adhesion in Epidermal Health and Disease. Cold Spring Harb. Perspect. Med. 2014; 4: a015297-a015297.

136. Kurzen H, Münzing I, Hartschuh W. Expression of desmosomal proteins in squamous cell carcinomas of the skin. J. Cutan. Pathol. 2003; 30: 621630.

137. Garrod D, Chidgey M. Desmosome structure, composition and function. Biochim. Biophys. Acta 2008; 1778: 572-587.

138. Broussard JA, Getsios S, Green KJ. Desmosome regulation and signaling in disease. Cell Tissue Res. 2015.

139. Delmar M, McKenna WJ. The cardiac desmosome and arrhythmogenic cardiomyopathies: From gene to disease. Circ. Res. 2010; 107: 700-714.

140. Holthöfer B, Windoffer R, Troyanovsky S, Leube RE. Structure and Function of Desmosomes. Int. Rev. Cytol. 2007; 264: 65-163.

141. Delva E, Tucker DK, Kowalczyk AP. The desmosome. Cold Spring Harb. Perspect. Biol. 2009; 1: a002543.

142. Kowalczyk AP, Bornslaeger EA., Borgwardt JE, Palka HL, Dhaliwal AS, Corcoran CM, Denning MF, Green KJ. The amino-terminal domain of desmoplakin binds to plakoglobin and clusters desmosomal cadherinplakoglobin complexes. J. Cell Biol. 1997; 139: 773-784.

143. Yonemura S, Itoh M, Nagafuchi A, Tsukita S. Cell-to-cell adherens junction formation and actin filament organization: similarities and differences between non-polarized fibroblasts and polarized epithelial cells. J. Cell Sci. 1995; 108 ( Pt 1: 127-142.

144. Uchida N, Honjo Y, Johnson KR, Wheelock MJ, Takeichi M. The catenin/cadherin adhesion system is localized in synaptic junctions bordering transmitter release zones. J. Cell Biol. 1996; 135: 767-779.

145. Hartsock A, Nelson WJ. Adherens and tight junctions: Structure, function and connections to the actin cytoskeleton. Biochim. Biophys. Acta - Biomembr. 2008; 1778: 660-669.

146. Geiger B, Tokuyasu KT, Dutton AH, Singer SJ. Vinculin, an intracellular protein localized at specialized sites where microfilament bundles terminate at cell membranes. Proc. Natl. Acad. Sci. U. S. A. 1980; 77: 4127-4131.

147. Kobielak A, Fuchs E. Alpha-catenin: at the junction of intercellular adhesion and actin dynamics. Nat. Rev. Mol. Cell Biol. 2004; 5: 614-625. 
148. Yonemura S, Wada Y, Watanabe T, Nagafuchi A, Shibata M. alphaCatenin as a tension transducer that induces adherens junction development. Nat. Cell Biol. 2010; 12: 533-542.

149. Abe K, Takeichi M. EPLIN mediates linkage of the cadherin catenin complex to F-actin and stabilizes the circumferential actin belt. Proc. Natl. Acad. Sci. U. S. A. 2008; 105: 13-19.

150. Taguchi K, Ishiuchi T, Takeichi M. Mechanosensitive EPLIN-dependent remodeling of adherens junctions regulates epithelial reshaping. J. Cell Biol. 2011; 194: 643-656.

151. Chervin-Pétinot A, Courçon M, Almagro S, Nicolas A, Grichine A, Grunwald D, Prandini MH, Huber P, Gulino-Debrac D. Epithelial Protein Lost In Neoplasm (EPLIN) interacts with a-catenin and actin filaments in endothelial cells and stabilizes vascular capillary network in vitro. J. Biol. Chem. 2012; 287: 7556-7572.

152. Dejana E, Orsenigo F, Lampugnani MG. The role of adherens junctions and VE-cadherin in the control of vascular permeability. J. Cell Sci. 2008; 121: 2115-2122.

153. Bravi L, Dejana E, Lampugnani MG. VE-cadherin at a glance. Cell Tissue Res. 2014; 355: 515-522.

154. Dejana E, Orsenigo F. Endothelial adherens junctions at a glance. J. Cell Sci. 2013; 126: 2545-2549.

155. Harris ES, Nelson WJ. VE-cadherin: At the front, center, and sides of endothelial cell organization and function. Curr. Opin. Cell Biol. 2010; 22: $651-658$.

156. Corada M, Liao F, Lindgren M, Lampugnani MG, Breviario F, Frank R, Muller WA., Hicklin DJ, Bohlen P, Dejana E. Monoclonal antibodies directed to different regions of vascular endothelial cadherin extracellular domain affect adhesion and clustering of the protein and modulate endothelial permeability. Blood 2001; 97: 1679-1684.

157. Corada M, Mariotti M, Thurston G, Smith K, Kunkel R, Brockhaus M, Lampugnani MG, Martin-Padura I, Stoppacciaro a, Ruco L, McDonald DM, Ward P a, Dejana E. Vascular endothelial-cadherin is an important determinant of microvascular integrity in vivo. Proc. Natl. Acad. Sci. U. S. A. 1999; 96: 9815-9820.

158. Mishra R, Singh S. HIV-1 Tat C phosphorylates VE-cadherin complex and increases human brain microvascular endothelial cell permeability. BMC Neurosci. 2014; 15: 80. 
159. Mishra R, Singh SK. HIV-1 Tat C modulates expression of miRNA-101 to suppress VE-cadherin in human brain microvascular endothelial cells. J. Neurosci. 2013; 33: 5992-6000.

160. Carmeliet P, Lampugnani MG, Moons L, Breviario F, Compernolle V, Bono F, Balconi G, Spagnuolo R, Oosthuyse B, Dewerchin M, Zanetti A, Angellilo A, Mattot V, Nuyens D, Lutgens E, Clotman F, De Ruiter MC, Groot AG De, Poelmann R, Lupu F, Herbert JM, Collen D, Dejana E. Targeted deficiency or cytosolic truncation of the VE-cadherin gene in mice impairs VEGF-mediated endothelial survival and angiogenesis. Cell 1999; 98: 147-157.

161. Carmeliet P, Collen D. Molecular basis of angiogenesis. Role of VEGF and VE-cadherin. Ann. N. Y. Acad. Sci. 2000; 902: 249-264.

162. Crosby C V., Fleming PA., Argraves WS, Corada M, Zanetta L, Dejana E, Drake CJ. VE-cadherin is not required for the formation of nascent blood vessels but acts to prevent their disassembly. Blood 2005; 105 : 2771-2776.

163. Vestweber D. VE-cadherin: The major endothelial adhesion molecule controlling cellular junctions and blood vessel formation. Arterioscler. Thromb. Vasc. Biol. 2008; 28: 223-232.

164. Wallez Y, Vilgrain I, Huber P. Angiogenesis: The VE-cadherin switch. Trends Cardiovasc. Med. 2006; 16: 55-59.

165. Bentley K, Franco CA, Philippides A, Blanco R, Dierkes M, Gebala V, Stanchi F, Jones M, Aspalter IM, Cagna G, Weström S, Claesson-Welsh L, Vestweber D, Gerhardt H. The role of differential VE-cadherin dynamics in cell rearrangement during angiogenesis. Nat. Cell Biol. 2014; 16: 309-321.

166. Caveda L, Martìn-Padura I, Navarro P, Breviario F, Corada M, Gulino D, Lampugnani MG, Dejana E. Inhibition of cultured cell growth by vascular endothelial cadherin (cadherin-5/VE-cadherin). J. Clin. Invest. 1996; 98: 886-893.

167. Dejana E, Vestweber D. The role of VE-cadherin in vascular morphogenesis and permeability control. Prog. Mol. Biol. Transl. Sci. 2013.

168. Giannotta M, Trani M, Dejana E. VE-cadherin and endothelial adherens junctions: Active guardians of vascular integrity. Dev. Cell 2013; 26: 441-454. 
169. Lampugnani MG, Orsenigo F, Rudini N, Maddaluno L, Boulday G, Chapon F, Dejana E. CCM1 regulates vascular-lumen organization by inducing endothelial polarity. J. Cell Sci. 2010; 123: 1073-1080.

170. Hayashi M, Majumdar A, Li X, Adler J, Sun Z, Vertuani S, Hellberg C, Mellberg S, Koch S, Dimberg A, Koh GY, Dejana E, Belting H-G, Affolter M, Thurston G, Holmgren L, Vestweber D, Claesson-Welsh L. VE-PTP regulates VEGFR2 activity in stalk cells to establish endothelial cell polarity and lumen formation. Nat. Commun. 2013; 4: 1672.

171. Iden S, Rehder D, August B, Suzuki A, Wolburg-Buchholz K, Wolburg H, Ohno S, Behrens J, Vestweber D, Ebnet K. A distinct PAR complex associates physically with VE-cadherin in vertebrate endothelial cells. EMBO Rep. 2006; 7: 1239-1246.

172. Diamond JM. Twenty-first Bowditch lecture. The epithelial junction: bridge, gate, and fence. Physiologist 1977; 20: 10-18.

173. Tsukita S, Furuse M. The Structure and Function of Claudins , Cell Adhesion Molecules at Tight Junctions. Ann. New York Acad. Sci. 2000; 915: 129-135.

174. Balkovetz DF. Claudins at the gate: determinants of renal epithelial tight junction paracellular permeability. Am. J. Physiol. Renal Physiol. 2006; 290: F572-F579.

175. Gumbiner B. Structure, biochemistry, and assembly of epithelial tight junctions. Am. J. Physiol. 1987; 253: C749-C758.

176. Schneeberger EE, Lynch RD. The tight junction: a multifunctional complex. Am. J. Physiol. Cell Physiol. 2004; 286: C1213-C1228.

177. Tsukita S, Furuse M. Pores in the wall: Claudins constitute tight junction strands containing aqueous pores. J. Cell Biol. 2000; 149: 1316.

178. Gumbiner BM. Breaking through the tight junction barrier. J. Cell Biol. 1993; 123: 1631-1633.

179. Anderson JM, Van Itallie CM. Tight junctions. Curr. Biol. 2008; 18: G467-G475.

180. Matter K, Balda MS. Signalling to and from tight junctions. Nat. Rev. Mol. Cell Biol. 2003; 4: 225-236.

181. González-Mariscal L, Betanzos A, Nava P, Jaramillo BE. Tight junction proteins. Prog. Biophys. Mol. Biol. 2003; 81: 1-44. 
182. Furuse M, Hirase T, Itoh M, Nagafuchi A, Yonemura S, Tsukita S, Tsukita S. Occludin: A novel integral membrane protein localizing at tight junctions. J. Cell Biol. 1993; 123: 1777-1788.

183. Furuse M, Fujimoto K, Sato N, Hirase T, Tsukita S, Tsukita S. Overexpression of occludin, a tight junction-associated integral membrane protein, induces the formation of intracellular multilamellar bodies bearing tight junction-like structures. J. Cell Sci. 1996; 109. Pt 2: 429-435.

184. Furuse M, Sasaki H, Fujimoto K, Tsukita S. A single gene product, claudin-1 or -2 , reconstitutes tight junction strands and recruits occludin in fibroblasts. J. Cell Biol. 1998; 143: 391-401.

185. Balda MS, Whitney JA, Flores C, González S, Cereijido M, Matter K. Functional dissociation of paracellular permeability and transepithelial electrical resistance and disruption of the apical-basolateral intramembrane diffusion barrier by expression of a mutant tight junction membrane protein. J. Cell Biol. 1996; 134: 1031-1049.

186. McCarthy KM, Skare IB, Stankewich MC, Furuse M, Tsukita S, Rogers RA, Lynch RD, Schneeberger EE. Occludin is a functional component of the tight junction. J. Cell Sci. 1996; 109. Pt 9: 2287-2298.

187. Kuwabara H, Kokai Y, Kojima T, Takakuwa R, Mori M, Sawada N. Occludin regulates actin cytoskeleton in endothelial cells. Cell Struct. Funct. 2001; 26: 109-116.

188. Van Itallie CM, Fanning AS, Holmes J, Anderson JM. Occludin is required for cytokine-induced regulation of tight junction barriers. $J$. Cell Sci. 2010; 123: 2844-2852.

189. Farshori P, Kachar B. Redistribution and phosphorylation of occludin during opening and resealing of tight junctions in cultured epithelial cells. J. Membr. Biol. 1999; 170: 147-156.

190. Tsukamoto T, Nigam SK. Role of tyrosine phosphorylation in the reassembly of occludin and other tight junction proteins. Am. J. Physiol. 1999; 276: F737-F750.

191. Sakakibara A, Furuse M, Saitou M, Ando-Akatsuka Y, Tsukita S. Possible involvement of phosphorylation of occludin in tight junction formation. J. Cell Biol. 1997; 137: 1393-1401.

192. Suzuki T, Elias BC, Seth A, Shen L, Turner JR, Giorgianni F, Desiderio D, Guntaka R, Rao R. PKC eta regulates occludin phosphorylation and epithelial tight junction integrity. Proc. Natl. Acad. Sci. U. S. A. 2009; 106: 61-66. 
193. Saitou M, Fujimoto K, Doi Y, Itoh M, Fujimoto T, Furuse M, Takano H, Noda T, Tsukita S. Occludin-deficient embryonic stem cells can differentiate into polarized epithelial cells bearing tight junctions. J. Cell Biol. 1998; 141: 397-408.

194. Schulzke JD, Gitter AH, Mankertz J, Spiegel S, Seidler U, Amasheh S, Saitou M, Tsukita S, Fromm M. Epithelial transport and barrier function in occludin-deficient mice. Biochim. Biophys. Acta - Biomembr. 2005; 1669: 34-42.

195. Saitou M, Furuse M, Sasaki H, Schulzke JD, Fromm M, Takano H, Noda T, Tsukita S. Complex phenotype of mice lacking occludin, a component of tight junction strands. Mol. Biol. Cell 2000; 11: 4131-4142.

196. Ikenouchi J, Sasaki H, Tsukita S, Furuse M, Tsukita S. Loss of occludin affects tricellular localization of tricellulin. Mol. Biol. Cell 2008; 19: 4687-4693.

197. Mineta K, Yamamoto Y, Yamazaki Y, Tanaka H, Tada Y, Saito K, Tamura A, Igarashi M, Endo T, Takeuchi K, Tsukita S. Predicted expansion of the claudin multigene family. FEBS Lett. 2011; 585: 606612.

198. Markov AG, Aschenbach JR, Amasheh S. Claudin clusters as determinants of epithelial barrier function. IUBMB Life 2015.

199. Furuse M, Fujita K, Hiiragi T, Fujimoto K, Tsukita S. Claudin-1 and -2 : Novel integral membrane proteins localizing at tight junctions with no sequence similarity to occludin. J. Cell Biol. 1998; 141: 1539-1550.

200. Cording J, Berg J, Käding N, Bellmann C, Tscheik C, Westphal JK, Milatz S, Günzel D, Wolburg H, Piontek J, Huber O, Blasig IE. In tight junctions, claudins regulate the interactions between occludin, tricellulin and marvelD3, which, inversely, modulate claudin oligomerization. J. Cell Sci. 2013; 126: 554-564.

201. Krause G, Winkler L, Mueller SL, Haseloff RF, Piontek J, Blasig IE. Structure and function of claudins. Biochim. Biophys. Acta - Biomembr. 2008; 1778: 631-645.

202. Van Itallie CM, Anderson JM. Claudins and epithelial paracellular transport. Annu. Rev. Physiol. 2006; 68: 403-429.

203. Cooper I, Cohen-Kashi-Malina K, Teichberg VI. Claudin-5 expression in in vitro models of the blood-brain barrier. Methods Mol. Biol. 2011; 762: 347-354. 
204. Nitta T, Hata M, Gotoh S, Seo Y, Sasaki H, Hashimoto N, Furuse M, Tsukita S. Size-selective loosening of the blood-brain barrier in claudin5-deficient mice. J. Cell Biol. 2003; 161: 653-660.

205. Schlingmann B, Molina SA, Koval M. Claudins: Gatekeepers of lung epithelial function. Semin. Cell Dev. Biol. 2015; .

206. Soini Y. Claudins in lung diseases. Respir. Res. 2011; 12: 70.

207. Furuse M, Hata M, Furuse K, Yoshida Y, Haratake A, Sugitani Y, Noda T, Kubo A, Tsukita S. Claudin-based tight junctions are crucial for the mammalian epidermal barrier: A lesson from claudin-1-deficient mice. J. Cell Biol. 2002; 156: 1099-1111.

208. Sugawara T, Iwamoto N, Akashi M, Kojima T, Hisatsune J, Sugai M, Furuse M. Tight junction dysfunction in the stratum granulosum leads to aberrant stratum corneum barrier function in claudin-1-deficient mice. J. Dermatol. Sci. 2013; 70: 12-18.

209. Muto S, Hata M, Taniguchi J, Tsuruoka S, Moriwaki K, Saitou M, Furuse K, Sasaki H, Fujimura A, Imai M, Kusano E, Tsukita S, Furuse M. Claudin-2-deficient mice are defective in the leaky and cationselective paracellular permeability properties of renal proximal tubules. Proc. Natl. Acad. Sci. U. S. A. 2010; 107: 8011-8016.

210. Matsumoto K, Imasato M, Yamazaki Y, Tanaka H, Watanabe M, Eguchi H, Nagano H, Hikita H, Tatsumi T, Takehara T, Tamura A, Tsukita S. Claudin 2 Deficiency Reduces Bile Flow and Increases Susceptibility to Cholesterol Gallstone Disease in Mice. Gastroenterology 2014; 147: 1134-1145.e10.

211. Kerr J, El Andalousi J, Yamanaka Y, Ryan A, Gupta I. Claudin 3 CRISPR Knockout Mice are Healthy and Fertile. FASEB $J$ 2015; 29: 666.13 .

212. Schröder K. Generierung und Charakterisierung eines Claudin-3defizienten Mausmodells. Humboldt-Universität zu Berlin, Mathematisch-Naturwissenschaftliche Fakultät I 2013.

213. Fujita H, Hamazaki Y, Noda Y, Oshima M, Minato N. Claudin-4 Deficiency Results in Urothelial Hyperplasia and Lethal Hydronephrosis. PLoS One 2012; 7: e52272.

214. Ding L, Lu Z, Foreman O, Tatum R, Lu Q, Renegar R, Cao J, Chen Y. Inflammation and disruption of the mucosal architecture in claudin-7deficient mice. Gastroenterology 2012; 142: 305-315. 
215. Breiderhoff T, Himmerkus N, Stuiver M, Mutig K, Will C, Meij IC, Bachmann S, Bleich M, Willnow TE, Muller D. Deletion of claudin-10 (Cldn10) in the thick ascending limb impairs paracellular sodium permeability and leads to hypermagnesemia and nephrocalcinosis. Proc. Natl. Acad. Sci. 2012; 109: 14241-14246.

216. Gow A, Davies C, Southwood CM, Frolenkov G, Chrustowski M, Ng L, Yamauchi D, Marcus DC, Kachar B. Deafness in Claudin 11-null mice reveals the critical contribution of basal cell tight junctions to stria vascularis function. J. Neurosci. 2004; 24: 7051-7062.

217. Gong Y, Renigunta V, Himmerkus N, Zhang J, Renigunta A, Bleich M, Hou J. Claudin-14 regulates renal Ca++ transport in response to CaSR signalling via a novel microRNA pathway. EMBO J. 2012; 31: 19992012 .

218. Tamura A, Kitano Y, Hata M, Katsuno T, Moriwaki K, Sasaki H, Hayashi H, Suzuki Y, Noda T, Furuse M, Tsukita S, Tsukita S. Megaintestine in claudin-15-deficient mice. Gastroenterology 2008; 134: $523-534$.

219. Will C, Breiderhoff T, Thumfart J, Stuiver M, Kopplin K, Sommer K, Günzel D, Querfeld U, Meij IC, Shan Q, Bleich M, Willnow TE, Müller D. Targeted deletion of murine Cldn16 identifies extra- and intrarenal compensatory mechanisms of $\mathrm{Ca} 2+$ and $\mathrm{Mg} 2+$ wasting. Am. J. Physiol. Renal Physiol. 2010; 298: F1152-F1161.

220. LaFemina MJ, Sutherland KM, Bentley T, Gonzales LW, Allen L, Chapin CJ, Rokkam D, Sweerus KA., Dobbs LG, Ballard PL, Frank JA. Claudin-18 Deficiency Results in Alveolar Barrier Dysfunction and Impaired Alveologenesis in Mice. Am. J. Respir. Cell Mol. Biol. 2014; 51: $550-558$.

221. Li G, Flodby P, Luo J, Kage H, Sipos A, Gao D, Ji Y, Beard LL, Marconett CN, Demaio L, Kim YH, Laird-offringa I a, Minoo P, Liebler JM, Zhou B, Edward D. Knockout mice reveal key roles for claudin 18 in alveolar barrier properties and fluid homeostasis. Am. J. Respir. Cell Mol. Biol. 2014; $1-70$.

222. Linares GR, Brommage R, Powell DR, Xing W, Chen ST, Alshbool FZ, Lau KHW, Wergedal JE, Mohan S. Claudin 18 is a novel negative regulator of bone resorption and osteoclast differentiation. J. Bone Miner. Res. 2012; 27: 1553-1565.

223. Kubota K, Furuse M, Sasaki H, Sonoda N, Fujita K, Nagafuchi A, Tsukita S. Ca2+-independent cell-adhesion activity of claudins, a family of integral membrane proteins localized at tight junctions. Curr. Biol. 1999; 9: 1035-1038. 
224. Furuse M, Sasaki H, Fujimoto K, Tsukita S. A single gene product, claudin-1 or -2 , reconstitutes tight junction strands and recruits occludin in fibroblasts. J. Cell Biol. 1998; 143: 391-401.

225. Morita K, Furuse M, Fujimoto K, Tsukita S. Claudin multigene family encoding four-transmembrane domain protein components of tight junction strands. Proc. Natl. Acad. Sci. U. S. A. 1999; 96: 511-516.

226. Furuse M, Sasaki H, Tsukita S. Manner of interaction of heterogeneous claudin species within and between tight junction strands. J. Cell Biol. 1999; 147: 891-903.

227. Piontek J, Fritzsche S, Cording J, Richter S, Hartwig J, Walter M, Yu D, Turner JR, Gehring C, Rahn HP, Wolburg H, Blasig IE. Elucidating the principles of the molecular organization of heteropolymeric tight junction strands. Cell. Mol. Life Sci. 2011; 68: 3903-3918.

228. Rosenthal R, Milatz S, Krug SM, Oelrich B, Schulzke J-D, Amasheh S, Günzel D, Fromm M. Claudin-2, a component of the tight junction, forms a paracellular water channel. J. Cell Sci. 2010; 123: 1913-1921.

229. Findley MK, Koval M. Regulation and roles for claudin-family tight junction proteins. IUBMB Life 2009; 61: 431-437.

230. Fanning AS, Jameson BJ, Jesaitis LA, Anderson JM. The tight junction protein ZO-1 establishes a link between the transmembrane protein occludin and the actin cytoskeleton. J. Biol. Chem. 1998; 273: 2974529753.

231. Itoh M, Morita K, Tsukita S. Characterization of ZO-2 as a MAGUK family member associated with tight as well as adherens junctions with a binding affinity to occludin and a catenin. J. Biol. Chem. 1999; 274: 5981-5986.

232. Itoh M, Furuse M, Morita K, Kubota K, Saitou M, Tsukita S. Direct binding of three tight junction-associated MAGUKs, ZO-1, ZO-2, and ZO3, with the COOH termini of claudins. J. Cell Biol. 1999; 147: 1351-1363.

233. Pan L, Chen J, Yu J, Yu H, Zhang M. The structure of the PDZ3-SH3GuK tandem of ZO-1 protein suggests a supramodular organization of the membrane-associated guanylate kinase (MAGUK) family scaffold protein core. J. Biol. Chem. 2011; 286: 40069-40074.

234. Haskins J, Gu L, Wittchen ES, Hibbard J, Stevenson BR. ZO-3, a novel member of the MAGUK protein family found at the tight junction, interacts with ZO-1 and occludin. J. Cell Biol. 1998; 141: 199-208. 
235. Ikenouchi J, Umeda K, Tsukita S, Furuse M, Tsukita S. Requirement of ZO-1 for the formation of belt-like adherens junctions during epithelial cell polarization. J. Cell Biol. 2007; 176: 779-786.

236. Itoh M, Nagafuchi A, Yonemura S, Kitani-Yasuda T, Tsukita S, Tsukita $\mathrm{S}$. The $220-\mathrm{kD}$ protein colocalizing with cadherins in non-epithelial cells is identical to ZO-1, a tight junction-associated protein in epithelial cells: cDNA cloning and immunoelectron microscopy. J. Cell Biol. 1993; 121: 491-502.

237. Schamberger AC, Mise N, Jia J, Genoyer E, Yildirim AÖ, Meiners S, Eickelberg O. Cigarette smoke-induced disruption of bronchial epithelial tight junctions is prevented by transforming growth factor-B. Am. J. Respir. Cell Mol. Biol. 2014; 50: 1040-1052.

238. Kausalya PJ, Reichert M, Hunziker W. Connexin45 directly binds to ZO1 and localizes to the tight junction region in epithelial MDCK cells. FEBS Lett. 2001; 505: 92-96.

239. Singh D, Solan JL, Taffet SM, Javier R, Lampe PD. Connexin 43 interacts with zona occludens-1 and -2 proteins in a cell cycle stagespecific manner. J. Biol. Chem. 2005; 280: 30416-30421.

240. Katsuno T, Umeda K, Matsui T, Hata M, Tamura A, Itoh M, Takeuchi K, Fujimori T, Nabeshima Y, Noda T, Tsukita S, Tsukita S. Deficiency of zonula occludens-1 causes embryonic lethal phenotype associated with defected yolk sac angiogenesis and apoptosis of embryonic cells. Mol. Biol. Cell 2008; 19: 2465-2475.

241. Xu J, Kausalya PJ, Phua DCY, Ali SM, Hossain Z, Hunziker W. Early embryonic lethality of mice lacking ZO-2, but Not ZO-3, reveals critical and nonredundant roles for individual zonula occludens proteins in mammalian development. Mol. Cell. Biol. 2008; 28: 1669-1678.

242. Adachi M, Inoko A, Hata M, Furuse K, Umeda K, Itoh M, Tsukita S. Normal establishment of epithelial tight junctions in mice and cultured cells lacking expression of ZO-3, a tight-junction MAGUK protein. Mol. Cell. Biol. 2006; 26: 9003-9015.

243. Szymanski K V., Toennies M, Becher A, Fatykhova D, N'Guessan PD, Gutbier B, Klauschen F, Neuschaefer-Rube F, Schneider P, Rueckert J, Neudecker J, Bauer TT, Dalhoff K, Dromänn D, Gruber AD, Kershaw O, Temmesfeld-Wollbrueck B, Suttorp N, Hippenstiel S, Hocke AC. Streptococcus pneumoniae-induced regulation of cyclooxygenase-2 in human lung tissue. Eur. Respir. J. 2012; 40: 1458-1467.

244. Schmeck B, Zahlten J, Moog K, van Laak V, Huber S, Hocke AC, Opitz B, Hoffmann E, Kracht M, Zerrahn J, Hammerschmidt S, Rosseau S, 
Suttorp N, Hippenstiel S. Streptococcus pneumoniae-induced p38 MAPK-dependent phosphorylation of RelA at the interleukin-8 promotor. J. Biol. Chem. 2004; 279: 53241-53247.

245. Koppe U, Högner K, Doehn J-M, Müller HC, Witzenrath M, Gutbier B, Bauer S, Pribyl T, Hammerschmidt S, Lohmeyer J, Suttorp N, Herold S, Opitz B. Streptococcus pneumoniae stimulates a STING- and IFN regulatory factor 3-dependent type I IFN production in macrophages, which regulates RANTES production in macrophages, cocultured alveolar epithelial cells, and mouse lungs. J. Immunol. 2012; 188: 811817.

246. Witzenrath M, Pache F, Lorenz D, Koppe U, Gutbier B, Tabeling C, Reppe K, Meixenberger K, Dorhoi A, Ma J, Holmes A, Trendelenburg G, Heimesaat MM, Bereswill S, van der Linden M, Tschopp J, Mitchell TJ, Suttorp N, Opitz B. The NLRP3 inflammasome is differentially activated by pneumolysin variants and contributes to host defense in pneumococcal pneumonia. J. Immunol. 2011; 187: 434-440.

247. Bättig P, Mühlemann K. Influence of the spxB gene on competence in Streptococcus pneumoniae. J. Bacteriol. 2008; 190: 1184-1189.

248. Noske N, Kämmerer U, Rohde M, Hammerschmidt S. Pneumococcal interaction with human dendritic cells: phagocytosis, survival, and induced adaptive immune response are manipulated by PavA. J. Immunol. 2009; 183: 1952-1963.

249. Hippenstiel S, Soeth S, Kellas B, Fuhrmann O, Seybold J, Krüll M, Eichel-Streiber C, Goebeler M, Ludwig S, Suttorp N. Rho proteins and the p38-MAPK pathway are important mediators for LPS-induced interleukin-8 expression in human endothelial cells. Blood American Society of Hematology; 2000; 95: 3044-3051.

250. Hocke AC, Hartmann IK, Eitel J, Optiz B, Scharf S, Suttorp N, Hippenstiel S. Subcellular expression pattern and role of IL-15 in pneumococci induced lung epithelial apoptosis. Histochem. Cell Biol. 2008; 130: 165-176.

251. Baudin B, Bruneel A, Bosselut N, Vaubourdolle M. A protocol for isolation and culture of human umbilical vein endothelial cells. Nat. Protoc. 2007; 2: 481-485.

252. Lucas R, Yang G, Gorshkov BA., Zemskov EA., Sridhar S, Umapathy NS, Jezierska-Drutel A, Alieva IB, Leustik M, Hossain H, Fischer B, Catravas JD, Verin AD, Pittet JF, Caldwell RB, Mitchell TJ, Cederbaum SD, Fulton DJ, Matthay MA, Caldwell RW, Romero MJ, Chakraborty T. Protein kinase $\mathrm{C}-\alpha$ and arginase I mediate pneumolysin-induced 
pulmonary endothelial hyperpermeability. Am. J. Respir. Cell Mol. Biol. 2012; 47: 445-453.

253. Maranhão JS A. Von Wright's Therapy to Jørgensen's Syndrome. Law Philos. 2009; 28: 163-201.

254. Giaever I, Keese CR. Micromotion of mammalian cells measured electrically. Proc. Natl. Acad. Sci. U. S. A. 1991; 88: 7896-7900.

255. Wegener J, Keese CR, Giaever I. Electric cell-substrate impedance sensing (ECIS) as a noninvasive means to monitor the kinetics of cell spreading to artificial surfaces. Exp. Cell Res. 2000; 259: 158-166.

256. Hartung T. Thoughts on limitations of animal models. Park. Relat. Disord. 2008; 14: S81-S83.

257. Hartung T. Food for thought... on cell culture. ALTEX Altern. zu Tierexperimenten 2007; 24: 143-152.

258. Mizgerd JP, Skerrett SJ. Animal models of human pneumonia. Am. J. Physiol. Lung Cell. Mol. Physiol. 2008; 294: L387-L398.

259. Matute-Bello G, Frevert CW, Martin TR. Animal models of acute lung injury. Am. J. Physiol. Lung Cell. Mol. Physiol. 2008; 295: L379-L399.

260. Irvin CG, Bates JHT. Measuring the lung function in the mouse: the challenge of size. Respir. Res. 2003; 4: 4.

261. Mestas J, Hughes CCW. Of mice and not men: differences between mouse and human immunology. J. Immunol. 2004; 172: 2731-2738.

262. Doulatov S, Notta F, Laurenti E, Dick JE. Hematopoiesis: A human perspective. Cell Stem Cell 2012; 10: 120-136.

263. Jäger J, Marwitz S, Tiefenau J, Rasch J, Shevchuk O, Kugler C, Goldmann T, Steinert M. Human lung tissue explants reveal novel interactions during Legionella pneumophila infections. Infect. Immun. 2014; 82: 275-285.

264. Rupp J, Droemann D, Goldmann T, Zabel P, Solbach W, Vollmer E, Branscheid D, Dalhoff K, Maass M. Alveolar epithelial cells type II are major target cells for C. pneumoniae in chronic but not in acute respiratory infection. FEMS Immunol. Med. Microbiol. 2004; 41: 197203.

265. Drömann D, Rupp J, Rohmann K, Osbahr S, Ulmer AJ, Marwitz S, Röschmann K, Abdullah M, Schultz H, Vollmer E, Zabel P, Dalhoff K, Goldmann T. The TGF-beta-pseudoreceptor BAMBI is strongly 
expressed in COPD lungs and regulated by nontypeable Haemophilus influenzae. Respir. Res. 2010; 11: 67.

266. Xu F, Droemann D, Rupp J, Shen H, Wu X, Goldmann T, Hippenstiel S, Zabel P, Dalhoff K. Modulation of the inflammatory response to Streptococcus pneumoniae in a model of acute lung tissue infection. Am. J. Respir. Cell Mol. Biol. 2008; 39: 522-529.

267. Chan MCW, Chan RWY, Chan LLY, Mok CKP, Hui KPY, Fong JHM, Tao KP, Poon LLM, Nicholls JM, Guan Y, Peiris JSM. Tropism and innate host responses of a novel avian influenza A H7N9 virus: An analysis of ex-vivo and in-vitro cultures of the human respiratory tract. Lancet Respir. Med. 2013; 1: 534-542.

268. Chan RWY, Hemida MG, Kayali G, Chu DKW, Poon LLM, Alnaeem A, Ali M a, Tao KP, Ng HY, Chan MCW, Guan Y, Nicholls JM, Peiris JSM. Tropism and replication of Middle East respiratory syndrome coronavirus from dromedary camels in the human respiratory tract: an in-vitro and ex-vivo study. Lancet Respir. Med. 2014; 2: 813-822.

269. Monici M. Cell and tissue autofluorescence research and diagnostic applications. Biotechnol. Annu. Rev. 2005; 11: 227-256.

270. Hung J, Lam S, LeRiche JC, Palcic B. Autofluorescence of normal and malignant bronchial tissue. Lasers Surg. Med. 1991; 11: 99-105.

271. Homasson JP, Capron F, Angebault M, Nguyen Bich N. Lung autofluorescence. Preliminary study of two systems without laser illumination or photosensitization. Rev. Pneumol. Clin. 2001; 57: 202207.

272. Zimmermann T. Spectral imaging and linear unmixing in light microscopy. Adv. Biochem. Eng. Biotechnol. 2005; 95: 245-265.

273. Tobioka H, Tokunaga Y, Isomura H, Kokai Y, Yamaguchi J, Sawada N. Expression of occludin, a tight-junction-associated protein, in human lung carcinomas. Virchows Arch. 2004; 445: 472-476.

274. Paschoud S, Bongiovanni M, Pache J-C, Citi S. Claudin- 1 and claudin-5 expression patterns differentiate lung squamous cell carcinomas from adenocarcinomas. Mod. Pathol. 2007; 20: 947-954.

275. Kaarteenaho R, Merikallio H, Lehtonen S, Harju T, Soini Y. Divergent expression of claudin $-1,-3,-4,-5$ and -7 in developing human lung. Respir. Res. 2010; 11: 59.

276. Weinheimer VK, Becher A, Tönnies M, Holland G, Knepper J, Bauer TT, Schneider P, Neudecker J, Rückert JC, Szymanski K, Temmesfeld- 
Wollbrueck B, Gruber AD, Bannert N, Suttorp N, Hippenstiel S, Wolff $\mathrm{T}$, Hocke AC. Influenza A viruses target type II pneumocytes in the human lung. J. Infect. Dis. 2012; 206: 1685-1694.

277. Knepper J, Schierhorn KL, Becher A, Budt M, Tönnies M, Bauer TT, Schneider P. The Novel Human Influenza A ( H7N9) Virus Is Naturally Adapted to Efficient Growth in Human Lung Tissue. MBio 2013; 4: 601613.

278. Hocke AC, Becher A, Knepper J, Peter A, Holland G, Tönnies M, Bauer TT, Schneider P, Neudecker J, Muth D, Wendtner CM, Rückert JC, Drosten C, Gruber AD, Laue M, Suttorp N, Hippenstiel S, Wolff T. Emerging human middle east respiratory syndrome coronavirus causes widespread infection and alveolar damage in human lungs. Am. J. Respir. Crit. Care Med. 2013; 188: 882-886.

279. Jinn Y, Inase N. Connexin 43, E-cadherin, beta-catenin and ZO-1 expression, and aberrant methylation of the connexin 43 gene in NSCLC. Anticancer Res. 2010; 30: 2271-2278.

280. Wan H, Winton HL, Soeller C, Stewart G a, Thompson PJ, Gruenert DC, Cannell MB, Garrod DR, Robinson C. Tight junction properties of the immortalized human bronchial epithelial cell lines Calu-3 and 16HBE14o-. Eur. Respir. J. Off. J. Eur. Soc. Clin. Respir. Physiol. 2000; 15: $1058-1068$.

281. Gohy ST, Hupin C, Fregimilicka C, Detry BR, Bouzin C, Gaide Chevronay H, Lecocq M, Weynand B, Ladjemi MZ, Pierreux CE, Birembaut P, Polette M, Pilette C. Imprinting of the COPD airway epithelium for dedifferentiation and mesenchymal transition. Eur. Respir. J. 2015; : 09031936.00135814 - .

282. Kaarteenaho-Wiik R, Soini Y. Claudin-1, -2, -3, -4, -5, and -7 in usual interstitial pneumonia and sarcoidosis. J. Histochem. Cytochem. 2009; 57: $187-195$.

283. Lappi-Blanco E, Lehtonen ST, Sormunen R, Merikallio HM, Soini Y, Kaarteenaho RL. Divergence of tight and adherens junction factors in alveolar epithelium in pulmonary fibrosis. Hum. Pathol. 2013; 44: 895907.

284. Niimi T, Nagashima K, Ward JM, Minoo P, Zimonjic DB, Popescu NC, Kimura S. claudin-18, a novel downstream target gene for the T/EBP/NKX2.1 homeodomain transcription factor, encodes lung- and stomach-specific isoforms through alternative splicing. Mol. Cell. Biol. 2001; 21: 7380-7390. 
285. Velden VHJ van der, Versnel HFJS and MA. Bronchial epithelium: morphology, function and pathophysiology in asthma. Eur. Cytokine Netw. 1999; 9: 585-598.

286. Ganesan S, Comstock AT, Sajjan US. Barrier function of airway tract epithelium. Tissue barriers 2013; 1: e24997.

287. Navarro P, Ruco L, Dejana E. Differential localization of VE- and Ncadherins in human endothelial cells: VE-cadherin competes with $\mathrm{N}$ cadherin for junctional localization. J. Cell Biol. 1998; 140: 1475-1484.

288. Herwig MC, Müller KM, Müller AM. Endothelial VE-cadherin expression in human lungs. Pathol. Res. Pract. 2008; 204: 725-730.

289. Furuse M, Itoh M, Hirase T, Nagaftichi A, Yonemura S, Tsukita S, Tsukita S. Direct association of occludin with ZO-1 and its possible involvement in the localization of occludin at tight junctions. J. Cell Biol. 1994; 127: 1617-1626.

290. Wang F, Daugherty B, Keise LL, Wei Z, Foley JP, Savani RC, Koval M. Heterogeneity of claudin expression by alveolar epithelial cells. Am. J. Respir. Cell Mol. Biol. 2003; 29: 62-70.

291. Mazzon E, Cuzzocrea S. Role of TNF-alpha in lung tight junction alteration in mouse model of acute lung inflammation. Respir. Res. 2007; 8: 75 .

292. Amasheh S, Meiri N, Gitter AH, Schöneberg T, Mankertz J, Schulzke JD, Fromm M. Claudin-2 expression induces cation-selective channels in tight junctions of epithelial cells. J. Cell Sci. 2002; 115: 4969-4976.

293. Wada M, Tamura A, Takahashi N, Tsukita S. Loss of claudins 2 and 15 from mice causes defects in paracellular $\mathrm{Na}+$ flow and nutrient transport in gut and leads to death from malnutrition. Gastroenterology Elsevier; 2013; 144: 369-380.

294. LaFemina MJ, Rokkam D, Chandrasena A, Pan J, Bajaj A, Johnson M, Frank JA. Keratinocyte growth factor enhances barrier function without altering claudin expression in primary alveolar epithelial cells. Am. J. Physiol. Lung Cell. Mol. Physiol. 2010; 299: L724-L734.

295. Morita K, Sasaki H, Furuse M, Tsukita S. Endothelial claudin: Claudin5/TMVCF constitutes tight junction strands in endothelial cells. J. Cell Biol. 1999; 147: 185-194.

296. Chen W, Sharma R, Rizzo AN, Siegler JH, Garcia JGN, Jacobson JR. Role of claudin-5 in the attenuation of murine acute lung injury by simvastatin. Am. J. Respir. Cell Mol. Biol. 2014; 50: 328-336. 
297. Matthay M a, Zemans RL. The acute respiratory distress syndrome: pathogenesis and treatment. Annu. Rev. Pathol. 2011; 6: 147-163.

298. Boitano S, Safdar Z, Welsh DG, Bhattacharya J, Koval M. Cell-cell interactions in regulating lung function. Am. J. Physiol. Lung Cell. Mol. Physiol. 2004; 287: L455-L459.

299. Crandall ED, Matthay MA. Alveolar Epithelial Transport. Am. J. Respir. Crit. Care Med. 2001; 163: 1021-1029.

300. Koval M. Claudin Heterogeneity and Control of Lung Tight Junctions. Annu. Rev. Physiol. 2012; 75: 121016121642003.

301. Gavard J. Endothelial permeability and VE-cadherin: A wacky comradeship. Cell Adhes. Migr. 2014; 8: 158-164.

302. Del Maschio A, Zanetti A, Corada M, Rival Y, Ruco L, Lampugnani MG, Dejana E. Polymorphonuclear leukocyte adhesion triggers the disorganization of endothelial cell-to-cell adherens junctions. J. Cell Biol. 1996; 135: 497-510.

303. Herman B, Bibert S, Concord E, Dublet B, Weidenhaupt M, Vernet T, Gulino-Debrac D. Identification of proteases involved in the proteolysis of vascular endothelium cadherin during neutrophil transmigration. $J$. Biol. Chem. 2003; 278: 14002-14012.

304. Sawant DA, Tharakan B, Adekanbi A, Hunter FA, Smythe WR, Childs EW. Inhibition of VE-Cadherin Proteasomal Degradation Attenuates Microvascular Hyperpermeability. Microcirculation 2011; 18: 46-55.

305. Herwig MC, Tsokos M, Hermanns MI, Kirkpatrick CJ, Müller AM. Vascular Endothelial Cadherin Expression in Lung Specimens of Patients with Sepsis-Induced Acute Respiratory Distress Syndrome and Endothelial Cell Cultures. Pathobiology 2013; 80: 245-251.

306. Li H, Singh S, Potula R, Persidsky Y, Kanmogne GD. Dysregulation of claudin-5 in HIV-induced interstitial pneumonitis and lung vascular injury: Protective role of peroxisome proliferator-activated receptor-Y. Am. J. Respir. Crit. Care Med. 2014; 190: 85-97.

307. Rao RK, Basuroy S, Rao VU, Karnaky Jr KJ, Gupta A. Tyrosine phosphorylation and dissociation of occludin-ZO-1 and E-cadherin-betacatenin complexes from the cytoskeleton by oxidative stress. Biochem. J. 2002; 368: 471-481.

308. Sheth P, Basuroy S, Li C, Naren AP, Rao RK. Role of phosphatidylinositol 3-kinase in oxidative stress-induced disruption of tight junctions. J. Biol. Chem. 2003; 278: 49239-49245. 
309. Yoseph BP, Breed E, Overgaard CE, Ward CJ, Liang Z, Wagener ME, Lexcen DR, Lusczek ER, Beilman GJ, Burd EM, Farris AB, Guidot DM, Koval M, Ford ML, Coopersmith CM. Chronic Alcohol Ingestion Increases Mortality and Organ Injury in a Murine Model of Septic Peritonitis. PLoS One 2013; 8: e62792.

310. Clary CR, Guidot DM, Bratina M a, Otis JS. Chronic alcohol ingestion exacerbates skeletal muscle myopathy in HIV-1 transgenic rats. AIDS Res. Ther. 2011; 8: 30.

311. Milatz S, Krug SM, Rosenthal R, Günzel D, Müller D, Schulzke JD, Amasheh S, Fromm M. Claudin-3 acts as a sealing component of the tight junction for ions of either charge and uncharged solutes. Biochim. Biophys. Acta - Biomembr. 2010; 1798: 2048-2057.

312. Kage H, Flodby P, Gao D, Kim YH, Marconett CN, DeMaio L, Kim K-J, Crandall ED, Borok Z. Claudin 4 knockout mice: normal physiological phenotype with increased susceptibility to lung injury. AJP Lung Cell. Mol. Physiol. 2014; 307: L524-L536.

313. Wray C, Mao Y, Pan J, Chandrasena A, Piasta F, Frank JA. Claudin-4 augments alveolar epithelial barrier function and is induced in acute lung injury. Am. J. Physiol. Lung Cell. Mol. Physiol. 2009; 297: L219L227.

314. Rokkam D, Lafemina MJ, Lee JW, Matthay MA, Frank JA. Claudin-4 levels are associated with intact alveolar fluid clearance in human lungs. Am. J. Pathol. 2011; 179: 1081-1087.

315. Kim BJ, Hancock BM, Bermudez A, Cid N Del, Reyes E, van Sorge NM, Lauth X, Smurthwaite CA, Hilton BJ, Stotland A, Banerjee A, Buchanan J, Wolkowicz R, Traver D, Doran KS. Bacterial induction of Snail1 contributes to blood-brain barrier disruption. J. Clin. Invest. 2015; 125: $2473-2483$.

316. Mohammadi MT, Dehghani GA. Acute hypertension induces brain injury and blood-brain barrier disruption through reduction of claudins mRNA expression in rat. Pathol. Res. Pract. 2014; 210: 985-990.

317. Zahlten J, Kim Y-J, Doehn J-M, Pribyl T, Hocke AC, Garcia P, Hammerschmidt S, Suttorp N, Hippenstiel S, Hubner R-H. Streptococcus pneumoniae-Induced Oxidative Stress in Lung Epithelial Cells Depends on Pneumococcal Autolysis and Is Reversible by Resveratrol. J. Infect. Dis. 2014; : jiu806.

318. Orihuela CJ, Gao G, Francis KP, Yu J, Tuomanen EI. Tissue-specific contributions of pneumococcal virulence factors to pathogenesis. $J$. Infect. Dis. 2004; 190: 1661-1669. 
319. Yoo IH, Shin HS, Kim YJ, Kim HB, Jin S, Ha UH. Role of pneumococcal pneumolysin in the induction of an inflammatory response in human epithelial cells. FEMS Immunol. Med. Microbiol. 2010; 60: 28-35.

320. Chapman KE, Waters CM, Miller WM. Continuous exposure of airway epithelial cells to hydrogen peroxide: Protection by KGF. J. Cell. Physiol. 2002; 192: 71-80.

321. Kevil CG, Oshima T, Alexander B, Coe LL, Alexander JS. H(2)O(2)mediated permeability: role of MAPK and occludin. Am. J. Physiol. Cell Physiol. 2000; .

322. Gonzalez JE, DiGeronimo RJ, Arthur DE, King JM. Remodeling of the tight junction during recovery from exposure to hydrogen peroxide in kidney epithelial cells. Free Radic. Biol. Med. 2009; 47: 1561-1569.

323. Kale G, Naren AP, Sheth P, Rao RK. Tyrosine phosphorylation of occludin attenuates its interactions with ZO-1, ZO-2, and ZO-3. Biochem. Biophys. Res. Commun. 2003; 302: 324-329.

324. Lee H-S, Namkoong K, Kim D-H, Kim K-J, Cheong Y-H, Kim S-S, Lee W-B, Kim K-Y. Hydrogen peroxide-induced alterations of tight junction proteins in bovine brain microvascular endothelial cells. Microvasc. Res. 2004; 68: 231-238.

325. Rai P, Parrish M, Tay IJJ, Li N, Ackerman S, He F, Kwang J, Chow VT, Engelward BP. Streptococcus pneumoniae secretes hydrogen peroxide leading to DNA damage and apoptosis in lung cells. Proc. Natl. Acad. Sci. U. S. A. 2015; : 1424144112 - .

326. Meyer TN, Schwesinger C, Ye J, Denker BM, Nigam SK. Reassembly of the Tight Junction after Oxidative Stress Depends on Tyrosine Kinase Activity. J. Biol. Chem. 2001; 276: 22048-22055.

327. Zhong Z, Deane R, Ali Z, Parisi M, Shapovalov Y, O'Banion MK, Stojanovic K, Sagare A, Boillee S, Cleveland DW, Zlokovic B V. ALScausing SOD1 mutants generate vascular changes prior to motor neuron degeneration. Nat. Neurosci. 2008; 11: 420-422.

328. Grommes J, Soehnlein O. Contribution of neutrophils to acute lung injury. Mol. Med. 17: 293-307.

329. Blasig IE, Bellmann C, Cording J, Del Vecchio G, Zwanziger D, Huber O, Haseloff RF. Occludin protein family: oxidative stress and reducing conditions. Antioxid. Redox Signal. 2011; 15: 1195-1219.

330. Xiao K, Allison DF, Kottke MD, Summers S, Sorescu GP, Faundez V, Kowalczyk AP. Mechanisms of VE-cadherin processing and degradation 
in microvascular endothelial cells. J. Biol. Chem. 2003; 278: 1919919208.

331. Sawant DA, Tharakan B, Adekanbi A, Hunter FA, Smythe WR, Childs EW. Inhibition of VE-Cadherin Proteasomal Degradation Attenuates Microvascular Hyperpermeability. Microcirculation 2011; 18: 46-55.

332. Tsukamoto T, Nigam SK. Cell-cell dissociation upon epithelial cell scattering requires a step mediated by the proteasome. J. Biol. Chem. 1999; 274: 24579-24584.

333. Utech M, Mennigen R, Bruewer M. Endocytosis and recycling of tight junction proteins in inflammation. J. Biomed. Biotechnol. 2010; 2010.

334. Kevil CG, Ohno N, Gute DC, Okayama N, Robinson SA, Chaney E, Alexander JS. Role of cadherin internalization in hydrogen peroxidemediated endothelial permeability. Free Radic. Biol. Med. 1998; 24: $1015-1022$.

335. Comhair S a a, Erzurum SC. Antioxidant responses to oxidant-mediated lung diseases. Am. J. Physiol. Lung Cell. Mol. Physiol. 2002; 283: L246L255.

336. Rahman I, MacNee W. Lung glutathione and oxidative stress: implications in cigarette smoke-induced airway disease. Am. J. Physiol. 1999; 277: L1067-L1088.

337. Cook J a, Pass HI, Iype SN, Friedman N, DeGraff W, Russo a, Mitchell JB. Cellular glutathione and thiol measurements from surgically resected human lung tumor and normal lung tissue. Cancer Res. 1991; 51: 4287-4294.

338. Griese M, Ramakers J, Krasselt A, Starosta V, Van Koningsbruggen S, Fischer R, Ratjen F, Müllinger B, Huber RM, Maier K, Rietschel E, Scheuch G. Improvement of alveolar glutathione and lung function but not oxidative state in cystic fibrosis. Am. J. Respir. Crit. Care Med. 2004; 169: 822-828.

339. Kode A, Rajendrasozhan S, Caito S, Yang S-R, Megson IL, Rahman I. Resveratrol induces glutathione synthesis by activation of Nrf2 and protects against cigarette smoke-mediated oxidative stress in human lung epithelial cells. Am. J. Physiol. Lung Cell. Mol. Physiol. 2008; 294: L478-L488. 


\section{APPENDIX}

\subsection{Supplementary videos}

A digital versatile disc is supplemented at the back of the book cover and contains Supplementary video 1, Supplementary video 2, Supplementary video 3, Supplementary video 4 as well as Supplementary video 5. The supplementary video legends are depicted in the following.

Supplementary Video 1. Histological sections of bronchiolar sections of human lung tissue were probed for occludin (green) and nuclei were counterstained with DAPI (blue). Z-stack of a $10 \mu \mathrm{m}$ section was surface rendered and movie was designed using ZEN 2011.

Supplementary Video 2. Histological sections of human lung tissue were probed for occludin (green) and VE-cadherin (red), nuclei were counterstained with DAPI (blue). Z-stack of a $10 \mu \mathrm{m}$ section was surface rendered and movie was designed using ZEN 2011.

Supplementary Video 3. HUVECs were transfected with adenoviral GFP-occludin (green) and live cell imaging was applied. Representative video of three independent experiments is shown.

Supplementary Video 4. HUVECs were transfected with adenoviral GFP-occludin (green), infected with S. pneumoniae D39 $\Delta c p s \Delta p l y$ at MOI 50 for $6 \mathrm{~h}$ and analyzed with live cell imaging. Representative video of three independent experiments is shown.

Supplementary Video 5. HUVECs were transfected with adenoviral

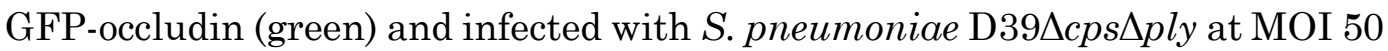
for $6 \mathrm{~h}$. Simultaneously $192 \mathrm{U}$ catalase was applied and slide was analyzed with live cell imaging. Representative video of three independent experiments is shown. 


\subsection{List of Abbreviations}

\begin{tabular}{|c|c|}
\hline $\mathrm{AM}$ & alveolar macrophage \\
\hline ALI & acute lung injury \\
\hline ARDS & acute respiratory distress syndrome \\
\hline BSA & bovine serum albumin \\
\hline BV & blood vessel \\
\hline $\mathrm{C}$ & capillary \\
\hline cAMP & cyclic adenosine monophosphate \\
\hline CAP & community-acquired pneumonia \\
\hline cDNA & complementary deoxyribonucleic acid \\
\hline $\mathrm{CbpD}$ & choline-binding protein D \\
\hline CFU & colony forming units \\
\hline CIL & cilia \\
\hline COPD & chronic obstructive pulmonary disease \\
\hline Cps & pneumococcal capsule \\
\hline dd & double distillated \\
\hline dNTPs & deoxy nucleotide triphosphates \\
\hline DAPI & 4',6-diamidino-2-phenylindole \\
\hline $\mathrm{DC}$ & protein assay \\
\hline DIC & differential interference contrast \\
\hline DNA & deoxyribonucleic acid \\
\hline E-Cadherin & epithelial cadherin \\
\hline ECIS & electric cell-substrate impedance sensing \\
\hline ECL & enhanced chemiluminescence \\
\hline EDTA & ethylenediaminetetraacetic acid \\
\hline ELISA & enzyme-linked immunosorbent assay \\
\hline EMP2 & epithelial membrane protein 2 \\
\hline $\mathrm{EP}$ & epithelium \\
\hline ERK & extracellular-signal-regulated kinase \\
\hline FCS & fetal calf serum \\
\hline Fig. & figure \\
\hline GAPDH & glyceraldehyde-3-phosphate dehydrogenase \\
\hline GFP & green fluorescent protein \\
\hline GUK & guanylate kinase \\
\hline HIV & human immunodeficiency virus \\
\hline $\mathrm{HRP}$ & horseradish peroxidase \\
\hline HUVEC & human umbilical vein endothelial cells \\
\hline Hyl & hyaluraonate lyase \\
\hline IL & interleukin \\
\hline JAM & junctional adhesion molecule \\
\hline $\mathrm{KGF}$ & keratinocyte growth factor \\
\hline $\mathrm{LDH}$ & lactate dehydrogenase \\
\hline
\end{tabular}




\begin{tabular}{|c|c|}
\hline Log & logarithmic \\
\hline MAGUK & membrane-associated guanylate kinases \\
\hline MERS-CoV & Middle East respiratory syndrome coronavirus \\
\hline MOI & multiplicity of infection \\
\hline mRNA & messenger RNA \\
\hline N-cadherin & neuronal cadherin \\
\hline OD & optical density \\
\hline p38 & p38 mitogen-activated protein kinase \\
\hline PBS & phosphate-buffered saline \\
\hline P-cadherin & placental cadherin \\
\hline PFU & plaque-forming units \\
\hline PLY & pneumolysin \\
\hline p. i. & post infection \\
\hline proSP-C & pro-surfactant protein $\mathrm{C}$ \\
\hline PVDF & polyvinylidene difluoride \\
\hline RIPA & radio-immunoprecipitation assay \\
\hline RNA & ribonucleic acid \\
\hline RNAse & ribonuclease \\
\hline $\mathrm{RT}$ & room temperature \\
\hline RT-PCR & Reverse transcription polymerase chain reaction \\
\hline $\mathrm{RQ}$ & relative quantity \\
\hline SDS & sodium dodecyl sulfate \\
\hline SEM & Standard error of the mean \\
\hline S. $p$. & Streptococcus pneumoniae \\
\hline S. pneumoniae & Streptococcus pneumoniae \\
\hline siRNA & small interfering RNA \\
\hline SM & smooth muscle \\
\hline STIKO & Standing Committee on Vaccination \\
\hline TEMED & tetramethylethylenediamine \\
\hline THY & Todd-Hewitt Broth + Yeast Extract \\
\hline TLR & Toll-like receptor \\
\hline VE-cadherin & vascular endothelial cadherin \\
\hline VEGF & vascular endothelial growth factor \\
\hline WHO & World Health Organization \\
\hline $\mathrm{ZO}$ & zonula occludens \\
\hline
\end{tabular}




\section{Appendix}

\subsection{List of Figures}

Figure 1.1: Overview of the anatomy of the lower human respiratory

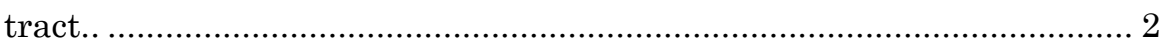

Figure 1.2: Cell types in bronchi, respiratory bronchioles and alveoli....................... 3

Figure 1.3: $\quad$ Streptococcus pneumoniae and its virulence factors. ............................... 8

Figure 1.4: Junctional complex and structure of tight junctions ............................. 11

Figure 3.1: VE-cadherin is expressed in capillary endothelial cells and blood vessels.

Figure 3.2: Occludin is expressed throughout the bronchiolar and alveolar epithelia and the vascular endothelium

Figure 3.3: Occludin is expressed at the type I-type I cell interface as well as at the interface of type II alveolar epithelial cells to adjacent cells and colocalizes with VE-cadherin in endothelial cells 45

Figure 3.4: ZO-1 is expressed in epithelial and endothelial cells 46

Figure 3.5: $\quad \mathrm{ZO}-1$ is expressed at the type I-type I cell interface as well as at the interface of type II alveolar epithelial cells to adjacent cells and colocalizes with occludin and VEcadherin

Figure 3.6: Claudin-2 is strongly expressed in bronchiolar epithelia

Figure 3.7: Claudin-2 does not colocalize with VE-cadherin

Figure 3.8: Claudin-3 is expressed in bronchiolar and alveolar epithelial cells

Figure 3.9: Claudin-3 is expressed at the interface of type II alveolar epithelial cells to adjacent cells and in alveolar capillaries.

Figure 3.10: Claudin-4 is expressed in bronchiolar and alveolar epithelial cells

Figure 3.11: Claudin-4 is expressed at the interface of type II alveolar epithelial cells to adjacent cells and colocalizes with claudin-3.

Figure 3.12: Claudin-5 is expressed in bronchiolar epithelial cells and vascular endothelium

Figure 3.13: Claudin-5 is not expressed in alveolar epithelial cells but colocalizes with VE-cadherin in endothelial cells

Figure 3.14: Claudin-18 is expressed in bronchiolar and alveolar epithelial cells

Figure 3.15: Claudin-18 is expressed at the interface of type II alveolar epithelial cells to adjacent cells 


\section{Appendix}

Figure 3.16: Schematic diagram of human lung tissue preparation for ex vivo cultivation and infection.

Figure 3.17: Growth of S. pneumoniae strains in human lung tissue.

Figure 3.18: Altered structure of VE-cadherin, occludin, ZO-1 and claudin-5 in S. pneumoniae (S. p.) infected human lung tissue

Figure 3.19: Reduced protein levels of VE-cadherin, occludin, ZO-1 and claudin-5 in S. pneumoniae infected human lung tissue

Figure 3.20: No altered structure of claudin-2, claudin-3, claudin-4 and claudin-18 in S. pneumoniae infected human lung tissue.

Figure 3.21: Constant protein levels of claudin-2, claudin-3, claudin-4 and claudin-18 in S. pneumoniae infected human lung tissue.

Figure 3.22: Alteration of cell junctions is not transcriptionally regulated.

Figure 3.23: Pneumolysin is not responsible for the alteration of occludin

Figure 3.24: S. pneumoniae impairs epithelial and endothelial barrier function independently of pneumolysin

Figure 3.25: Hydrogen peroxide impairs epithelial and endothelial barrier function

Figure 3.26: Catalase prevents gap formation and impairment of barrier function induced by $S$. pneumoniae D39 $\Delta c p s \Delta p l y$ in HUVECs.

Figure 3.27: S. pneumoniae D39 $\Delta s p x B$ rescues pneumococci-induced alteration of occludin

Figure 3.28: S. pneumoniae D39 $\Delta$ spxB infection does not reduce protein levels of VE-cadherin, occludin, ZO-1 and claudin-5 in human lung tissue

Figure 4.1: $\quad$ Proposed model of cell junctions in healthy and $S$.

pneumoniae infected human lungs. 


\subsection{List of Tables}

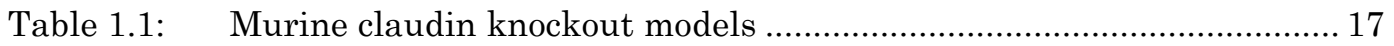

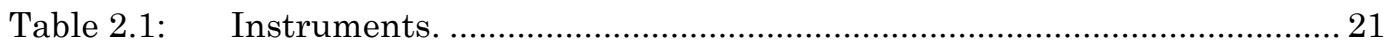

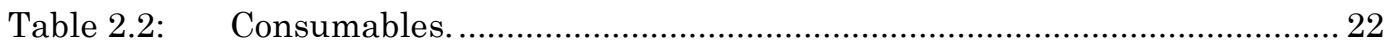

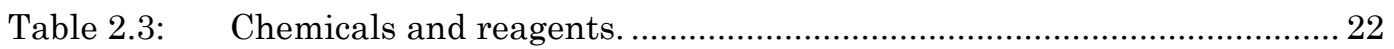

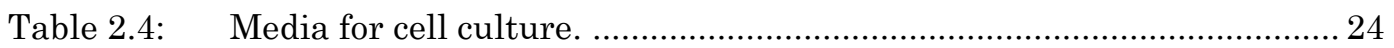

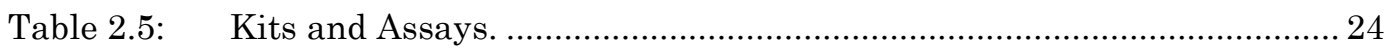

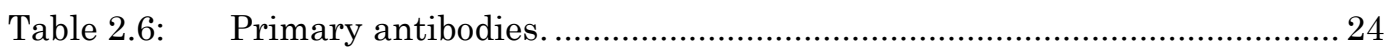

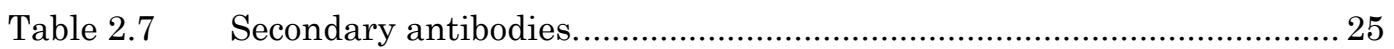

Table 2.8: $\quad$ Taqman Gene Expression Assays for quantitative RT-PCR. ................. 32

Table 2.9: $\quad$ Buffers and gels for western blot analysis............................................... 34

Table 2.10: $\quad$ Paraffin embedding of tissue samples...................................................... 38

Table 2.11: Deparaffinization and rehydrating of tissue samples............................ 39

Table 3.1: $\quad$ Summary of expression patterns for VE-cadherin, occludin, ZO-1, claudin-2, claudin-3, claudin-4, claudin-5 and claudin-18 in anatomical structures of human lung tissue. 


\section{ACKNOWLEDGEMENTS}

$\mathrm{A} \mathrm{PhD}$ project requires and involves the support and work of many people, which herewith I would like to thank. First of all, I would like to express my gratitude to Prof. Suttorp for giving me the opportunity to perform my $\mathrm{PhD}$ work in the Department for Infectious Diseases and Pulmonary Medicine at the Charité. Moreover, I would like to thank Prof. Hippenstiel for giving me the opportunity to work on this fascinating and cutting-edge project, for his enthusiastic supervision and support during the last four years. I thank Prof. Rappsilber and Prof. Lauster for being my $\mathrm{PhD}$ reviewers and providing input on my project. Further, I would like to thank Prof. Haase for agreeing to be the chair of my PhD committee.

The ex vivo human lung infection model is based on our collaboration partners at thoracic surgery centers in Berlin, which provide the human lung explants: Charité - Universitätsmedizin Berlin, HELIOS Klinikum Emil von Behring, DRK Kliniken Berlin Mitte and Vivantes Klinikum Neukölln. I also thank Prof. Gruber and Dr. Kershaw from the FU Berlin for technical assistance. Additionally, I want to thank the research group of Prof. Hippenstiel and Dr. Hocke and its former and current members for creating a supportive and stimulating atmosphere inside and outside of the lab, namely Andreas, Anne B., Christin, Diana, Doris, Janine, Janis, Jan-Moritz, Johanna, Katja Z., Kathi, Kolja, Patricia und Toni. Also many thanks to Alex, Anne R., Birgitt, Elena K., Elena N., Elisa, Franziska, Jan, Kathrin, Katja F., Ling, Mara, Phillip S., Philipp G. and Uwe from the Department of Infectious Diseases and Pulmonary Medicine for their scientific but also moral support.

Finally, I would like to express my deepest gratitude to my beloved family, especially Jan and all my friends for always believing in me and their continuous support during the last years. 


\section{SELBSTSTÄNDIGKEITSERKLÄRUNG}

Hiermit erkläre ich an Eides Statt, dass ich die vorliegende Arbeit „Studies on cell junctions in an ex vivo human lung infection model" selbstständig verfasst und keine anderen als die angegebenen Quellen und Hilfsmittel verwendet habe. Ich versichere, dass diese Arbeit in dieser oder anderer Form noch keiner anderen Prüfungsbehörde vorgelegt wurde. Der Inhalt der Promotionsordnung der Fakultät III - Prozesswissenschaften der Technischen Universität Berlin vom 05. Februar 2014 ist mir bekannt.

Berlin, den 27.07.2015

Andrea Peter 